\title{
Stratification on the Skagit Bay Tidal Flats
}

\author{
by \\ Vera L. Pavel \\ B.S., California Institute of Technology, 2006 \\ Submitted in partial fulfillment of the requirements for the degree of \\ Doctor of Philosophy \\ at the \\ MASSACHUSETTS INSTITUTE OF TECHNOLOGY \\ and the \\ WOODS HOLE OCEANOGRAPHIC INSTITUTION
}

September 2012

(C) 2012 Vera Pavel. All rights reserved

The author hereby grants to MIT and WHOI permission to reproduce and to distribute publicly paper and electronic copies of this thesis document in whole or in part in any medium now known or hereafter created.

Signature of Author

Joint Program in Applied Ocean Science and Engineering Massachusetts Institute of Technology and Woods Hole Oceanographic Institution

June 26, 2011

Certified by

Britt Raubenheimer

Associate Scientist, Woods Hole Oceanographic Institution

Thesis supervisor

Approved by

David E. Hardt

Chairman, Department of Mechanical Engineering Committee on Graduate Theses Massachusetts Institute of Technology

Approved by

Henrik Schmidt

Chairman, Joint Committee for Applied Ocean Science and Engineering Massachusetts Institute of Technology/ Woods Hole Oceanographic Institution 


\section{Stratification on the Skagit Bay tidal flats}

by Vera Pavel

Submitted to the Department of Mechanical Engineering at MIT and the Joint Committee for Applied Ocean Science and Engineering at MIT and WHOI on June 26, 2012 in partial fulfillment of the requirements for the degree of Doctor of Philosophy in Oceanographic Engineering.

\section{Abstract}

Estuarine density stratification may be controlled primarily by cross-shore processes (analogous to longitudinal control in narrow estuaries), or by both cross- and alongshore processes (typical of coastal plumes). Here field observations and numerical modeling are used to investigate stratification on the low-sloped, periodically inundated Skagit Bay tidal flats. Advection of stratification by the depth-averaged velocity, straining of the horizontal density gradient by velocity shear, and turbulent mixing are shown to be the dominant processes. On the south-central flats (near the south fork river mouth) velocities are roughly rectilinear, and the largest terms are in the major velocity direction (roughly cross-shore). However, on the north flats (near the north fork river mouth), velocity ellipses are nearly circular owing to strong alongshore tidal flows and alongshore stratification processes are important. Stratification was largest in areas where velocities and density gradients were aligned. The maximum stratification occurred during the prolonged high water of nearly diurnal tides when advection and straining with relatively weak flows increased stratification with little mixing. Simulations suggest that the dominance of straining (increasing stratification) or mixing (decreasing stratification) on ebb tides depends on the instantaneous Simpson number being above or below unity.

Thesis Supervisor: Britt Raubenheimer

Title: Associate Scientist in Applied Ocean Physics and Engineering 


\section{Acknowledgements}

I thank T.H.C. Herbers and J. MacMahan for providing current profilers, and W. Boyd, S. Burnet, D. Darnell, D. Giffen, L. Gorrell, S. Kilgallin, E. Ladouceur, L. Siegel, E.

Williams, R. Yopak, and S. Zippel for helping obtain the field observations. I also thank D. Ralston for providing the numerical model runs. Support for the work was provided by the Office of Naval Research, contracts N00014-10-10220, N00014-08-10050, N0001407-10461, N00014-0710755, N00014-0810787, N00014-0910933, the National Science foundation, grant OCE-0622844 the PADI Foundation, grant 74, an MIT Linden Earth Systems Fellowship, 2006-2007, and Academic Programs Office funds. 


\section{Contents}

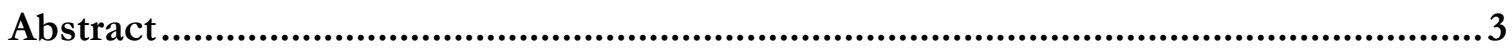

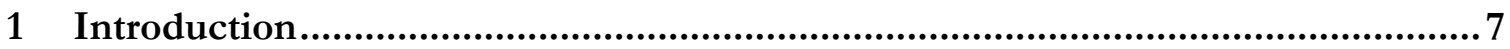

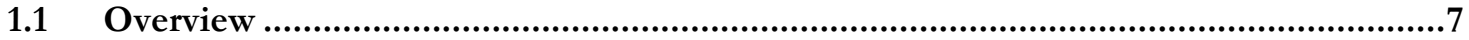

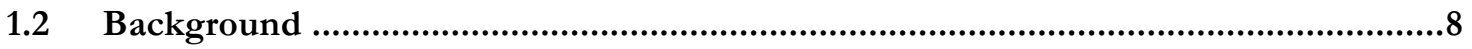

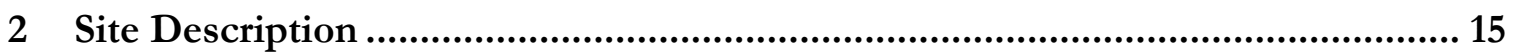

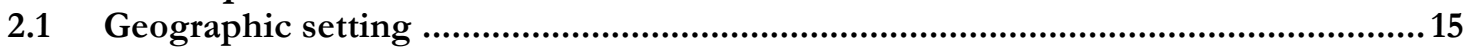

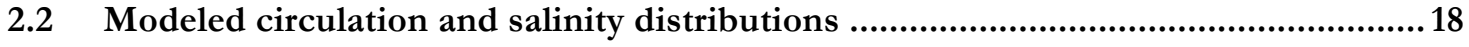

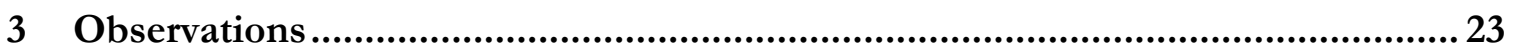

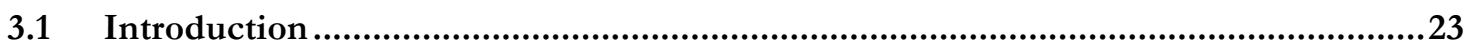

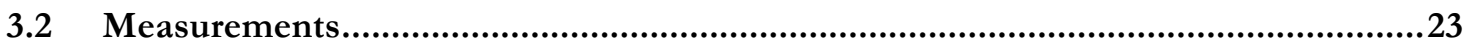

3.3 Theory and Processing .............................................................................................2

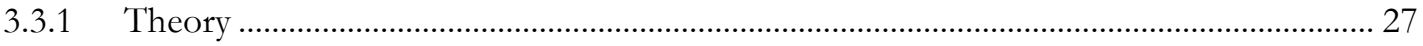

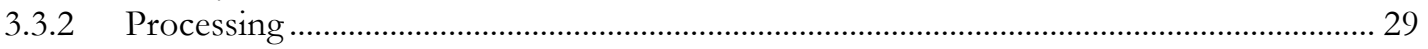

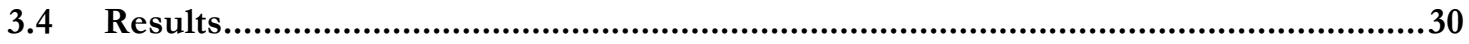

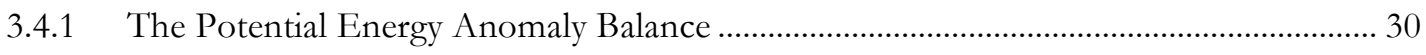

3.4.2 Spatial Variability ………………………………………………………………………….... 37

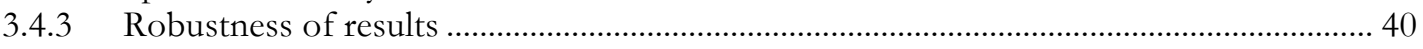

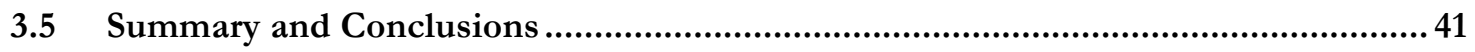

4 Numerical model simulations of stratification processes ....................................... 47

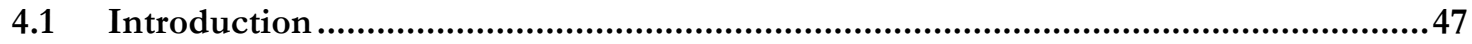

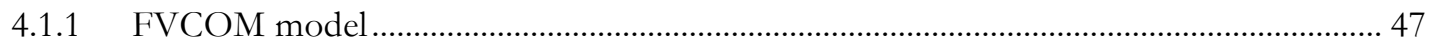

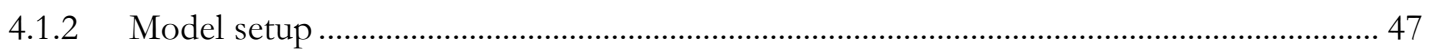

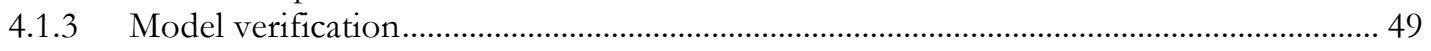

4.1.4 Time series of individual terms (phase-averaged) ……………………………………….... 50

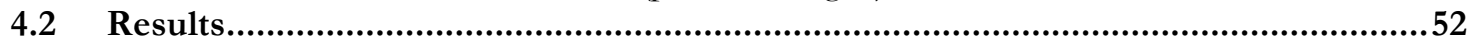

4.2.1 Process activity in different directions …………………………………………………... 52

4.2.2 Differences in ebb stratification processes between type 1 and type 2 tides ...................58

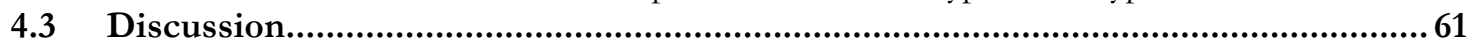

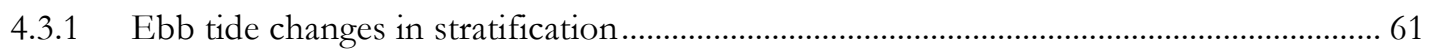

4.3.2 Density effects on the flow structure ……………………………………………………… 65

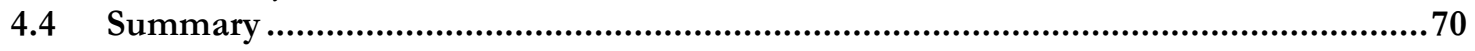

5 Conclusions and future directions ……………….............................................. 73

Appendix: Mixing Parameterization .......................................................................... 77

References:................................................................................................................. 79 


\section{Introduction}

\subsection{Overview}

Shallow, periodically submerged, low-sloped tidal flats bordering coasts and estuaries may affect water circulation and temperature in the surrounding region. They can be protective barriers to low-lying land as well as sources of economic activity, habitats for juvenile fish, and systems of natural water purification by the benthic organisms living inside the flats. The viability of tidal flat systems near river mouths is affected by the density distribution, including stratification, and by circulation and sediment transport, which also are affected by stratification. However, most prior studies of density stratification near river mouths have focused on estuaries and coastal plumes, and there have been few studies of stratification on deltaic tidal flats. It is expected that mixing and stratifying processes may be different on flats owing to the shallow water depths. Here, observations and model predictions will be used to examine the processes controlling the generation and destruction of stratification on tidal flats, leading to a better understanding of these systems, which may allow improved predictions of the effects of human activity.

The specific goals of this work are to:

- Determine the dominant processes controlling changes in stratification over a tidal cycle.

- Investigate the temporal changes in the stratifying processes using field data.

- Use model output to examine the spatial variability of the different processes.

- Examine the relative importance of cross- and alongshore processes.

- Relate spatial and temporal differences in stratification to tidal and estuarine parameters.

- Indicate effects of stratification on circulation. 


\subsection{Background}

Tidal flats with broad, low-slope intertidal (intermittently submerged) shoals, or "flats", traversed or bordered by deeper riverine or tidal channels are common along the edges of estuaries. The channels are significant, being the primary conduits of freshwater and sediment to the coast (Chen et al., 2010), but the flats contain the majority of area and habitat.

Although tidal flats form a relatively small portion of the total coastal and estuarine area, they can affect the circulation patterns throughout larger basins by increasing heating (Kim et al., 2010; Kim and Cho, 2011), bed friction (Nicolle and Karpytchev, 2007), and tidal volume storage (Friedrichs and Aubrey, 1988), and by altering basin resonance characteristics (Fortunato et al., 1997, 1999) and nonlinear tidal interactions (Speer and Aubrey, 1985; Fortunato et al., 1999; Blanton et al., 2002). Tidal flats also can provide a coastal buffer (Kirby, 2000; Kim, 2003) and important habitat for fish and game (Grossman et al., 2007). A healthy wetland ecosystem will contain intertidal flats as well as marshes and subtidal (always submerged) areas (Havens et al., 1995). The benthic organisms in the flats constitute a natural system of water purification, removing suspended organic matter that can be detrimental to local fisheries (Suzuki, 2001). Some of the work relating to tidal flats has focused on the hydrodynamics in the deeper channels (e.g., Ralston and Stacey 2005a,b, 2007), sediment transport (e.g. Chen et al., 2010; Talke and Stacey 2008; Lee et al., 2004), or the effects of the flats on their surroundings (e.g. Kim et al., 2010; Nicolle and Karpytchev, 2007; Fortunato et al., 1999). However, understanding the complicated circulation and salinity characteristics resulting from the shallow depths, periodic inundation, tidal flows, and river discharge on the shoals is vital to managing these natural resources.

Stratification, the layering of different densities of water, affects the location and magnitude of fluid turbulence, which affects the flow field and the sediment transport. In 
particular, stratification affects the viscous term in the momentum balance, which changes the velocity profile by changing the production and magnitude of turbulence. For example, a well-mixed water column over a rough bed has a shear flow with a log profile given by $\frac{u_{*}}{k} \log \left(\mathrm{z} / \mathrm{z}_{0}\right)$, where $\mathrm{z}_{0}$ is the roughness length, $\mathrm{z}$ is height above bed, $\mathrm{u} *$ is the friction velocity, and k is von Karman's constant (von Karman, 1930). For the same external forcing, but with stable stratification, the flow profile will be log-linear and goes as $\frac{u_{*}}{k} \log \left(\frac{\mathrm{z}}{z_{0}}+\mathrm{bz}\right)$, where $\mathrm{b}$ is a scaling parameter that depends on the stratification. Under stably stratified conditions, the flows that are far from the bed are larger than they would be given a log profile because some of the turbulent energy is dissipated by destabilizing the fluid rather than by slowing the upper water column (Turner, 1973). Overall, stratification tends to decouple the water near the bed from that near the surface. However, although stratification tends to suppress turbulent production near the bed, velocity shear can produce instabilities at the pycnocline when the Richardson number (ratio of buoyancy to shear) is small (Ralston et al., 2010b; Peters and Bockhorst, 2000; Peters 1997).

Stratification can affect sediment transport through the effects on the flow profile and turbulence. In a stratified fluid, reduced turbulence leads to reduced re-suspension, and thus the sediment is more likely to settle out and collect on the bed (Dyer, 1986). This phenomenon enhances the concentration of sediment in an estuarine turbidity maximum (Geyer, 1993). The effect is most pronounced on silt-sized particles. Substantially coarser particles fall out of suspension too easily for the stratification to have much of an effect, and very fine particles settle slowly enough that they remain in suspension with or without stratification or additional turbulence.

Intra- and intertidal (within and averaged over the tidal cycle, respectively) temporal variations of stratification in estuaries and on estuarine tidal flats have been shown to change circulation patterns (Monismith et al., 1996; Geyer et al., 2000; Stacey et al., 2001; Ralston and Stacey, 2005a; Becker et al., 2009; Cheng et al., 2009), suppress 
turbulence (Nepf and Geyer, 1996; Peters and Bokhorst, 2001; Rippeth et al., 2001; Ralston and Stacey, 2005b; Stacey et al., 1999; Ralston et al., 2010b; Wang et al., 2011), and reduce bottom stress and suspended sediment concentration (Chant and Stoner, 2001; Ralston and Stacey, 2007; Chen et al., 2010).

The potential energy anomaly (Simpson and Bowers, 1981), the amount of energy per unit volume required to homogenize the water column, often is used to quantify changes in stratification (Simpson et al., 1990; Wiles et al., 2006; Marques et al., 2010, 2011; Ralston et al., 2010b). The potential energy anomaly, denoted by $\Phi$, is defined as: $\Phi=-\frac{g}{D} \int_{-h}^{\eta}(\rho-\bar{\rho}) z d z$

where $\mathrm{g}=9.8 \mathrm{~m} / \mathrm{s}$ is gravitational acceleration, $\mathrm{D}=\eta+\mathrm{h}$ is the water depth, $\eta$ is the surface elevation, $\mathrm{h}$ is bed level below the mean surface, $\rho$ is the water density, the overbar denotes a depth-average, and $\mathrm{z}$ is the vertical coordinate, positive up.

In many estuaries the potential energy anomaly owing to longitudinal tidal straining (the vertically sheared velocity profile acting on the along-channel horizontal density gradient) increases stratification and suppresses turbulent mixing on the ebb and decreases stratification and enhances mixing on the flood (Simpson et al., 1990; Chant and Stoner, 2001; Burchard and Hofmeister, 2008). In shallow salt-wedge estuaries longitudinal advection may enhance straining effects on the flood and may oppose the straining-induced increase in stratification on the ebb (Giddings et al. 2011). Vertical advection processes also may be important in regions with large, spatially inhomogeneous horizontal density gradients (Nepf and Geyer, 1996; Burchard and Hofmeister, 2008; de Boer et al., 2008; Marques et al., 2011), whereas in estuaries with complex bathymetry and in coastal regions near river plumes (e.g., regions of freshwater influence or ROFIs) both cross- and alongshore processes contribute to the stratification (Valle-Levinson and Atkinson, 1999; Lacy et al., 2003; de Boer et al., 2008; Marques et al., 2010). Furthermore, nonlinear effects may be important near river mouths and estuarine inlets (de Boer et al., 2008; Marques et al., 2010), and wind-driven currents can 
affect the potential energy anomaly balance in estuaries and ROFIs during storms (Yang and Khangaonkar, 2009; Marques et al., 2010, 2011).

Overall, the magnitudes of the river discharge, tidal and wind-driven currents, and horizontal density gradients influence which processes dominate the stratification balance (Nepf and Geyer, 1996; Burchard and Hofmeister, 2008; de Boer et al., 2008; Hofmeister et al., 2009). These forcing mechanisms and the stratification can vary on seasonal (Marques et al., 2010), spring-neap (Peters, 1997), storm (Marques et al., 2010, 2011), and tidal timescales (Simpson et al., 1990; Nepf and Geyer, 1996; Stacey et al., 1999; Rippeth et al., 2001). In the Merrimack (Massachusetts) during high river discharge maximum stratification occurred on the flood and the dominant processes were the advection and mixing of a highly stratified salt wedge (Ralston et al., 2010a). During more moderate river discharge, maximum stratification occurred on the ebb and tidal straining and mixing were the dominant processes. In the Snohomish estuary (Washington) the dominant processes were the upstream advection of a salt wedge, straining of the stratified water by the sheared flows, and mixing (Giddings et al., 2011). During spring tides, strong flood flows mixed the water column offshore of (behind) the salt wedge front, and thus stratification first increased as the salt wedge was advected upstream and then decreased as the front passed. In contrast, during neap tides flood flows (and mixing) were weaker, and thus the water behind the salt wedge remained stratified.

The stratification balance and the dominant processes are spatially variable. For example, numerical simulations of a region-of-freshwater-influence (ROFI, a coastal river plume) suggested that the dominant processes change with distance from the freshwater source. Alongshore advection was found to dominate at the edge of the bulge but cross-shore straining dominated farther down stream in the coastal current region (de Boer et al., 2008) despite strong alongshore velocities. Simulations of a salt-wedge channel estuary showed a balance of advection, straining, and vertical processes at the salt wedge front 
but strain-induced periodic stratification farther downstream (Burchard and Hofmeister, 2008). Just as stratification can be different between in the thalweg (main channel) and over the shoals of estuaries (Cheng et al., 2009) because there are additional layers of dense water at the bottom of the deeper area, stratification on the shoals of estuarine tidalflat regions, which make up the majority of the total surface area, can differ significantly from that in the river and tidal channels. In some cases the water over the shoals may remain well mixed and saline despite stratifying fresh-water influence in the channels (Ralston and Stacey, 2005b). Stratification can result in or near channels from density gradients between channels and shoals (Ralston and Stacey, 2005a) by having fast flows bring different density water down the channel than is present over the shoals.

Similar to macrotidal salt-wedge estuaries on the Merrimack (Massachusetts) (Ralston et al., 2010a,b), Columbia (Washington/Oregon border) (Jay and Smith, 1990), Fraser (British Columbia) (Geyer and Farmer, 1989), and Snohomish (Washington) rivers (Wang et al., 2009; Giddings et al., 2011) where the length of the salinity transition is similar to the tidal intrusion, tidal flats and the associated channels have strong crossshore density gradients, and periodically are strongly stratified. Tidal-flat channels can be similar to narrow estuaries, especially at low tide and during periods of high river runoff. For example, stratification increasing on ebbs and decreasing on floods in a San Francisco Bay (California) tidal-flat channel during the spring freshet was primarily a result of straining of the longitudinal density gradient and advection of the salinity front (Ralston and Stacey, 2005a,b, 2007). However on tidal flats the tidal range is greater than the mean water depth. Thus the effects of depth changes can be significant (Ralston and Stacey, 2005b, 2007; Giddings et al., 2011), and the effects of the periodic inundation and drying of tidal flats on the balance of stratification is uncertain.

Water levels, velocities, and densities in estuaries (Ralston et al., 2010a,b) and on tidal flats (Yang and Khangaonkar, 2009; Kim and Cho, 2011; Ralston et al., 2012), have been predicted with the Finite Volume Coastal Ocean Model (FVCOM), a three-dimensional 
finite volume, unstructured grid, primitive equation model (Chen et al., 2003) that was developed to simulate coastal regions. Model comparisons have shown that tidal amplitudes and phases in regions with irregular coastlines or bathymetry are predicted significantly better by models with unstructured grids than by models with rectangular mesh elements (Chen et al., 2003). In addition, the wet/dry point technique used in FVCOM enables accurate predictions in areas that are periodically submerged or exposed. For the Baeksu tidal flats (South Korea), tidal elevation predictions from FVCOM agreed well with observations $(r>0.95)$ while tidal velocity ellipse predictions were of similar magnitude but slightly rotated counterclockwise from the observations (Kim and Cho, 2011). Observations of water level, velocity, and salinity have been predicted well (correlation $r>0.9$ ) in estuaries (e.g., Ralston et al., 2010a) and on tidal flats (Kim and Cho, 2011; Ralston et al., 2012). Tidal evolution of salinity fronts also is reproduced, although time series of surface salinity are more difficult to simulate owing to large spatial and temporal variations (up to 20 PSU over $100 \mathrm{~m}$ ) near fronts.

In this thesis, observations and FVCOM-simulations of water levels, velocities, and densities in Skagit Bay, Washington (described further in Chapter 2) are used to investigate the processes leading to production, destruction, and movement of stratification on tidal flats. Overall, the following questions are addressed in Chapters 3 and 4:

1. What processes affect the stratification, and what causes spatial variations in the magnitudes of these processes?

2. What is the relative importance of cross- and alongshore processes, and what controls this balance?

3. Where is stratification generated and destroyed?

In Chapter 3, the observations collected during August 2009 on the north flats are used to examine the relative importance of across- and alongshore straining, advection, and mixing in a region with strong alongshore flows. Prior studies have shown that FVCOM accurately predicts water depths and velocities near the deepest river channels, and 
salinity in the tidal channel along the western edge of the bay (Yang and Khangaonkar, 2009). The model also has been shown to reproduce the water levels, velocities, and salinities in a tidal flat channel near the south fork of the Skagit River (Ralston et al., 2012). In Chapter 4, this field-verified model is used to examine the spatial dependence of the processes affecting stratification. The flats extend from the mouth of the north fork of the Skagit River, about $10 \mathrm{~km}$ south east to the mouth of the south fork of the Skagit River. Freshwater discharge is large near the river mouths at either end of the bay, but there is little direct freshwater discharge from the marshes between the two river mouths. Thus, the processes affecting stratification on the flats are examined as a function of proximity to the freshwater supplies. Furthermore, the tidal velocities are nearly rectilinear and aligned with the density gradients on the south-central flats (similar to an estuarine channel), but have similar cross- and alongshore magnitudes on the north flats (similar to a ROFI), so the stratification processes for these different types of coastal regimes are compared and contrasted. 


\section{Site Description}

\subsection{Geographic setting}

The Skagit Bay tidal flats, near La Conner, WA, have an area of about $100 \mathrm{~km}^{2}$ (Fig. 21). A deep channel runs along the edge of Whidbey Island, which forms the western border of Skagit Bay. To the north and south, Skagit Bay connects with the Strait of Juan de Fuca and the rest of Puget Sound via Deception Pass and Saratoga Passage, respectively. Tides propagate northwestward from Saratoga Passage towards Deception Pass.

About $5 \mathrm{~km}$ upstream of the flats, the Skagit River splits into north and south forks that carry approximately $60 \%$ and $40 \%$ of the flow, respectively (Grossman et al., 2007; Yang and Khangaonkar, 2009). Data from the field study discussed in Chapter 3 were collected on the shoals between the north and south forks during the month of August, 2009. Additional data collected in July are compared with a numerical model in Chapter 4. Typical monthly-average river discharge, as measured at Mt. Vernon (upstream of the fork) is about $500 \mathrm{~m}^{3} / \mathrm{s}$ with a maximum in June during the spring freshet averaging 700 $\mathrm{m}^{3} / \mathrm{s}$ and a minimum at the end of the summer in September averaging about $250 \mathrm{~m}^{3} / \mathrm{s}$. The field study period of early July to late August was selected to capture as much variability in river discharge as possible over a short field season. River flow during the summer of 2009 was lower than average, about $200 \mathrm{~m}^{3} / \mathrm{s}$ during the August study period and between 300 and $500 \mathrm{~m}^{3} / \mathrm{s}$ during the July period (USGS gage 12200500 http://waterdata.usgs.gov/nwis/nwisman/?site no=12200500). Numerous small channels (depth $O(0.10-0.25 \mathrm{~m})$ ) split off from the north fork of the Skagit and extend across the marshes onto the tidal flats near the measurement locations (Elgar and Raubenheimer, 2011; Webster et al., 2012). However, the majority of the discharge from the north 
(south) fork exits onto the flats about $2.5 \mathrm{~km}$ northwest ( $4.5 \mathrm{~km}$ southeast) of the field study area.

In contrast with many intertidal flats in low energy environments (Banas et al., 2004; Lee et al., 2004; Fan et al., 2006), the sediment on the Skagit flats is primarily sandy (Webster et al., 2012). The cross-shore bed slope on the flats ranges between approximately 1/2000 and $1 / 1000$. The spring tidal range is about $4 \mathrm{~m}$, and much of the lower part of the flats are dry at lower low tide. Thus, the tidal range is larger than the mean water depth, in contrast to deeper estuaries and ROFIs. Tides are mixed (Fig. 2-2), and can be nearly semidiurnal (denoted here as "type 1") or nearly diurnal ("type 2").

The two tide types were defined according to the diurnal inequality to enable averaging over tidal cycles. For the field data discussed in Chapter 3, cycles where the difference between the heights of the two low tides measured on the mid flats (where the bed sometimes is dry) in one diurnal period was $<1 / 4$ of the local daily tidal range were defined as type 1 tides, and cycles where the difference was $>1 / 3$ of the tidal range were defined as type 2. For the model results (Chapter 4), the criteria for the difference in offshore (always submerged) low tide levels were $<5 / 12$ and $>7 / 12$ of the daily range for type 1 and type 2 tides, respectively. The use of offshore rather than local tide levels necessitated the change in empirical criteria. The fortnightly transition between low and high diurnal inequality with the latter manifesting as a long high tide during type 2 tides is common along the west coast of North America, and in particular the local region (Nidzieko 2010). 

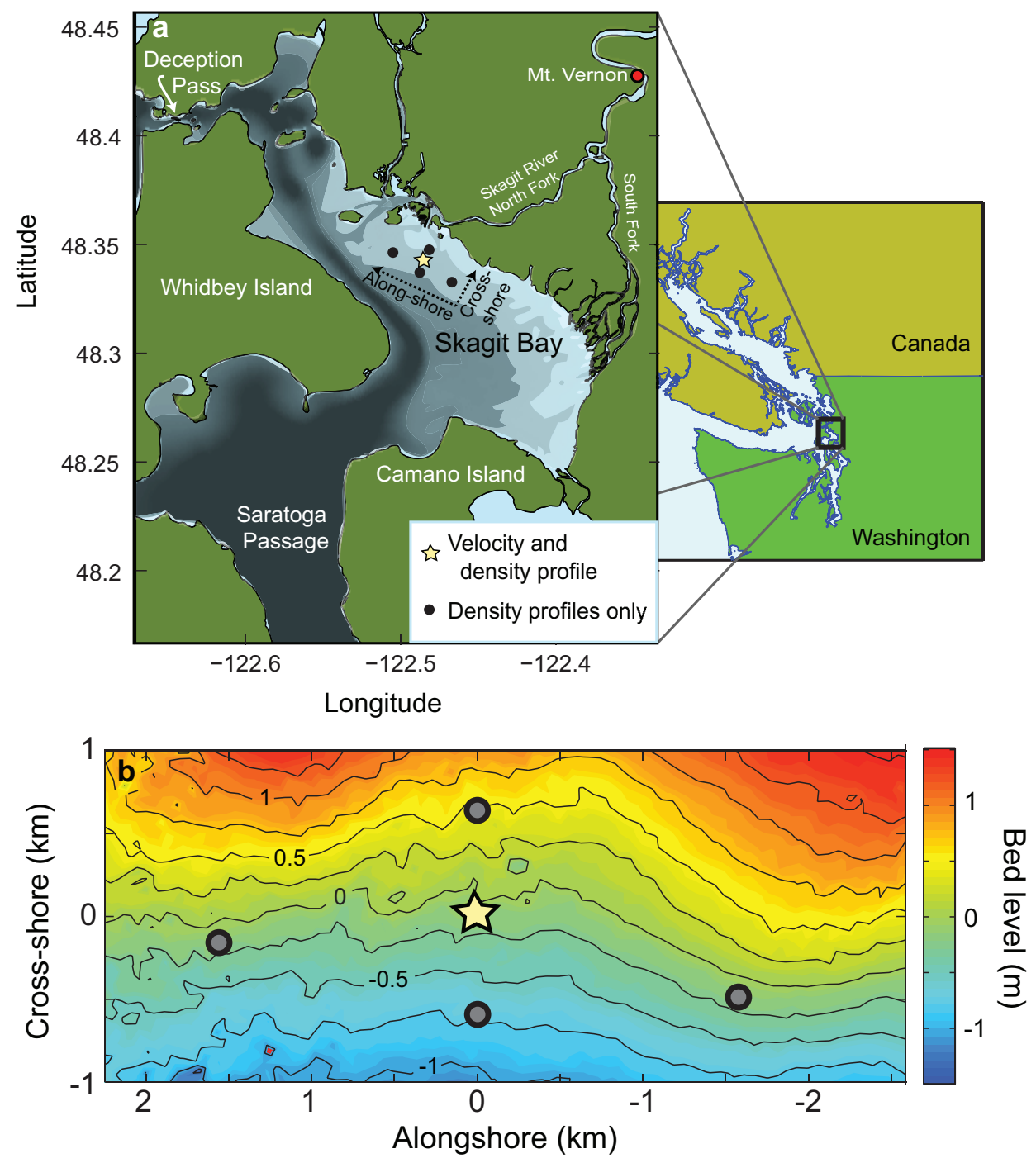

Figure 2-1: (a) Map of Skagit Bay and surrounding area (from NOAA/NOS Medium Resolution Coastline Database) and instrument array (black circles and yellow star indicate where density profiles and co-located velocity and density profiles, respectively, were obtained). Bottom pressure (and water depth) was measured at all instrument locations. Shading indicates four levels of bathymetry with darker being deeper water. The smaller map (NOAA World Vector Shoreline Database) on the right shows the location of Skagit Bay on the Pacific Northwest coast. Positive cross-shore is toward the northeast and positive alongshore is toward the northwest. (b) Bathymetry (relative to NAVD88) around the instrument area rotated into alongshore and crossshore directions. 


\subsection{Modeled circulation and salinity distributions}

Differences in mean water level and tidal range between Deception Pass and Saratoga Passage result in strong flows through Skagit Bay, particularly in the deep channel ("gutter") on the western edge of the bay. The circulation and surface salinity fields during different tidal stages are illustrated using snapshots of the FVCOM numerical simulations. Northing and Easting are for UTM zone 10U.

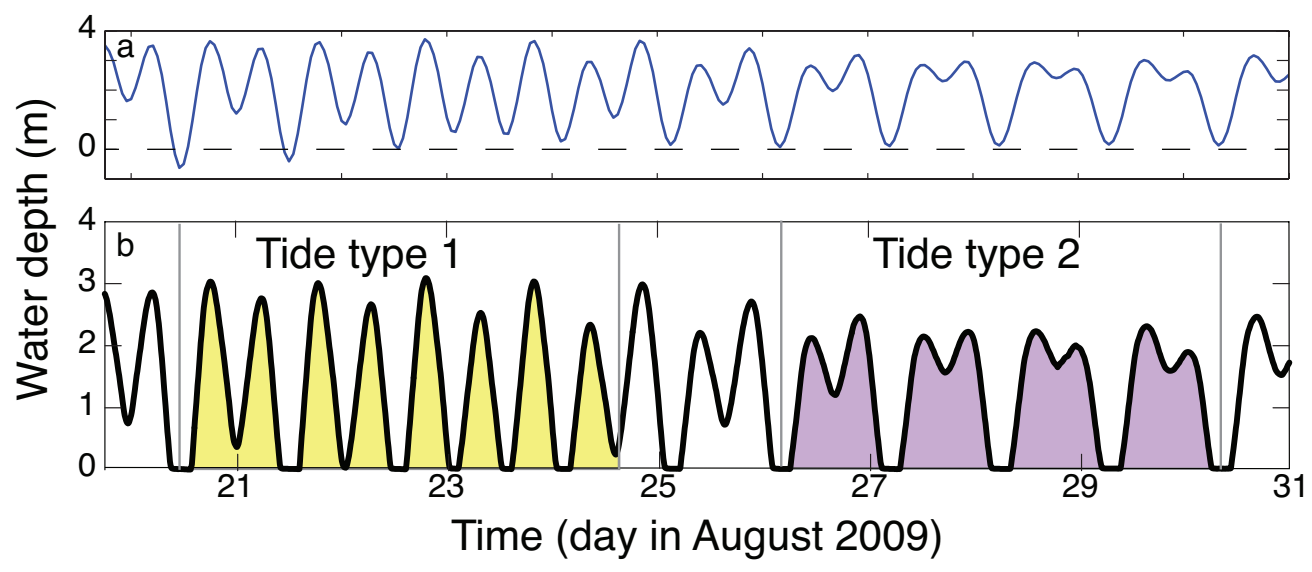

Figure 2-2: (a) Recorded water levels in Seattle, WA relative to MLLW (from NOAA tidal gage \#9447130) (b) Measured water depth versus time at the central sensor location with type 1 and type 2 tides shaded in yellow and purple, respectively

During the type 1 strong flood, water spreads out of the gutter and flows onto the flats towards the east on the south flats and towards the northeast on the north flats (Fig. 2-3a). At this mid-flood stage, the fresh surface water (remaining from the last ebb) has been transported shoreward towards the marshes with more saline surface water behind. At high tide, flow magnitudes are similar to those on flood and ebb and are directed towards Deception Pass except on the south-central flats, which are shadowed by Camano Island, which forms the southern border of the tidal flats (Fig. 2-3c). Saline water has propagated onshore and a roughly alongshore-homogeneous sharp surface front occurs on the upper flats (Fig. 2-3d). 
During the type $1 \mathrm{ebb}$, the water flows towards the west over most of the flats, and towards Deception Pass in the northern part of the gutter (Fig. 2-3e). The sharp surface salinity front is transported offshore, with north fork discharge rounding the islands and going northwest towards Deception Pass (Fig. 2-3f). Near low tide, when water is shallow on the flats, flows on the south and central flats are small, flows on the north flats are slightly larger and southeastward, and flows in the gutter are strong with water flowing toward Saratoga Passage (Fig. 2-3g). Strong flows also occur in the south fork channels as water drains from the river. The surface water remaining on the flats and in the gutter is brackish or fresh. Throughout the tide cycle, the freshest surface water is contained near the south fork channels and near the mouth of the north fork, with partially mixed water along the marshes between the river mouths (Fig 2-3b, d, f, and h, regions of dark blue).

Flows and surface salinities during the type 2 strong flood, the following (first) high tide, and the strong ebb (not shown) are similar to those during type 1 tides. During the type 2 weak ebb (not shown), flows are weaker than, but similar to, those during the type 1 strong ebb, and the surface freshwater propagates offshore slowly. However, in contrast to the type 1 low tide, during the type 2 higher low water the majority of the flats remain submerged and the southeastward flows occur over most of the north flats (similar to the type 1 low tide, flows are small on the south flats) (compare Fig. 2-4a with Fig. 2-3g). Furthermore, strong alongshore-inhomogeneous surface salinity fronts occur near the offshore edge of the flats and over the north-central flats. During the type 2 weak flood flows are small (Fig. 2-4c) and form a counterclockwise circulation cell just south of the north fork, which results in spreading of the freshwater plume (Fig. 2-4d). Flows and surface salinities during the second type 2 high tide (Fig. 2-4e and f) are similar to those during the type 1 high tide (Fig. 2-3c and d), but the fresh surface water extends farther from the marshes. 

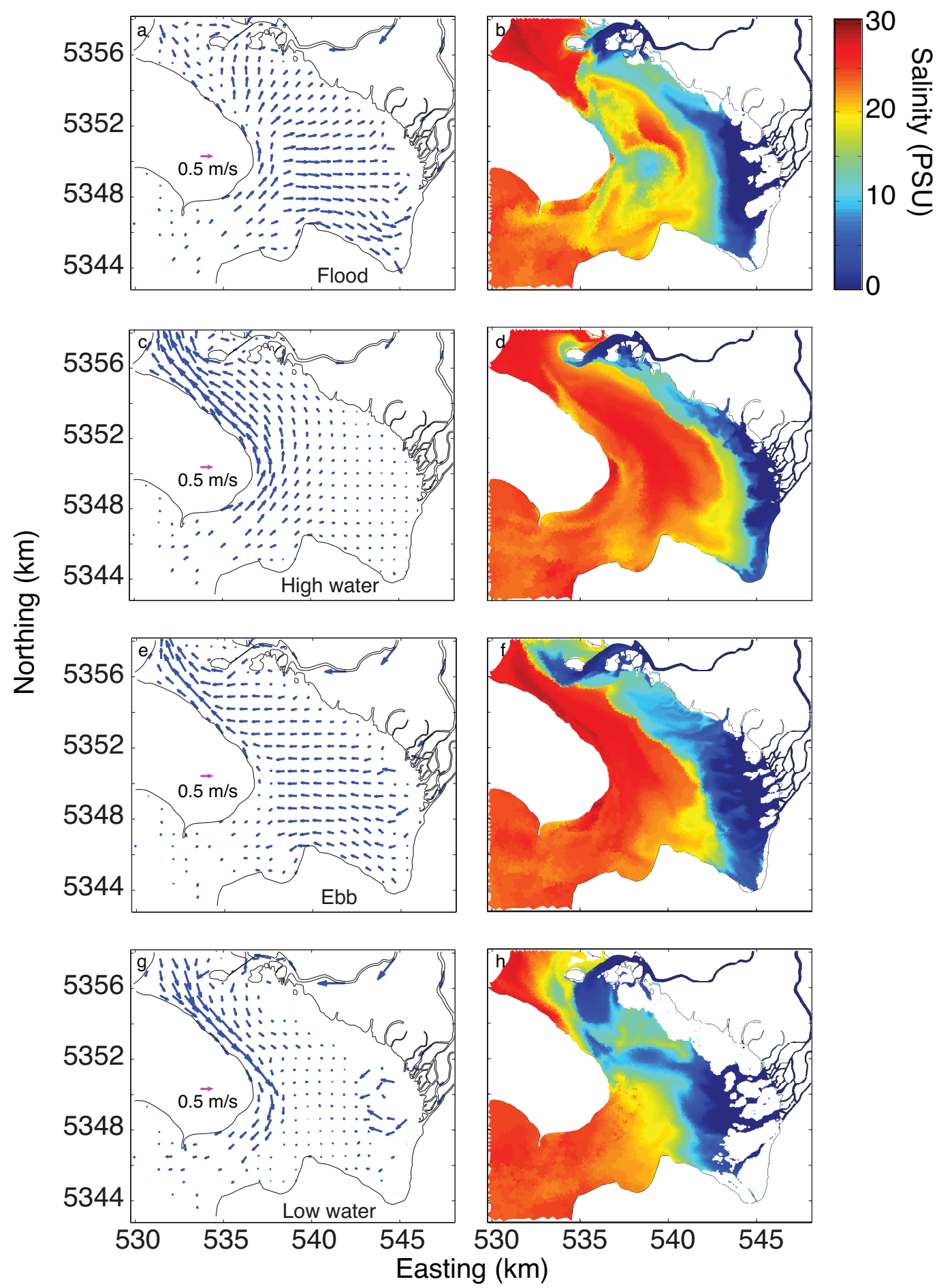

Figure 2-3: Snapshots of depth-averaged velocity (a, c, e, and g) and surface salinity (b, d, f, and h) for type 1 flood (a and b), high water (c and d), ebb (e and f), and low water (g and h) 

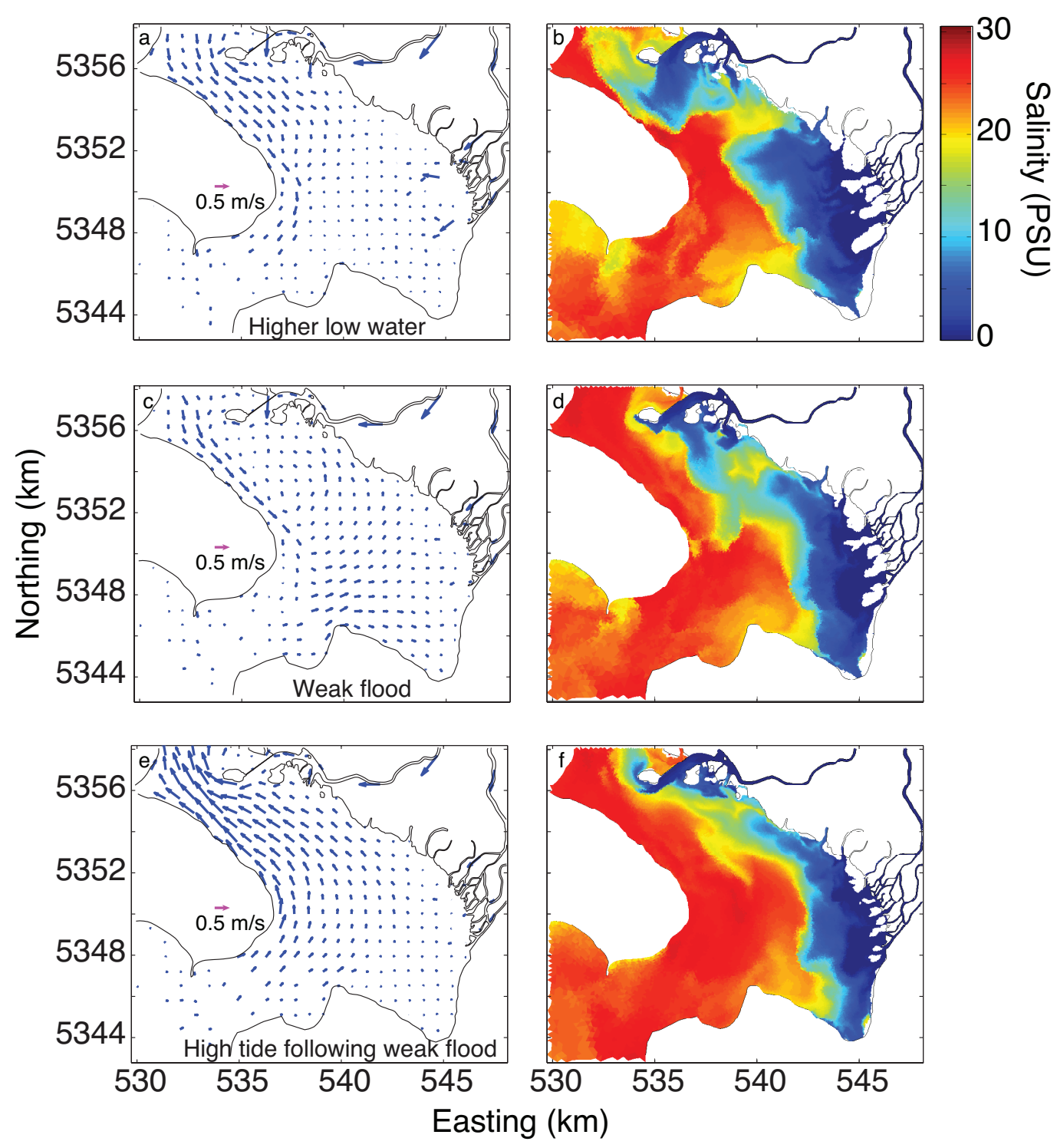

Figure 2-4 Snapshots of depth-averaged velocity (a, c, and e) and surface salinity (b, d, and f) for type 2 higher low water (a and b), weak flood (c and d), and high water after the weak flood (e and f).

The tides have been separated into type 1 and type 2 to account for the temporally dependent structure observed in this area. Type 1 tides are similar to the semi-diurnal tides often observed along the U.S. east coast. In contrast, the type 2 tides have an 
extended period of high water during the weak ebb and flood. The weak ebb and flood have distinct circulation patterns, and consequently the salinity transport and the evolution of stratification can be expected to differ from the stronger floods and ebbs. The weak flows during the weak flood and ebb also allow density driven flows to become more prominent, which is shown to cause differences in stratification between the two types of tides. 


\section{Observations}

This chapter is based on a paper submitted to Continental Shelf Research entitled Processes controlling stratification on the northern Skagit Bay tidal flats. The authors are Vera Pavel, B. Raubenheimer, and Steve Elgar. The appendix is part of this manuscript.

\subsection{Introduction}

Stratification has been studied in estuaries and coastal river plumes, but rarely on tidal flats where the ratio of tidal amplitude to depth is large and the bed is dry at low tide (effectively "resetting" the system). In addition, the Skagit tidal flats are short and wide, have freshwater discharge at both the north and south ends, and have tidal propagation parallel to the bathymetry contours, unlike many estuaries that are relatively long and narrow. In this chapter, field observations of flows, water density, and water levels on the Skagit Bay tidal flats will be used to evaluate the processes creating and destroying stratification during tides with small and large diurnal inequalities, The relative strength of tidal and density-driven processes will be examined. The stratification and the processes that control it affect turbulence and particle transport, and thus the results presented here will improve our understanding of the hydrodynamic and ecological development of tidal flats.

\subsection{Measurements}

Measurements of water level, currents, and water density were collected between 18 and 31 August 2009 at 5 locations (symbols in Fig. 2-1) perpendicular to and along (northwest to southeast) the $2.5-\mathrm{m}$ depth contour on the tidal flats. Water density was estimated from measurements with induction-type conductivity-temperature-depth (CTD) sensors. Near-bed density was measured with a fixed CT located $0.4 \mathrm{~m}$ above the bed. 
Near-surface density was measured with a CT and CTD mounted on a pole at distances of 0.2 and $0.7 \mathrm{~m}$ below a surface float, respectively. The tilt of the pole, and thus the depth of the upper CT sensor, was estimated from the along-pole distances and the depth measured by the lower CTD. Laboratory tests showed that errors in temperature and salinity are less than about $0.1^{\circ} \mathrm{C}$ and $0.1 \mathrm{PSU}$, respectively. The resulting density accuracy is about $\pm 0.1 \mathrm{~kg} / \mathrm{m}^{3}$ and the depth accuracy is about $\pm 0.01 \mathrm{~m}$. Bottom pressure was measured at $4 \mathrm{~Hz}$ with pressure sensors buried about $0.1 \mathrm{~m}$ below the bed level. Atmospheric pressure was measured at $4 \mathrm{~Hz}$ near La Conner, WA. Nearbed flows were measured about $0.1 \mathrm{~m}$ above the bed with acoustic Doppler velocimeters (ADVs) (accuracy about $\pm 0.01 \mathrm{~m} / \mathrm{s}$ ) that collected $3072 \mathrm{~s}$ of data at $2 \mathrm{~Hz}$ starting at the beginning of each hour. Flow profiles were measured at about $2 \mathrm{~Hz}$ in $0.25-\mathrm{m}$ bins from about $0.4 \mathrm{~m}$ above the bed to one to two bin-sizes from the water surface with $2 \mathrm{MHz}$ upward-facing current profilers (accuracy about $\pm 0.03 \mathrm{~m} / \mathrm{s}$ for 1 -min averages). Instrument locations were surveyed with post-processed differential GPS (accuracy about $0.03 \mathrm{~m}$ ). Instruments were separated in the cross- and alongshore by about 600 and $1600 \mathrm{~m}$, respectively. Tidally averaged salinity fields from model simulations suggest that alongshore spatial scales of salinity gradients are $\sim 2-10$ times as long as cross-shore scales.

Density measurements were averaged over 512-s periods. At the central location, the upper floating CT failed, and the data were replaced by an average of the 4 other upper CTs. Root-mean-square differences between the 512-s averaged densities from individual CT measurements and the average of the values from all sensors at the same elevation were about $2 \mathrm{~kg} / \mathrm{m}^{3}$, or about $25 \%$ of the surface-to-bottom density difference. Differences between the sensor-averaged density and the measurement at the central location for the lower floating CTD sensor also were about $2 \mathrm{~kg} / \mathrm{m}^{3}$. Results were similar for averages including data from only the alongshore (on the same depth contour) or only the cross-shore sensors. Atmospheric pressure was removed from measured bottom pressures. These adjusted pressures were averaged over $512 \mathrm{~s}$, and used to estimate water levels assuming hydrostatic pressure and using water density measured by the $\mathrm{CT}$ 
sensors. Pressure drifts were then removed by subtracting a quadratic fit to low-tide data, when the flat was dry and the water depth should have been negligible. ADVs were assumed to be fouled or out of the water and data were discarded when the signal strength was low or flows were noisy (defined as times when the root-mean-square velocity fluctuations were more than twice the fluctuations expected from applying linear theory to the pressure signal). Flows measured with ADVs were averaged over $512 \mathrm{~s}$, ignoring any points where the data were discarded. The estimated water levels were used to determine which profiler bins were actually giving measurements of the water column. Current profiles based on profiler data were averaged over 600 -s periods, then interpolated in time and output every $512 \mathrm{~s}$ to combine with ADV data.
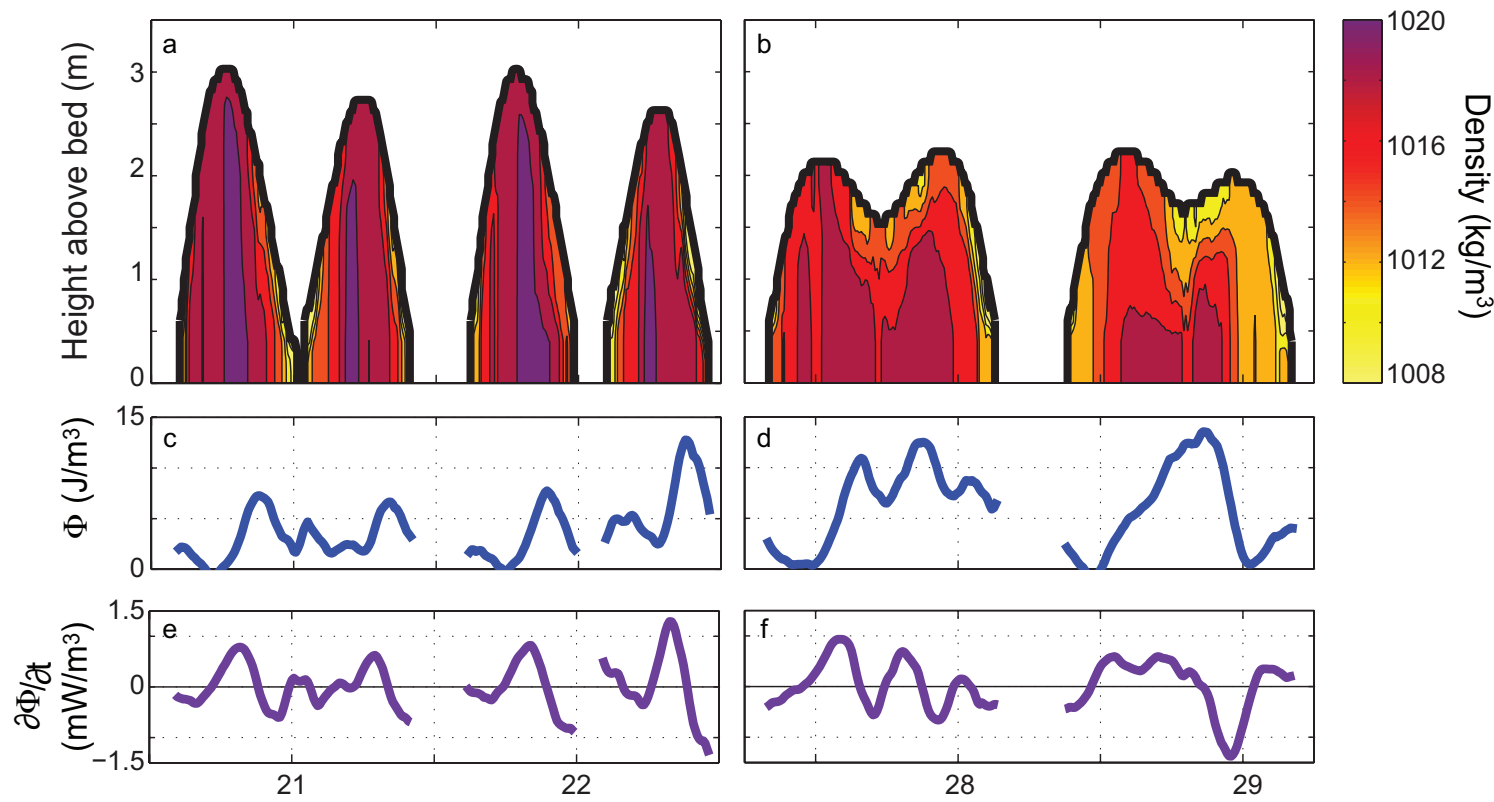

Time (day in August)

Figure 3-1: ( $\mathrm{a}$ and $\mathrm{b}$ ) Water density (color contours) as a function of depth (thick black curve) and time, and (c and d) $\Phi$ and (e and f) $\partial \Phi / \partial \mathrm{t}$ vs. time for selected times of type 1 (a, c, and e) and type $2(b, d$, and $f)$ tides.

Density is dominated by salinity, which ranges from fresh river water (density 1000 $\mathrm{kg} / \mathrm{m}^{3}$ ) to Puget Sound water with salinity 28 PSU (density $\sim 1020 \mathrm{~kg} / \mathrm{m}^{3}$ ). Cross-shore and alongshore density gradients, based on differences between sensors, had median 
values of about $5 \times 10^{-3}$ and $5 \times 10^{-4} \mathrm{~kg} / \mathrm{m}^{4}$, respectively. Maximum water depths ranged from about $4 \mathrm{~m}$ at the most offshore sensor to about $2 \mathrm{~m}$ at the most onshore sensor. Cross-shore and alongshore velocity ranged between about $\pm 0.5 \mathrm{~m} / \mathrm{s}$.

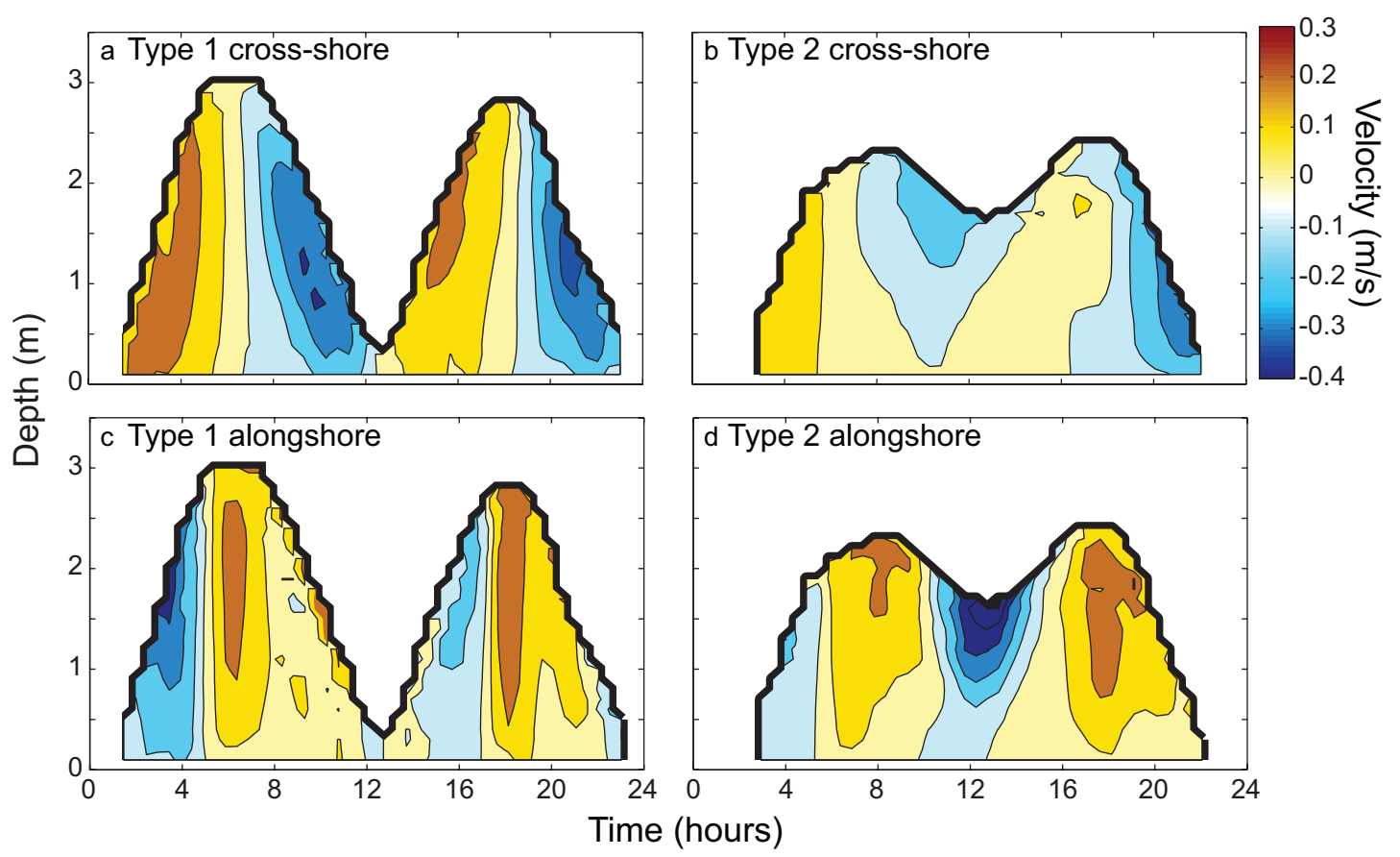

Figure 3-2: Phase-averaged ( $\mathrm{a}$ and b) cross- and (c and d) alongshore velocity (color contours) as a function of depth (thick black curve) and time for type 1 (a and c) and type 2 ( $b$ and d) tides

Similar to prior observations of salt-wedge estuaries (Ralston et al., 2010; Giddings et al., 2011) and numerical simulations of Skagit Bay (Yang and Khangaonkar, 2009), the water column is fresh at the beginning of flood tide, just after the tidal flat is submerged (Fig. 31). The salinity front moves onshore during flood, with the water column becoming increasingly saline. During ebb, the salinity front moves offshore and the water freshens while draining off the tidal flats. 
During type 1 tides, cross- and alongshore velocities (Figs. 3-2a and c) have similar magnitudes (see also Webster et al., 2012). Cross-shore flows are relatively weak during type 2 tides (Fig. 3-2b), which correspond to neap tides during this time period, but alongshore flows are large (Fig. 3-2d), resulting in similar total flow magnitudes during both types of tides.

\subsection{Theory and Processing}

\subsubsection{Theory}

The stratification is quantified using the potential energy anomaly $(\Phi)$, the amount of energy per unit volume required to homogenize the water column:

$$
\Phi=-\frac{g}{D} \int_{-h}^{\eta} \rho^{\prime} z d z,
$$

where $g$ is the gravitational acceleration, $h$ and $\eta$ are the mean depth and the elevation of the surface above the mean, $D=h+\eta$ is the total water depth, $\rho=\bar{\rho}+\rho^{\prime}$ is the density, where $\bar{\rho}$ and $\rho^{\prime}$ are the depth-mean and residual values, and $z$ is the vertical coordinate, which is zero at the mean surface and positive upward.

The temporal evolution of $\Phi$ (Fig. 3-1) is given by (Burchard and Hofmeister 2008):

$$
\begin{aligned}
\frac{\partial \Phi}{\partial t} & =-\nabla_{h}(\overline{\mathbf{u}} \Phi)+\frac{g}{D} \nabla_{h} \bar{\rho} \cdot \int_{-h}^{\eta} \mathbf{u}^{\prime} z d z-\frac{g}{D} \int_{-h}^{\eta}\left(\eta-\frac{D}{2}-z\right) \mathbf{u}^{\prime} \cdot \nabla_{h} \rho^{\prime} d z \\
& -\frac{g}{D} \int_{-h}^{\eta}\left(\eta-\frac{D}{2}-z\right) \hat{w} \frac{\partial \rho^{\prime}}{\partial z} d z+\frac{g}{D} \int_{-h}^{\eta} K_{v} \frac{\partial \rho}{\partial z} d z-\frac{\rho_{0}}{2}\left(P_{b}^{s}+P_{b}^{b}\right) \\
& +\frac{g}{D} \int_{-h}^{\eta}\left(\eta-\frac{D}{2}-z\right) Q d z+\frac{g}{D} \int_{-h}^{\eta}\left(\eta-\frac{D}{2}-z\right) \nabla_{h}\left(K_{h} \nabla_{h} \rho\right) d z
\end{aligned}
$$

where $t$ is time, $\nabla_{\mathrm{h}}$ indicates the horizontal components of the gradient operator, $\mathbf{u}$ is the vector horizontal velocity where the overbar denotes the depth-average and the prime is 
the deviation from the depth-average, $\rho_{0}$ is a reference density, $P_{b}^{S}$ and $P_{b}^{b}$ are surface and bottom buoyancy flux, respectively, $\mathrm{Q}$ represents inner sinks and sources, $\mathrm{K}_{\mathrm{h}}$ is the horizontal eddy diffusivity and $\widehat{w}$ is the deviation of the vertical velocity $(w)$ from a linear profile:

$$
\hat{w}=w-\left[\left(\frac{\partial \eta}{\partial t}+\overline{\mathbf{u}} \cdot \nabla_{h} \eta\right) \frac{z+h}{D}-\overline{\mathbf{u}} \cdot \nabla_{h} h \frac{\eta-z}{D}\right] .
$$

The eddy diffusivity $K_{v}$ is estimated as (Munk and Anderson, 1948; Nepf and Geyer, 1996; Burchard and Hofmeister, 2008; Becker et al., 2009):

$$
K_{v}=K_{0}\left(1+3.33 R_{i}\right)^{-3 / 2}
$$

where $R_{i}$ is the bulk Richardson number (Byun and Wang, 2005; Stacey and Ralston, $2005)$ and $K_{0}$ is the estimated eddy diffusivity for an unstratified water column (see Appendix for further details on the mixing parameterization). The last three terms on the right side of equation (2) are expected to be small compared with the other terms and are neglected. To examine the effects of changing depth, the first term is separated into an advection and depth change term:

$-\nabla_{h}(\overline{\mathbf{u}} \Phi)=-\overline{\mathbf{u}} \nabla_{h} \Phi-\Phi \nabla_{h} \overline{\mathbf{u}}$

By continuity, the horizontal gradient of the mean velocity can be expressed in terms of depth changes as:

$$
\nabla_{h} \overline{\mathbf{u}}=-\frac{1}{D}\left(\frac{\partial \eta}{\partial t}+\overline{\mathbf{u}} \cdot \nabla_{h} D\right)
$$

Finally, rearranging the integrals as:

$$
-\int_{-h}^{\eta}\left(\eta-\frac{D}{2}-z\right) \chi d z=\int_{-h}^{\eta} z \chi^{\prime} d z
$$

where $\chi$ is an arbitrary depth-dependent function, the overbar denotes the depth-average, and the prime denotes the deviation from the depth-average, results in: 


$$
\begin{aligned}
\frac{\partial \Phi}{\partial t} & =\underbrace{\overline{\mathbf{u}} \cdot \nabla_{h} \Phi}_{A}+\underbrace{\frac{\Phi}{D} \cdot\left(\frac{\partial \eta}{\partial t}+\overline{\mathbf{u}} \cdot \nabla_{h} D\right)}_{D C}+\underbrace{\frac{g}{D} \nabla_{h} \bar{\rho} \cdot \int_{-h}^{\eta} \mathbf{u}^{\prime} z d z}_{D S}+\underbrace{\frac{g}{D} \int_{-h}^{\eta}\left(\mathbf{u}^{\prime} \cdot \nabla_{h} \rho^{\prime}\right)^{\prime} \cdot z d z}_{N S} \\
& +\underbrace{\frac{g}{D} \int_{-h}^{\eta} K_{v} \frac{\partial \rho}{\partial z} d z}_{M}+\underbrace{\frac{g}{D} \int_{-h}^{\eta}\left(\hat{w} \frac{\partial \rho}{\partial z}\right)^{\prime} \cdot z d z}_{V A}
\end{aligned}
$$

where term $\mathrm{A}$ is direct advection of stratification, DC is the effect of depth changes in both time and space, DS is depth-mean straining, NS is non-mean straining caused by shear acting on a non-depth-uniform density gradient, $\mathrm{M}$ is mixing, and VA is vertical advection shifting the isopycnals up and down,

\subsubsection{Processing}

To evaluate the integrals in equation (8), density and velocity profiles were linearly interpolated onto a $0.1-\mathrm{m}$ vertical grid. Profiles were extended to the surface and bed assuming constant values given by the highest and lowest measurement, respectively. Results are similar to assuming zero flux at the bed and surface and using a linear extrapolation of the vertical gradient. Errors in $\Phi$ owing to the vertically sparse density measurements are of order $10 \%$, based on differences between this method and fitting to a two-layer model. Near-bottom density was interpolated along the sloping bed. The vertical structure of cross-shore density gradients at elevations between the bed levels at any two locations was calculated using the density profile at the deeper location and the corresponding densities (same elevations) estimated along the sloping bed (Fortunato and Baptista, 1996). Horizontal gradients were evaluated using upstream (determined from the depth-averaged velocity at the central location) differences.

Profiler measurements of horizontal flows coupled with a mass balance suggest that vertical velocities $(\mathrm{w})$ were smaller than the resolution of the instrument $(0.001 \mathrm{~m} / \mathrm{s})$, so the vertical advection term could not be calculated from data. Previous results suggest that this term is unlikely to be large except in a small region near the density front (Nepf 
and Geyer, 1996; Burchard and Hofmeister, 2008; de Boer et al., 2008; Hofmeister et al., 2009; Marques et al., 2010), and thus it is neglected here. However, vertical advection may contribute to the errors in the estimated stratification balance.

The water depth, $\Phi$, and all terms in equation (8) were smoothed using a 7200 -s running average. The averaging period was chosen to be shorter than $1 / 4$-tidal period to resolve tidal fluctuations, but longer than the advective timescale between sensor locations (about $3600 \mathrm{~s}$ and $4800 \mathrm{~s}$ in the cross- and alongshore, respectively). This temporal averaging and smoothing reduces errors owing to unresolved small-scale spatial variability. $\Phi$ was smoothed before difference calculations were performed and the results were smoothed again after computing $\partial \Phi / \partial \mathrm{t}$ and the advection term to remove jitter artifacts that result from numerical differencing of noisy data. All terms were phase averaged over 24-h long (diurnal) cycles for type 1 ( 5 cycles) and type 2 ( 4 cycles) tides. The distinction between the tide types 1 and 2 was made by comparing the difference in water level of the two low tides to the total tidal range for that diurnal cycle. If the difference was less than $1 / 4$ the tidal range it was considered a type 1 tide. If the difference was greater than $1 / 3$ the tidal range it was considered a type 2 tide.

\subsection{Results}

\subsubsection{The Potential Energy Anomaly Balance}

The ensemble-averaged diurnal variations of $\partial \Phi / \partial \mathrm{t}$ (Fig. 3-3), including the timing of the maxima and minima, are consistent with the stratification balance (equation (8)). The good agreement between the left hand side of the equation (Fig. 3-3c and d, black curve), which was calculated directly from the central site's $\Phi$ (Fig. 3-3a and b), and the right side of the balance (Fig. 3-3c and d, purple dashed curve) suggests that the sum of the neglected terms (vertical advection, additional sources of mixing, and surface or bed 
buoyancy fluxes) is not large compared with the retained terms, possibly because the neglected terms cancel, as in numerical simulations of the Patos Lagoon ROFI (Marques et al., 2010).
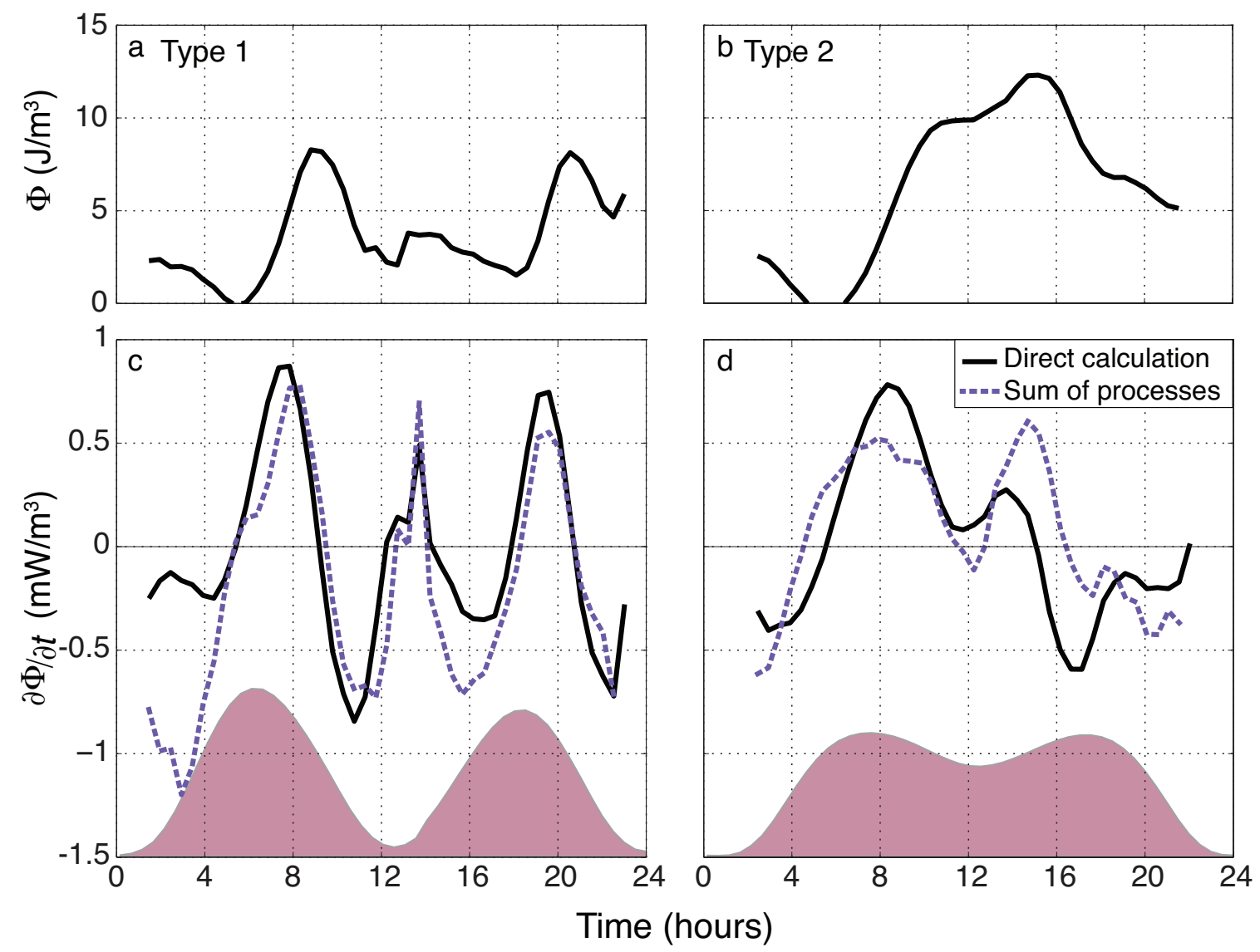

Figure 3-3: Phase-averaged $\Phi$ (a and b) and $\partial \Phi / \partial t$ (c and d) based on the observed density profiles (solid black curves) and on estimations of stratification-related processes (right-hand side of equation (1), dotted purple curves) versus time for (a and c) type 1 and (b and d) type 2 tides. Squared correlations between the direct and process estimates are about 0.7. The shaded area shows the relative water depth over the tidal cycle.

During the type 1 and 2 strong flood tides the thin layer of water initially submerging the flats is slightly stratified (Figs. 3-3a and b), but becomes increasingly well-mixed (Figs. $3-3 \mathrm{c}$ and $\mathrm{d}, \partial \Phi / \partial \mathrm{t}<0$. In contrast to many partially mixed estuaries and ROFIs in which 
depth-mean straining dominates and maximum stratification occurs during late ebb or low water (Nepf and Geyer, 1996; Rippeth et al., 2001; Burchard and Hofmeister, 2008), but similar to observations in strongly-forced salt-wedge estuaries (Ralston et al., 2010a; Giddings et al., 2011), maximum stratification occurs at about mid ebb tide (Fig. 3-3c time about 9 and $21 \mathrm{~h}$, where $\partial \Phi / \partial \mathrm{t}$ changes from positive to negative). During type 2 tides, stratification increases during the beginning of the weak flood (Fig. 3-3d, time from about 13 to $16 \mathrm{~h}, \partial \Phi / \partial \mathrm{t}>0$, and Fig. 3-4b). Although, temporal changes in stratification vary during individual type 2 tidal cycles, in 3 of 4 cases $\Phi$ is larger at the end of the weak flood than at the beginning of the weak ebb (Fig. 3-4b).

In prior studies of stratification for mixed tides (Ralston and Stacey, 2005b; Wang et al., 2009; Giddings et al., 2011), the stratification decreases during the weak flood, briefly increases during the beginning of the following strong ebb, then decreases again, which appears to be a result of straining on the weak flood and beginning of ebb, that is then combined with mixing, and possibly advection, later on the ebb. The measurements in the Skagit for similar time periods (Fig. 3-4b time $\sim 16$ to $22 \mathrm{~h}$ ) show high variability, but on average, the stratification decreases from about mid weak flood through the second high tide and the following strong ebb. Although the same processes are likely acting, this difference suggests that the advection process may be more influential in the Skagit for this tidal phase.

The individual terms in the balance (Fig. 3-5) indicate which processes dominate the stratification. The fresh water draining off the flats during the strong ebbs remains partly stratified (Figs. 3-1c and d). Thus, on the strong floods, advection and depth-mean straining (solid blue and dashed purple curves in Fig. 3-5a for time about 2 to 6 and 12 to $16 \mathrm{~h}$, and Fig. 3-5b for time about 2 to $6 \mathrm{~h}$ ) often are negative as the thin, mostly fresh tongue that initially covers the flats is replaced by water from offshore that is increasingly well-mixed and saline (Figs. 2-3 b and d). Advection usually opposes the positive depthmean straining on the ebb (Fig. 3-5 time about 8 to 12 and 18 to $22 \mathrm{~h}$ ), indicating that the 
fresh water that is trapped near the shore at high tide (Fig. 2-3 d) is less stratified than the offshore water, similar to many estuaries (Burchard and Hofmeister, 2008; Ralston et al., 2010a; Giddings et al., 2011) where river discharge occurs onshore, but in contrast to models of ROFIs (de Boer et al., 2008) where the freshwater source is not directly onshore. The negative advection also suggests that stratified water is removed from the upper flats and transported to the offshore flats during the strong ebb, where it would be transported northward towards Deception Pass (Fig 2-3e). Comparison of the terms during type 1 tides with those during type 2 tides suggests that large negative values of $\partial \Phi / \partial t$ occur on strong (but not weak) ebbs at least partly because advection of well-mixed water is larger on strong ebbs (compare the maximum negative values of the dark blue curve in Fig. 3-5a with those in Fig. 3-5b, e.g., near time is 10 h). The larger advection on strong ebbs than weak ebbs is a primarily a result of the difference in the strength of the tidal flows.
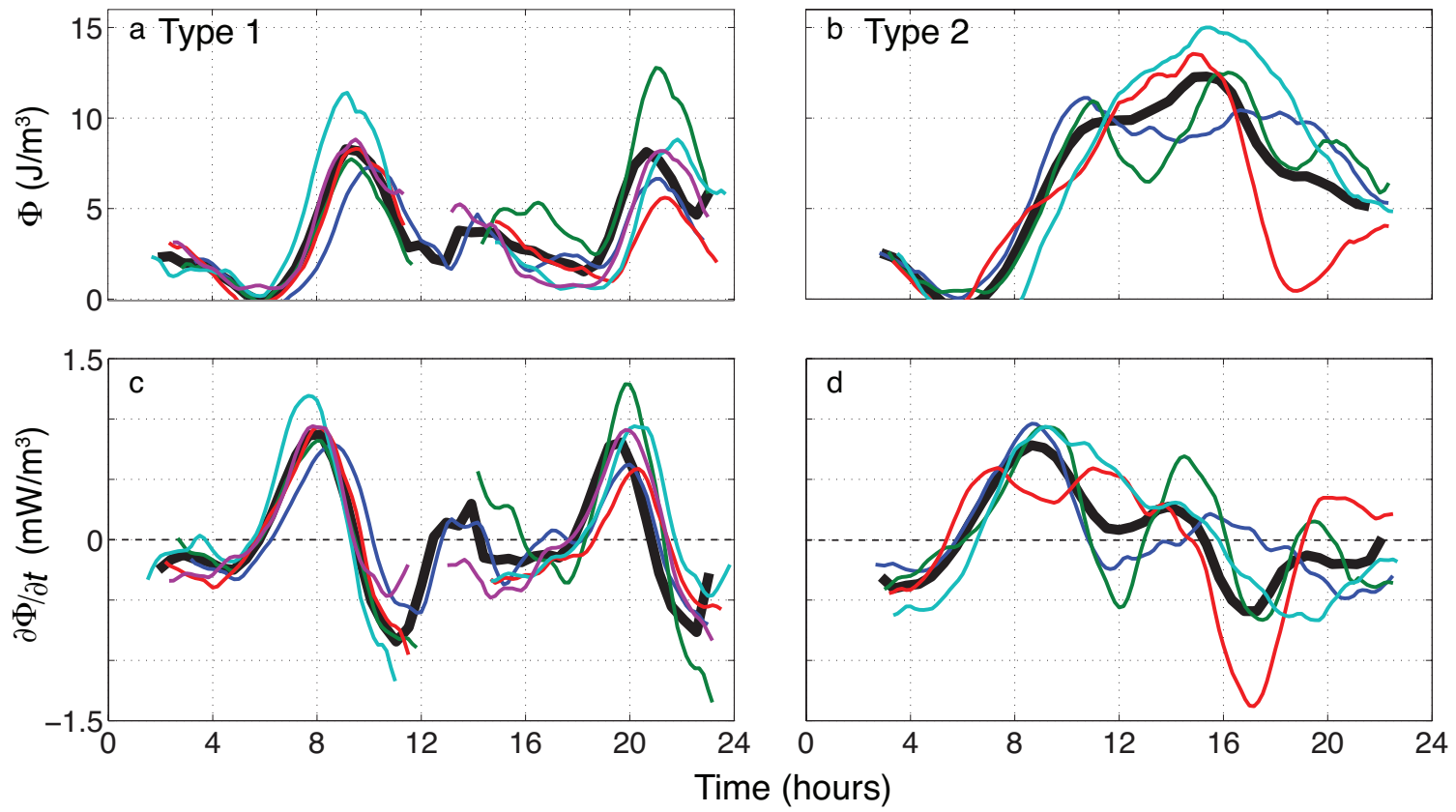

Figure 3-4: Comparison of individual tidal cycles (thin curves) to the average (thick black curve) for $\Phi(\mathrm{a}$ and $\mathrm{b}$ ) and $\partial \Phi / \partial t$ (c and d) for type 1 (a and c) and type 2 (b and d) tides. 
Near the end of the type 2 weak ebb, advection is small and switches from negative to positive (dark blue curve in Fig. 3-5b near time about $12 \mathrm{~h}$ ), at least partly owing to positive alongshore advection (Fig. 3-6b) caused by strong southeasterly alongshore flows (Figs. 2-3e and 3-2d) transporting stratified water alongshore from the north fork of the Skagit River towards the instrument location and the central flats (Fig 3-7b). The water on the offshore flats remains stratified following the weak ebb (Fig. 3-7d), and thus cross-shore advection is positive throughout the weak flood. Cross-shore depth-mean straining also remains positive during the small low and until about mid weak flood (Fig. $3-5 b$ ) owing to vertically sheared currents with offshore flow near the surface (Fig. 3-2b).

Mixing (Fig. 3-5, green dashed curve), which always is negative (reducing stratification), is largest when internal or bottom shear is large and when the water is not well mixed already. During type 1 tides, mixing is strongest during the ebbs, which is consistent with the combined interfacial- and bottom-generated mixing observed in strongly forced saltwedge estuaries (Ralston et al., 2010b; Giddings et al., 2011; Wang et al., 2011). Mixing is weak during floods despite strong near-bed flows primarily because there is a lack of stratification to be mixed. However, complete mixing does not seem to occur and the minimum (geometrically) phase-averaged bulk Richardson number is about 0.2 , occurring after the strong flood of type 1 tides. During type 2 tides, mixing is relatively large during the small low tide (dashed green curve in Fig. 3-5b for time about $12 \mathrm{~h}$ ), similar to observations and model predictions in the Snohomish estuary (Wang et al., 2009; Giddings et al., 2011). Near-bed flows are weak, while mid-water column shear is strong (Figs. 3-2b and d), suggesting the mixing on type 2 tides primarily is caused by internal shear, especially for the more highly vertically sheared alongshore currents (Fig. $3-2 \mathrm{~d})$. The bulk Richardson number at the higher low water is about 0.5 , which is the lowest value during phase-averaged type 2 tides, equal to that occurring at the end of the type 2 strong flood. Similar to other systems with strong stratification (Burchard and Hofmeister, 2008; de Boer et al., 2008), mixing usually is smaller than advection and 
depth-mean straining (Fig. 3-5), but here mixing remains significant owing to the shallow depths.

The non-mean straining is small during type 1 tides (Fig. 3-5a, solid light blue curve). However, in contrast to numerical simulations showing that non-mean straining typically is large only near the river or estuarine mouth (de Boer et al., 2008; Marques et al., 2010), here it is similar in magnitude to the other terms during type 2 tides (Fig. 3-5b), and it reduces the increase in stratification during the small low tide (Fig. 3-3d, $\partial \Phi / \partial \mathrm{t}>0$ ) and the decrease in stratification during the latter half of the weak flood (Fig. 3-3d, $\partial \Phi / \partial \mathrm{t}<$ 0 ). The prior simulations suggest vertical advection may balance non-mean straining, and thus the discrepancies between the direct- and process-based estimates of $\partial \Phi / \partial \mathrm{t}$ (Fig. 3$3 d$ ) during the small low tide and weak flood may result partly from neglecting vertical advection. Discrepancies also may occur because the depth dependence of density (which affects non-mean straining) is not well-resolved by the field measurements.

Similar to long, narrow estuaries (Simpson et al., 1990; Nepf and Geyer, 1996; Burchard and Hofmeister, 2008; Giddings et al., 2011), the cross-shore advection (Fig. 3-6a) and depth-mean straining (Fig. 3-6c) during type 1 tides are 5 and 15 times larger, respectively, than the alongshore components. However, the cross- and alongshore velocities (Figs. 3-2a and c) have similar magnitudes, consistent with the dominance of cross-shore processes being a result of larger cross-shore density gradients (see also Figs. 2-3 and 2-4). The depth-mean (Fig. 3-6d) and non-mean (Fig. 3-6f) straining also are dominated by the cross-shore component during type 2 tides, but the alongshore component of the advection during type 2 tides has about half the magnitude of its crossshore component (Fig. 3-6b). The largest magnitudes of alongshore advection for type $2 \mathrm{t}$ 

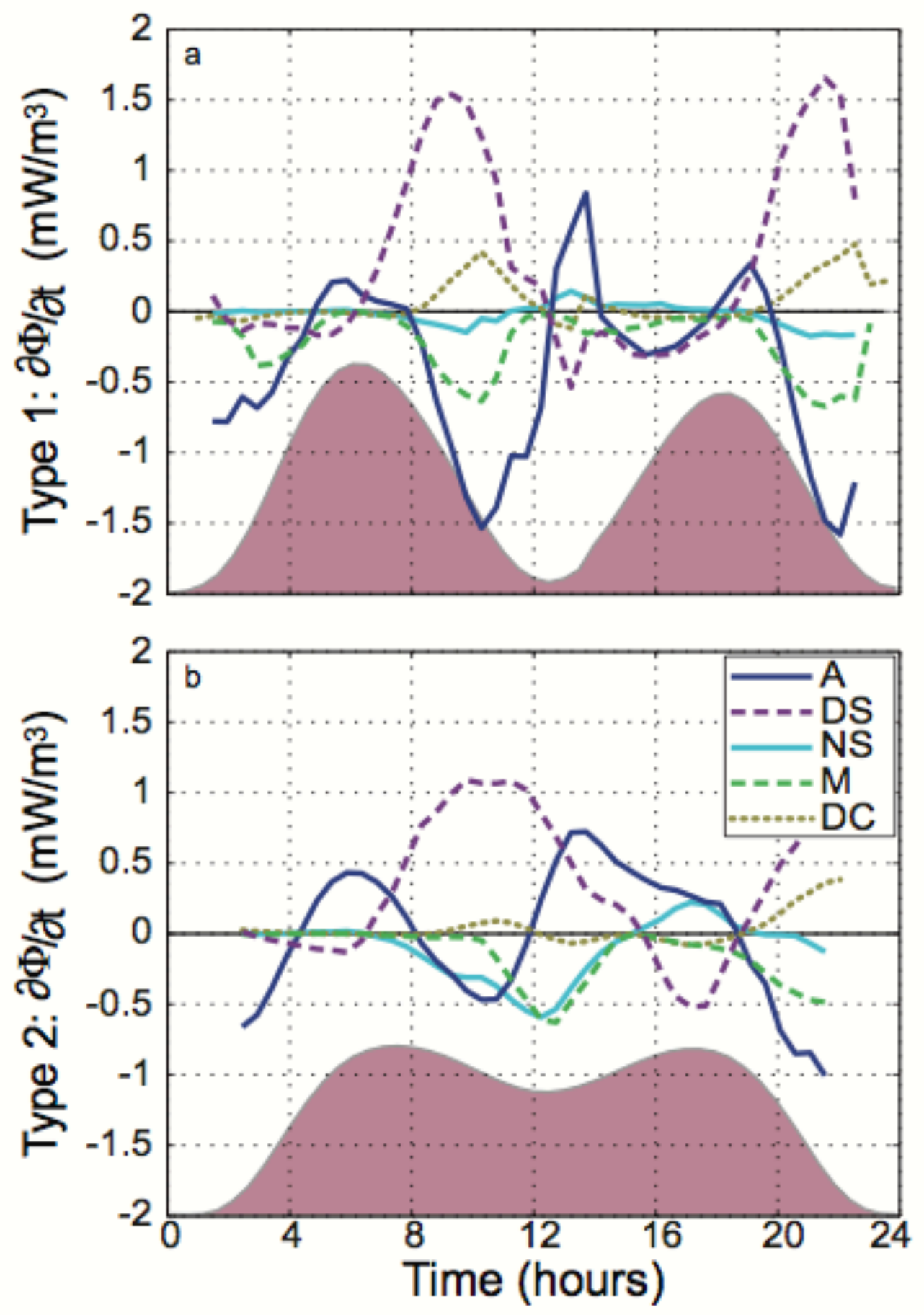

Figure 3-5 Phase-averaged values of terms on the right side of equation (2) versus time for (a) type 1 and (b) type 2 tides. The shaded area shows the relative water depth over a tidal cycle. 
ides result from large alongshore stratification variations (Fig. 3-7b time from 10 to $16 \mathrm{~h}$ ) and alongshore-dominated flows (compare Figs. 3-2d with 3-2b for time from 10 to $16 \mathrm{~h}$ ) during the end of the weak ebb and the beginning of the weak flood owing to the largescale tidal circulation (Yang and Khangaonkar, 2009). Owing to the difference in tidal range at Deception Pass and Saratoga Passage, there is a flow to the northwest at high tides and a flow to the southeast at low tides. The high tide effect is not seen in the stratification balance of type 1 tides, and is smaller than the low tide effect during type 2 tides because alongshore density and stratification gradients are small during the high tide, a result of the measurement location being well inside the unstratified salt wedge. The low tide effect is not seen on type 1 tides because there is no water on the flats at the measurement location.

\subsubsection{Spatial Variability}

As in prior studies (Burchard and Hofmeister, 2008; de Boer et al., 2008; Marques et al., 2010), the potential energy anomaly and the dominant processes controlling the stratification can be spatially variable (Fig. 3-7). Here, the strength of the stratification typically increases towards the northwest (towards the mouth of the north fork, Figs. 3-7a and b) and offshore (Figs. 3-7c and d). For both type 1 and 2 tides, the local maxima in stratification occur earlier at onshore locations (red dotted curves in Figs. 3-7c and d) than at offshore locations (purple solid curves), possibly owing to the earlier passage of the density front.

During type 1 tides, temporal changes in $\Phi$ are similar at all sensors (Figs. 3-7a and c), in contrast to larger, more spatially variable estuaries and ROFIs (de Boer et al., 2008; Burchard and Hofmeister, 2008; Wang et al., 2009; Marques et al., 2010, 2011; Ralston et al., 2010a; Giddings et al., 2011). The front-induced stratification maximum on the flood following the smaller low becomes stronger at the northwest (closer to the north fork, Fig. 3-7a for time about 20 to 24 h) and offshore (Fig. 3-7c for time about 20 to 24 
h) locations, possibly because the salt wedge becomes stronger closer to the river mouth and offshore.
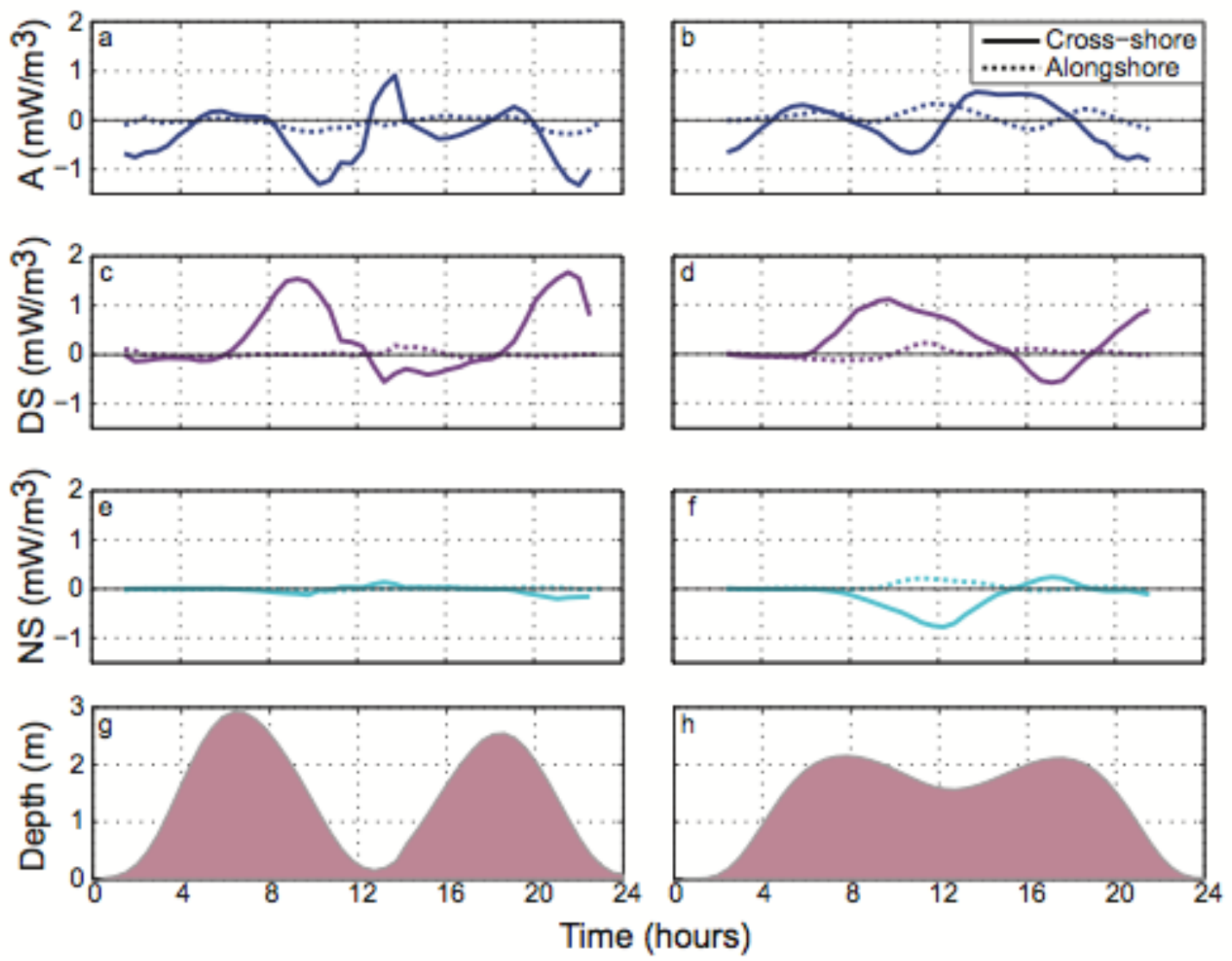

Figure 3-6: Phase-averaged cross- (solid curves) and alongshore (dotted curves) components of (a and b) advection, (c and d) depth-mean straining, and (e and f) non-mean straining for (a, c, and e) type 1 and ( $b, d$, and f) type 2 tides versus time. The shaded area ( $g$ and $h$ ) shows the relative water depth over a tidal cycle.

The maximum stratification is larger during type 2 tides than during type 1 tides at most locations (Fig. 3-7). Consistent with prior observations in shallow channels and in strongly forced salt-wedge estuaries (Ralston and Stacey, 2005b; Wang et al., 2009; Ralston et al., 2010a; Giddings et al., 2011), the water column remains stratified during the type 2 small low tide. The density-driven circulation dominates during these weak tidal flows, except at the most onshore location, which may have uniform density at that 
time (Fig. 3-7d). The stratification increases during the weak flood at most locations (Figs. 3-7b and d), presumably owing to the same advection of stratified water (Fig. 3-6b) and depth-mean straining (Fig. 3-6d) observed at the central location. Except at the southeastern and onshore locations, the water column remains partly stratified until water drains off the flat.
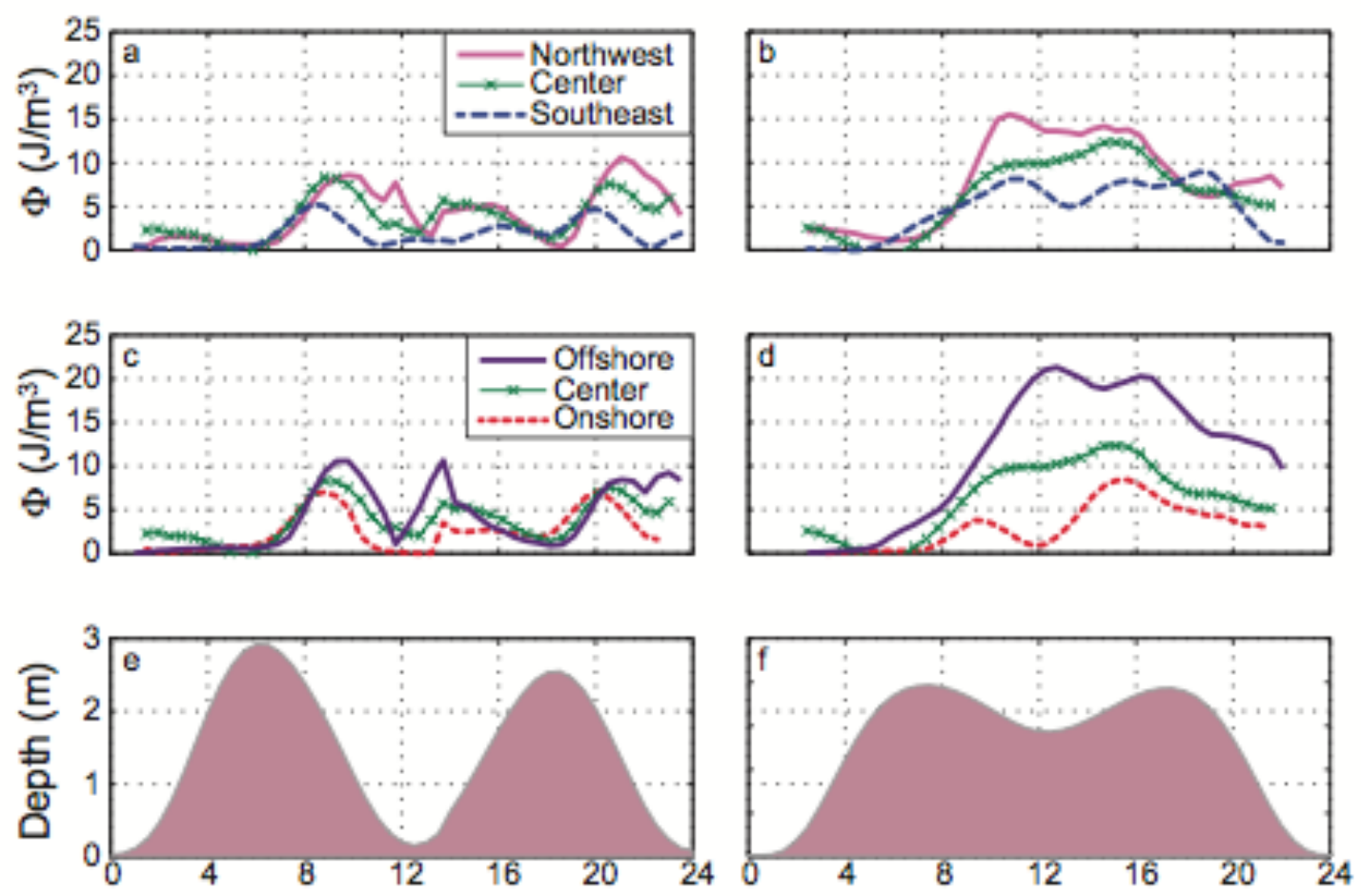

Time (hours)

Figure 3-7: Phase-averaged potential energy anomaly for ( $a$ and b) alongshore and (c and d) cross-shore sensor lines for (a and c) type 1 and (b and d) type 2 tides, and (e and f) water depth versus time.

The spatially uniform temporal evolution of stratification during type 1 tides suggests that the processes affecting stratification are similar across the flats. However, the spatial variability during type 2 tides suggests that different processes may dominate depending on location, similar to numerical model simulations over large regions of salt-wedge estuaries (Wang et al., 2009; Ralston et al., 2010a) and ROFIs (Marques et al., 2010). The difference between type 1 and type 2 stratification is at least partly owing to the relative 
importance of tidal barotropic circulation, which affects the advection and mixing. In particular, barotropic forcing is larger than density-driven estuarine-style circulation during the strong floods and ebbs. In contrast, during the type 2 weak flood and ebb, the estuarine circulation increases stratification with little modulation from the weakened barotropic forcing. During this period, spatial variations in stratification are relatively large because, unlike the externally forced tides, the strength of estuarine circulation is sensitive to local density gradients and water depth.

\subsubsection{Robustness of results}

\begin{tabular}{|r|c|c|c|c|c|c|}
\hline & \multicolumn{3}{|c|}{ Type 1 tides } & \multicolumn{3}{c|}{ Type 2 tides } \\
\hline & Min & Mean & Max & Min & Mean & Max \\
\hline $\boldsymbol{\Phi}$ & 0.75 & 0.83 & 0.86 & 0.67 & 0.84 & 0.95 \\
\hline$\partial \Phi / \partial t$ & 0.76 & 0.84 & 0.95 & 0.49 & 0.66 & 0.83 \\
\hline Advection & 0.53 & 0.71 & 0.80 & 0.34 & 0.68 & 0.83 \\
\hline Depth-mean straining & 0.77 & 0.85 & 0.93 & 0.66 & 0.74 & 0.86 \\
\hline Non-mean straining & 0.37 & 0.58 & 0.72 & 0.34 & 0.68 & 0.93 \\
\hline Mixing & 0.40 & 0.59 & 0.89 & 0.62 & 0.71 & 0.76 \\
\hline Depth Change & 0.48 & 0.71 & 0.88 & 0.57 & 0.80 & 0.96 \\
\hline
\end{tabular}

Table 3-1: Correlation coefficients as $\mathrm{r}^{2}$. Minimum, mean, and maximum are given for individual tidal cycles compared against the phase averaged results given in Figs. 3-3 and 3-5 .

Correlations of $\Phi$, directly calculated $\partial \Phi / \partial t$, and each of the terms shown in Fig. 3-5 were performed between individual tidal cycles (Fig. 3-4) and the phase-averaged results (Table 3-1). Most of the values of $\mathrm{r}^{2}$ were above 0.6 , and many were above 0.8 , which shows that the phase-averaging method preserves most of the variability of these processes. Depth-mean straining, $\Phi$, and $\partial \Phi / \partial t$ had particularly high correlations, 
indicating that tidal variations of these quantities are more stable between cycles. For type 1 tides correlations are similar for $\partial \Phi / \partial t$ and $\Phi$, while for type 2 tides the $\Phi$

correlation is higher. For type 1 tides, both $\Phi$ and $\partial \Phi / \partial t$ have 2 or 3 strong maxima and minima associated with the strong floods and ebbs (Fig. 3-4a and c). In contrast, during type 2 tides, $\Phi$ rises on the weak ebb and remains high until the strong ebb (Fig. 3-4b). Small fluctuations during this period cause oscillations in $\partial \Phi / \partial t$ that are different in magnitude and phase between the individual tidal cycles (Fig. 3-4d).

\subsection{Summary and Conclusions}

The key features of the different tidal stages are listed below.

Processes occurring on strong floods during type 1 and type 2 tides (Fig. 3-8) include:

- Water moves onshore.

- $\Phi$ is positive at the start of the flood as the salt wedge encroaches (initially near the seafloor) on the riverine water remaining on the flats.

- The velocity shear moves the denser offshore water onshore faster at the surface than near the bed, reducing $\Phi$ through (negative) depth-mean straining.

- The offshore, previously unstratified, water is advected onshore. 

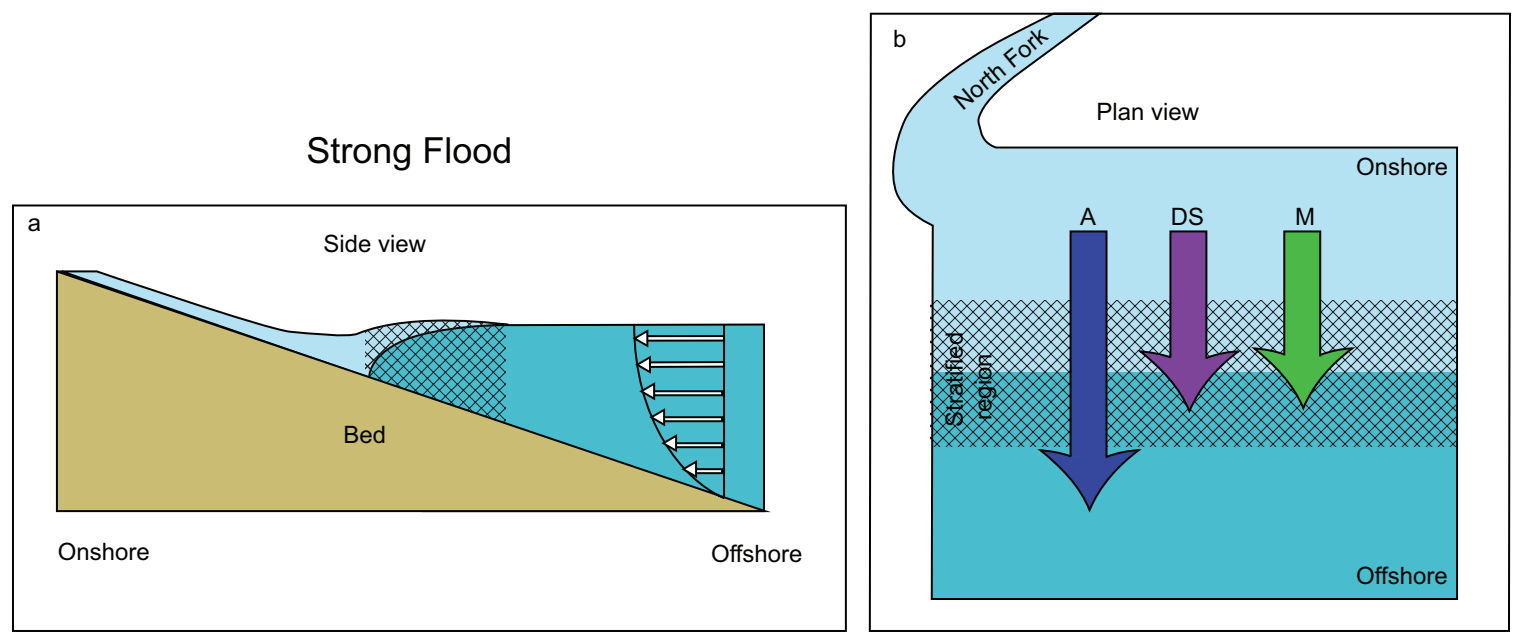

Figure 3-8: Cross-section (a) and plan view (b) diagrams of the flats during the strong flood. The white arrows (a) indicate the cross-shore flow profile, and colored arrows (b) indicate the stratification processes with onshore- and offshore-directed arrows indicating increasing and decreasing stratification, respectively. The length of each arrow indicates the relative strength of the flow or process. Blue shading represents water, with lighter colors representing fresher water. The cross-hatching indicates the stratified region.

Processes occurring on type 1 strong ebbs (Fig. 3-9) are:

- Water moves offshore.

- $\Phi$ initially is small, then increases strongly, and then decreases.

- During the increase in $\Phi$, the velocity shear moves the fresher water from onshore to offshore faster at the surface than near the bed, increasing $\Phi$ through depthmean straining

- $\Phi$ created by the depth-mean straining tends to be larger in deeper water, so as the ebb progresses, the low- $\Phi$ onshore water is advected offshore by the mean flow, resulting in negative values of advection.

- Mixing also becomes relevant on the ebb in the presence of strong stratification and relatively strong flows. 

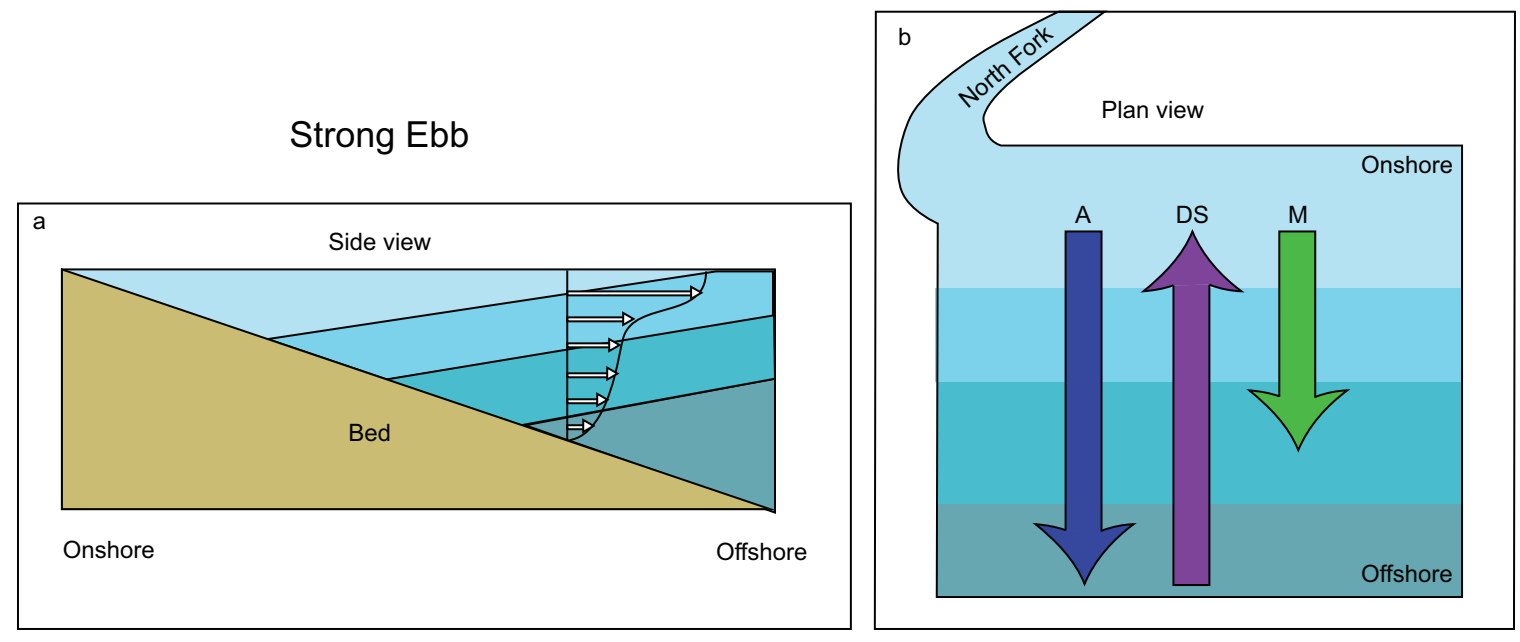

Figure 3-9: Cross-section (a) and plan view (b) diagrams of the flats during the type 1 strong ebb. The white arrows (a) indicate the cross-shore flow profile, and colored arrows (b) indicate the stratification processes with onshore- and offshore-directed arrows indicating increasing and decreasing stratification, respectively. The length of each arrow indicates the relative strength of the flow or process. Blue shading represents water with lighter colors representing fresher water. Stratification is present throughout the flats and is not noted.

Processes occurring during the extended inundation (weak ebb, higher low water, and weak flood) of type 2 tides (Fig. 3-10):

- On average, $\Phi$ increases quickly on the weak ebb and continues to increase slowly through higher low water and the beginning of weak flood, before decreasing at the end of the weak flood.

- The tidal velocity is relatively weak, and density-driven estuarine-style circulation is present, which results in positive depth-mean straining throughout this time.

- $\Phi$ is higher offshore than onshore, resulting in cross-shore advection that is negative on ebb and positive on flood.

- Mixing peaks at low water, corresponding to the strongest flows during the high$\Phi$ period.

- Owing to alongshore differences in $\Phi$, but not depth-averaged density, strong alongshore flows with strong shear result in alongshore advection, but not alongshore straining. 
The processes on the strong ebb of type 2 tides are the same as those on type 1 strong ebbs, except there is no delay between the onset of straining and the onset of negative advection and mixing because the water column starts stratified instead of unstratified.

Overall, the stratification observed on the shallow and wide tidal flats near the north fork of the Skagit River, where flows are similar in both across-and along-isopycnal directions, has similarities to both deeper-water nearshore regions of fresh water influence (ROFIs) where strong flows are perpendicular to the density gradient (Rippeth et al., 2001; de Boer et al., 2008; Marques et al., 2010, 2011), and to narrow tidal-flat channels (Ralston and Stacey, 2005a,b) and strongly forced salt-wedge estuaries (Wang et al., 2009; Ralston et al., 2010a,b; Giddings et al., 2011) where tidal flows and density gradients are aligned.
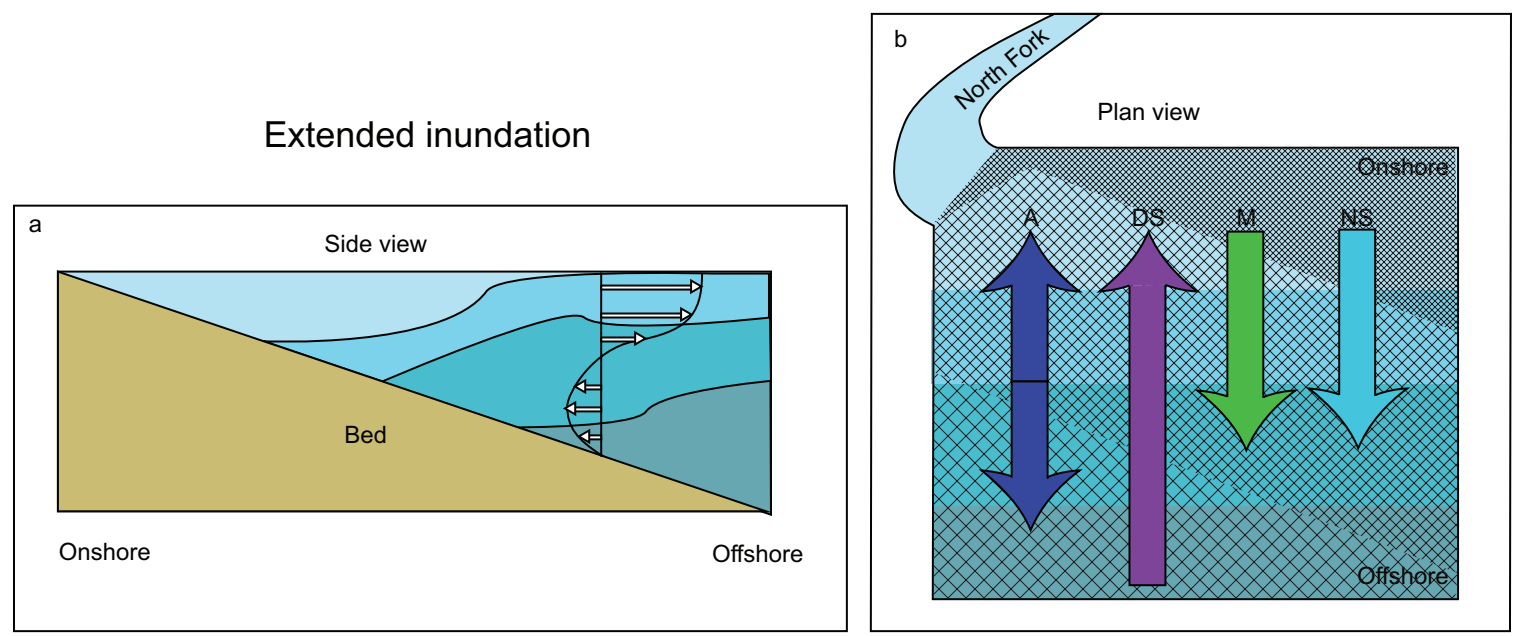

Figure 3-10: Cross-section (a) and plan view (b) diagrams of the flats during the type 2 extended inundation. The white arrows (a) indicate the cross-shore flow profile, and colored arrows (b) indicate the stratification processes with onshore- and offshore-directed arrows indicating increasing and decreasing stratification, respectively. The length of each arrow indicates the relative strength of the flow or process. Blue shading represents water with lighter colors representing fresher water. The cross-hatching (b) indicates the stratified region, with larger squares indicating higher stratification.. 
The water on the tidal flats did not become completely mixed during the strong ebb, and thus the initial, partially stratified tongue of water crossing the flats on strong floods may have some leftover stratification from the previous tidal cycle as well as from the intrusion of incoming Puget Sound water into the residual river water. As in prior studies, the water becomes increasingly saline during the strong flood, and for nearly semidiurnal tides, the maximum stratification occurs during mid ebb tide. Throughout the tidal cycle, changes in stratification result primarily from cross-shore tidal straining and advection.

Stratification is stronger during nearly diurnal (type 2) tides than during nearly semidiurnal (type 1) tides. In contrast to prior estuarine studies, but similar to many ROFIs, alongshore flows are stronger than cross-shore flows, and the increased stratification on type 2 tides is owing to both alongshore advection of stratified water from the north fork of the Skagit River, and straining effects of density-driven cross-shore shear flows that remain offshore-directed at the surface until mid weak flood, when stratification is maximum (Fig. 3-10). The non-mean straining during the extended high water of type 2 tides indicates that the isopycnals are not parallel during that tidal stage, while the negligible non-mean straining during the type 1 tides suggests that they are during that type of tide.

The large advection terms suggest that strong fronts are moved across and along the flats. Positive straining (indicating generation of stratification) usually is larger than negative mixing (indicating destruction of stratification), suggesting water that becomes stratified near the measurement location is either mixed elsewhere on the flats, or exported to the surrounding basins.

Temporal changes in stratification are similar across and along the flats in this region. However, stratification increases offshore and alongshore towards the north fork (the river mouth closest to the instruments). 
Overall, type 1 tidal processes can be roughly described as a salt wedge with a nearly vertical front that is transported onshore on the flood tide, which is then strained so it is more stratified and covers a larger area while it is advected offshore on the ebb. During type 2 tides, the salt wedge again passes onto the flats during the strong flood, but during the prolonged high water of the weak ebb and flood, additional cross-shore straining and alongshore advection occur with minimal mixing (owing to weak mean flows), resulting in increased stratification. Runaway stratification in the measurement location is prevented by water draining off the flats during the strong ebb, and probably offshore mixing. 


\section{Numerical model simulations of stratification processes}

\subsection{Introduction}

The observations (Chapter 3) provide information about the processes affecting stratification. However, the results are applicable only to the northern flats and to a period of low discharge. Here, the spatial dependence of the processes controlling the creation and destruction of stratification are examined using the Finite Volume Coastal Ocean Model (FVCOM).

\subsubsection{FVCOM model}

Water level fluctuations, flows, water density, and mixing were simulated from July 1 to 15, 2009, using FVCOM, a three-dimensional finite volume, unstructured grid, primitive equation model (Chen et al., 2003). FVCOM has been used with success in modeling the Baeksu tidal flats (Kim and Cho, 2011) and compares well with field observations in the Merrimack estuary (Ralston et al., 2010a) as well as having been used to investigate circulation in the Skagit (Ralston et al., 2012; Yang and Khangaonkar, 2009).

\subsubsection{Model setup}

The model domain encompasses Skagit Bay and a portion of the surrounding waters of Saratoga passage and the Strait of Juan de Fuca. Cell sizes range from $15 \mathrm{~m}$ within Skagit Bay to $500 \mathrm{~m}$ near the open boundaries. The model is similar to that used by Yang and Khangaonkar (2009), but with an expanded domain, higher resolution on the flats, and updated bathymetry. Uniform sigma coordinates were used in the vertical and "wet" and "dry" mesh elements were used to account for the moving water level. Turbulence was

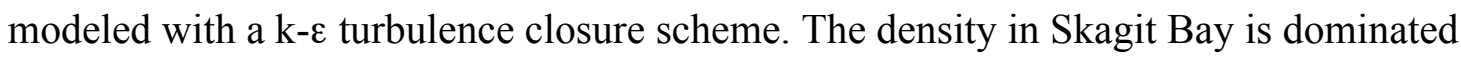


by salinity fluctuations, and thus the temperature was assumed uniform $\left(18^{\circ} \mathrm{C}\right)$.

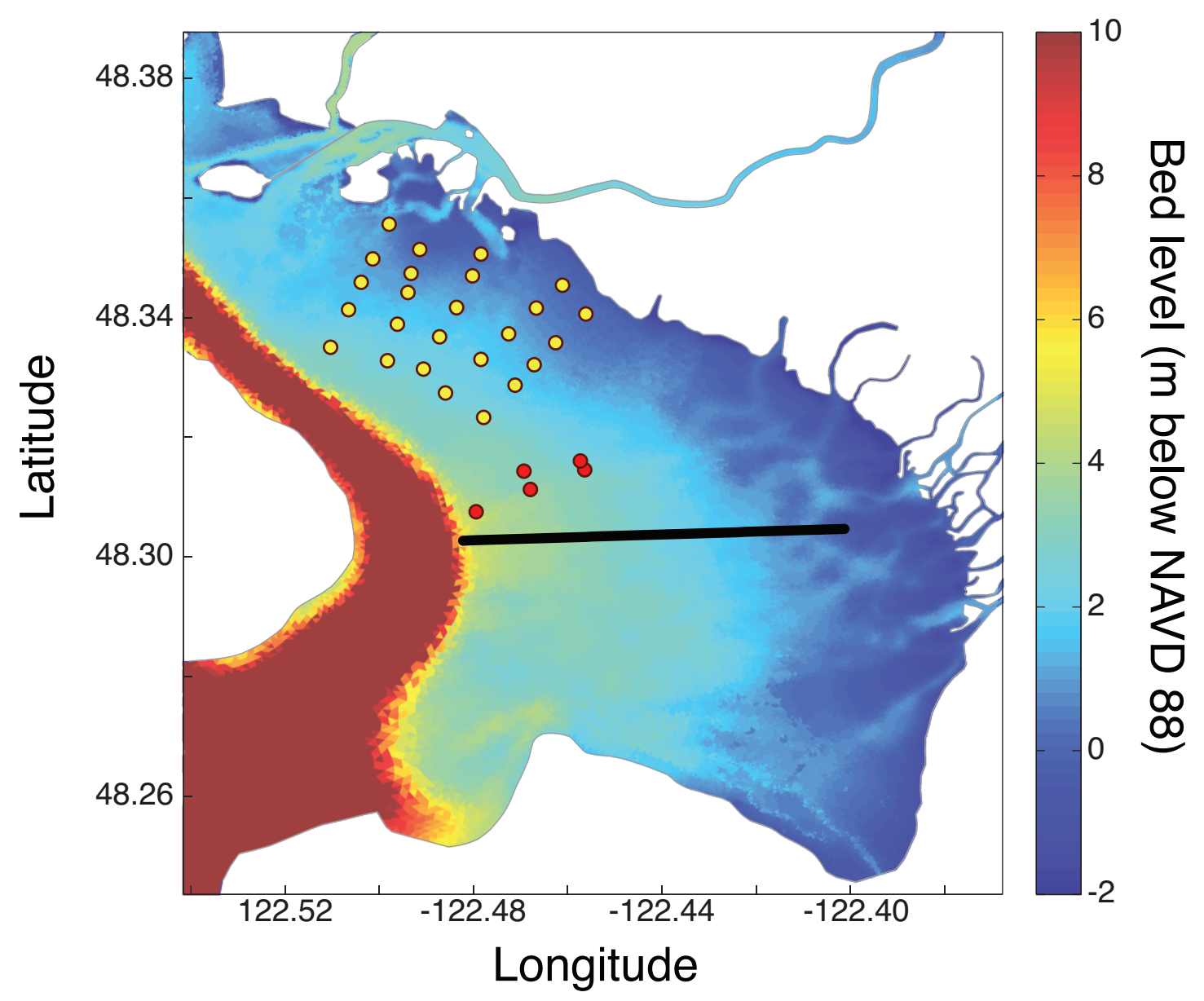

Figure 4-1: Model bathymetry and instrument locations on the north flats (yellow, July, 2009) and south-central flats (red, June, 2009). The black line segment is the transect examined in section 4.2.2.

The model was forced at open boundaries with predicted tidal fluctuations and observed subtidal water level fluctuations from the tidal reference stations of Seattle (\#9447130) and Port Townsend (\#9444900), and measured river discharge at the USGS station at Mt. Vernon, WA (\#12200500). Winds were forced using the regional Weather Research and Forecasting model. A more detailed description of the FVCOM setup for the Skagit Bay tidal flats is given by Ralston et al. (2012). 


\subsubsection{Model verification}

\begin{tabular}{|c|c|c|c|c|c|c|}
\hline & \multicolumn{6}{|c|}{ North flats, July 2009} \\
\hline & \multicolumn{2}{|c|}{ Min } & \multicolumn{2}{|c|}{ Mean } & \multicolumn{2}{|c|}{ Max } \\
\hline & $\mathrm{r}^{2}$ & $\mathrm{SS}$ & $r^{2}$ & $\mathrm{SS}$ & $\mathrm{r}^{2}$ & SS \\
\hline Depth & 0.97 & $0.40 *$ & 0.99 & 0.94 & 1.00 & 1.00 \\
\hline Cross-shore Velocity & 0.37 & 0.22 & 0.61 & 0.53 & 0.78 & 0.68 \\
\hline Alongshore Velocity & 0.25 & -0.32 & 0.52 & 0.39 & 0.69 & 0.64 \\
\hline Near-bed salinity & 0.07 & -0.52 & 0.49 & 0.35 & 0.80 & 0.72 \\
\hline Surface salinity & 0.11 & -0.61 & 0.36 & 0.02 & 0.47 & 0.24 \\
\hline & 0.07 & -0.62 & 0.20 & -0.33 & 0.36 & -0.03 \\
\hline
\end{tabular}

Table 4-1: Squared correlation coefficients $\left(r^{2}\right)$ and skill scores (SS) for the North flats. $(*)$ One location had a large mean difference in depth. The next lowest depth skill score was 0.81 .

The model simulations are compared with time series of measured water depths, crossand along-shore velocities, near-bed and surface salinity (which dominates the water density), and stratification (defined by the potential energy anomaly, $\Phi$ ) at 5 locations on the south-central flats in June, 2009 (described further by Ralston et al., 2012), and at 25 locations on the north flats in July, 2009 (red and yellow symbols, respectively, in Fig. 41). Skill scores were calculated as (Murphy 1988):

$S S=r^{2}-\left(r-\frac{s_{m}}{s_{d}}\right)^{2}-\left(\frac{\bar{m}-\bar{d}}{s_{d}}\right)^{2}$

where $r$ is the correlation coefficient, and $s_{m}$ and $s_{d}$ are the sample standard deviations and $\bar{m}$ and $\bar{d}$ are the sample means of the model and data, respectively. The model simulates accurately the depth variations (primarily tidal fluctuations) (mean $r^{2}$ and $S S>$ 0.9 ) and the cross-shore velocities (mean $r^{2}$ and $S S>0.5$ on the north flats and $>0.9$ on the south flats). The alongshore velocity typically is weaker than the cross-shore velocity, and is more sensitive to wind and pressure gradients, and thus more difficult to simulate. Similarly, surface salinity is dependent on small-scale structure of fronts and winds, and 
thus it is not simulated as well as near-bottom salinity. FVCOM has higher skill on the south-central flats than on the north flats.

\begin{tabular}{|r|c|c|c|c|c|c|}
\hline & \multicolumn{4}{|c|}{ South-central flats, June 2009 } \\
\hline & \multicolumn{2}{|c|}{ Min } & \multicolumn{2}{c|}{ Mean } & \multicolumn{2}{c|}{ max } \\
\hline & $\mathrm{r}^{2}$ & $\mathrm{SS}$ & $\mathrm{r}^{2}$ & $\mathrm{SS}$ & $\mathrm{r}^{2}$ & $\mathrm{SS}$ \\
\hline Depth & 0.99 & 0.99 & 1.00 & 1.00 & 1.00 & 1.00 \\
\hline Cross-shore Velocity & 0.88 & 0.87 & 0.93 & 0.92 & 0.95 & 0.95 \\
\hline Alongshore Velocity & 0.39 & 0.33 & 0.50 & 0.45 & 0.62 & 0.56 \\
\hline Near-bed salinity & 0.61 & 0.42 & 0.74 & 0.59 & 0.81 & 0.72 \\
\hline Surface salinity & 0.40 & -0.01 & 0.45 & 0.17 & 0.50 & 0.36 \\
\hline $\boldsymbol{\Phi}$ & 0.40 & 0.04 & 0.44 & 0.13 & 0.52 & 0.23 \\
\hline
\end{tabular}

Table 4-2: Squared correlation coefficients $\left(r^{2}\right)$ and skill scores (SS) for the South-central flats.

The potential energy anomaly is sensitive to both surface and bottom salinity, and thus predictions are sensitive to small errors. Compared with the data (Tables 4-1 and 4-2), FVCOM underestimates $\Phi$, which may be partly an effect of the reduction of maximum horizontal density gradients by finite cell sizes. Although the correlation coefficients between observed and predicted $\Phi$ are low, the FVCOM model exhibits behavior consistent with the data, showing freshwater surface plumes spreading over the flats at variable rates.

\subsubsection{Time series of individual terms (phase-averaged).}

Model results for the phase-averaged terms of the $\Phi$-balance were estimated using simulated water depths, velocities, and densities at the locations of the field measurements discussed in Chapter 3. Although the processing for model and data was 
similar, the available model results are for July, whereas the field data was collected in
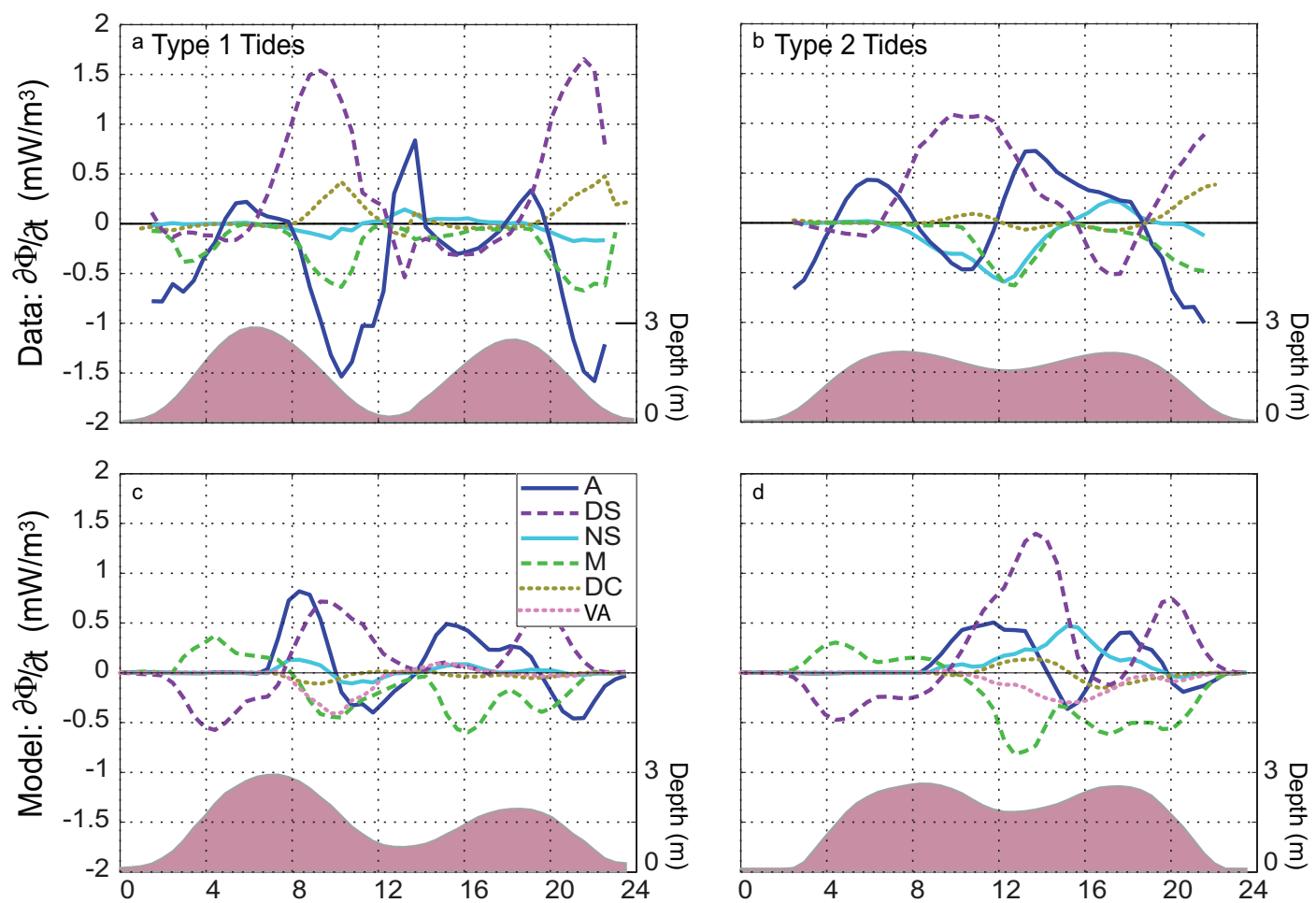

Figure 4-2: Time series of the different terms of the phase-averaged $\Phi$ dynamic equation based on measurements ( $a$ and b) and FVCOM model results ( $c$ and d) for type 1 ( $a$ and c) and type 2 (b and d) tides. Measurements were collected in late August (as in Chapter 3) and model results are from early July. The shaded region indicates the water depth. FVCOM results are for the location in the model corresponding to the measurement location in Chapter 3.

August. Despite the different time periods, the stratification balance in the model is qualitatively similar to that in the data (Fig. 4-2). Type 1 tides (Fig. 4-3, blue shading) have positive depth-mean straining on the ebb and negative depth-mean straining on the flood (Fig. 4-2a and c, dashed purple curve). On type 2 tides (Fig. 4-3, red shading) dataand model-based depth-mean straining is positive during most of the prolonged high water (Fig. 4-2b and d, dashed purple curve). Mixing (Fig. 4-2 dashed green curve) is stronger in the FVCOM model than in the data, but tends to be negative on ebb tides and during the prolonged high water of type 2 tides. Advection (Fig. 4-2, solid dark blue curve) is smaller in the FVCOM model than the data. Similar to the data, modeled non- 
mean straining (Fig. 4-2 solid light blue curve) is negligible during type 1 tides but becomes similar in size to the other terms during the prolonged high water of type two tides, although of opposite sign to the data. The model results confirm that vertical advection (Fig. 4-2d, pink dotted curve) partially balances the non-mean straining. Depthchange is a relatively small term (Fig. 4-2, dotted yellow curve).

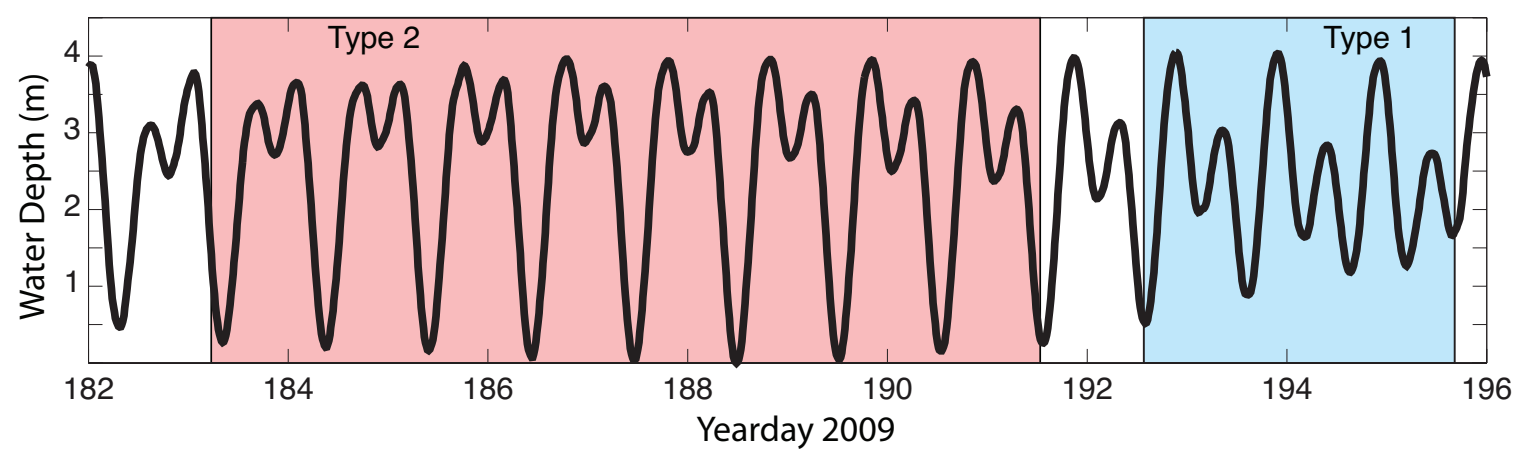

Figure 4-3: Simulated water depths at the offshore edge of the north flats with the red and blue shaded regions indicating type 2 and type 1 tides, respectively.

Although the data- and model-based processes had similar magnitudes, the phase relationships (e.g., the timing of maxima and minima) between the processes are different for the data and model, presumably owing to small errors in location and frontal positions. Consequently, the model is primarily used to examine the magnitude of the tidal variability of the processes, defined as the rms value of the phase averaged process over a type 1 or type 2 tidal cycle, rather than the timing of the intratidal behavior.

\subsection{Results}

\subsubsection{Process activity in different directions}

The observations (Chapter 3) suggest that alongshore processes can be important to the stratification, similar to ROFIs and other regions with strong alongshore density gradients and flows. Here the simulated spatial dependence of the along- and across-flow 
advection, depth-mean straining, and non-mean straining are examined during type 1 and type 2 tides (Fig. 4-3). The major and minor axes of depth-mean velocity (Figs. 4-4c and d), rather than the directions along and across bathymetric contours, are chosen to define the $\mathrm{x}$ - and $\mathrm{y}$-coordinate directions, respectively, because it is the mean or shear velocity

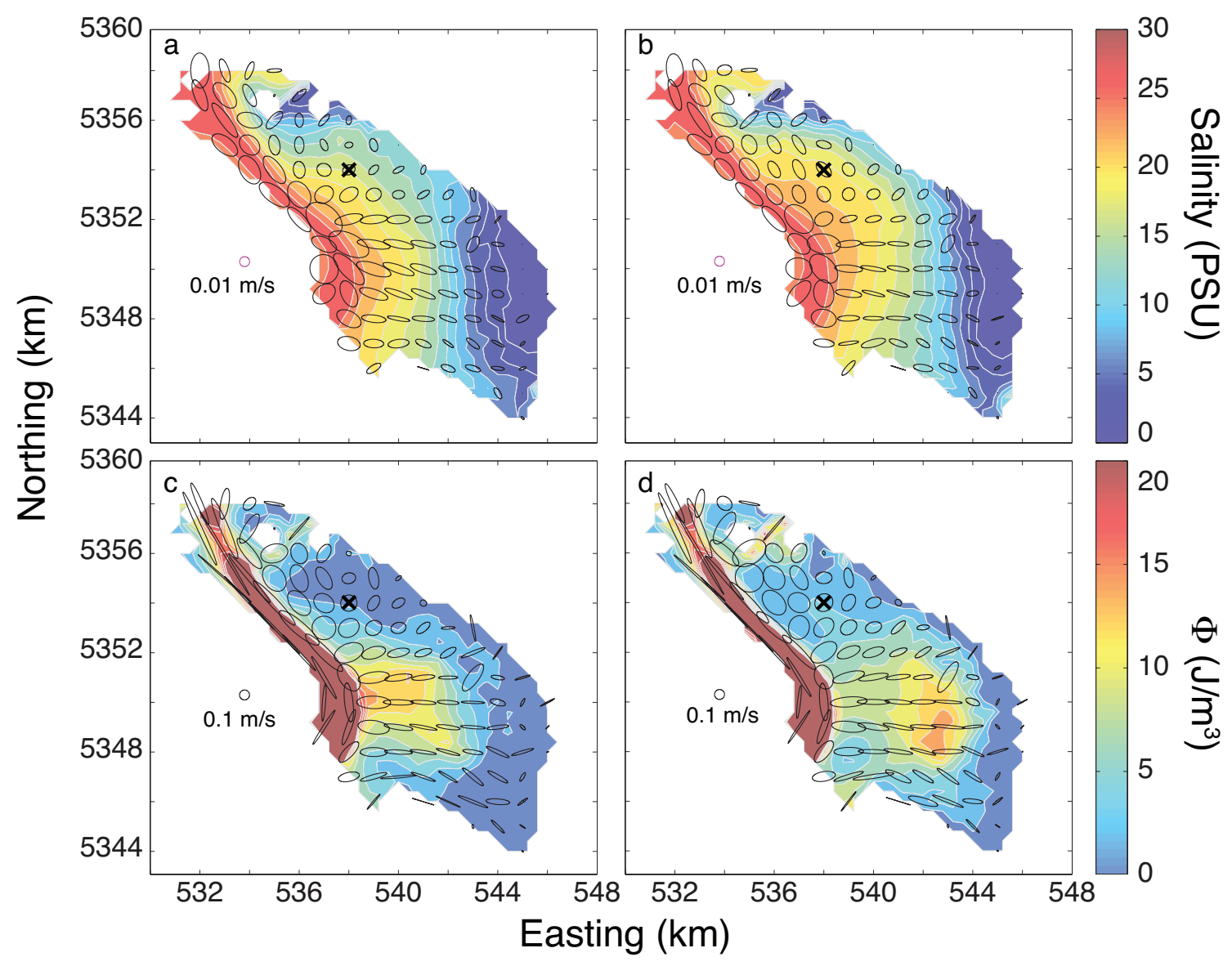

Figure 4-4: ( $a$ and $b$ ) Ellipses encompassing the major- and minor axes of velocity shear over a tidal cycle and contours of tidally averaged depth-mean salinity, and (c and d) ellipses encompassing the major and minor axes of depth-mean velocity over a tidal cycle and contours of tidally averaged $\Phi$ for type 1 (a and c) and type 2 tides ( $b$ and d). The black ' $x$ ' indicates the central location examined in Chapter 3.

acting on the horizontal density or $\Phi$ gradient that produces the directional stratifying processes. Depth-mean flows tend to be rectilinear (and aligned with the cross-shore direction, not shown) on the south flats, but are near equal in both directions on the north 
flats. In some cases the velocity major axis (x) direction is roughly alongshore on the north flats.

The largest tidal variability in advection and depth-mean straining occurs in the $\mathrm{x}$ direction in the gutter, near the mouth of the north fork, and on the south-central flats (dark red in Figs. 4-5- and 4-6a, b, d, and e). The maximum rms depth-mean straining on the flats occurs slightly closer to the marshes during type 2 than during type 1 tides (compare Fig. 4-6d with Fig. 4-5d). Variations in advection and depth-mean straining on the north flats are about a factor 4 smaller than those on the south-central flats. Non-mean straining variability typically is small, except in the gutter (Figs. 4-5- and 4-6g and h).

The advection and depth-mean straining have more variability in the x-direction than in the $y$-direction at most locations on the central and south flats (Figs. 4-5- and 4-6c and f, greens and blues). However, although the maximum y-direction contribution $(\sim 0.0006)$ is about a factor of 3 smaller than the maximum $x$-direction variations $(0.0020)$, the rms advection and depth-mean straining along the y-axis are equal to or greater than those in the x-direction at many locations on the north flats (Figs. 4-5- and 4-6c and f, pinks and reds). The y-component of rms depth-mean straining also dominates between the channels near the marshes on the south-central flats.

The importance of y-axis terms on the north flats is related to the large tidal variability of the depth-averaged velocity and of the integrated shear velocity along the minor axis. The latter of the two, integrated shear (Fig. 4-3a and b), is defined as

$\frac{1}{D} \int_{-h}^{\eta}(\mathbf{u}-\overline{\mathbf{u}}) \frac{z}{D} d z$

where $\mathbf{u}$ is the vector velocity, the overbar is the depth average, $\eta$ is the surface height, $h$ is the depth of the bed, $D=\eta+h$ is the total water depth, and $z$ is the vertical coordinate with positive upward. Integrated shear is used rather than the maximum velocity difference because it appears in the DS term of the dynamic $\Phi$ equation (Chapter 3, equation (8)). Shear given as maximum differences in velocity is between 10 and 100 
times as large as the integrated shear, and typically is similar in magnitude to the depthaveraged velocity.
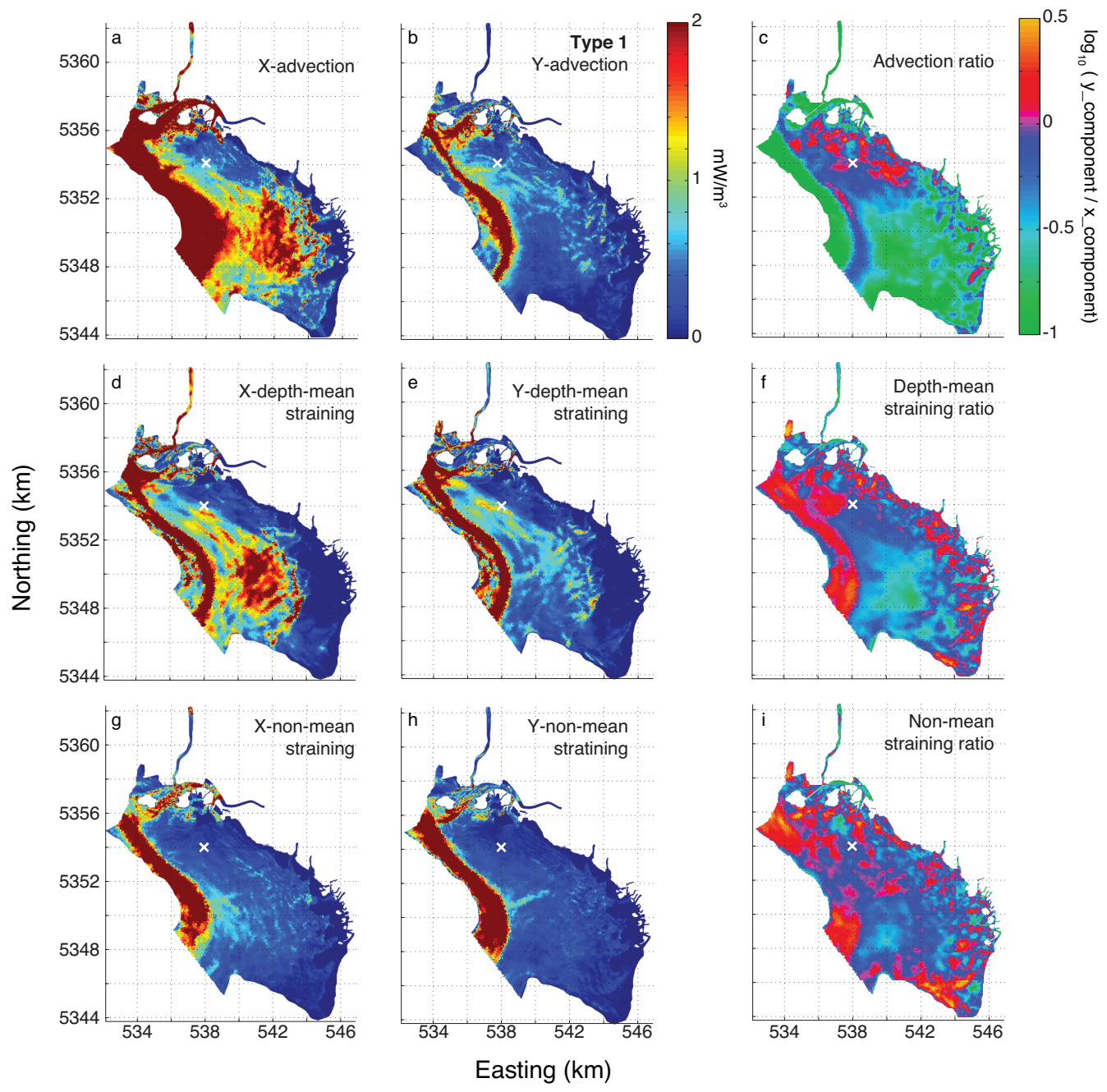

Figure 4-5: Advection (a, b, and c), depth-mean straining (d, e, and f) and non-mean straining (g, $\mathrm{h}$, and i) for type 1 tides. The columns from left to right are rms value in the $\mathrm{x}$-direction (a, d, g), rms value in the $y$ - direction (b,e, h), and the log base 10 of the ratio of rms y-axis component divided by the rms $\mathrm{x}$-axis component $(\mathrm{c}, \mathrm{f}, \mathrm{i})$. The $\mathrm{x}$ - and $\mathrm{y}$-directions are defined by the velocity major and minor axes shown in Fig. 4-4c. The white ' $x$ ' indicates the equivalent of the central location examined in Chapter 3. 

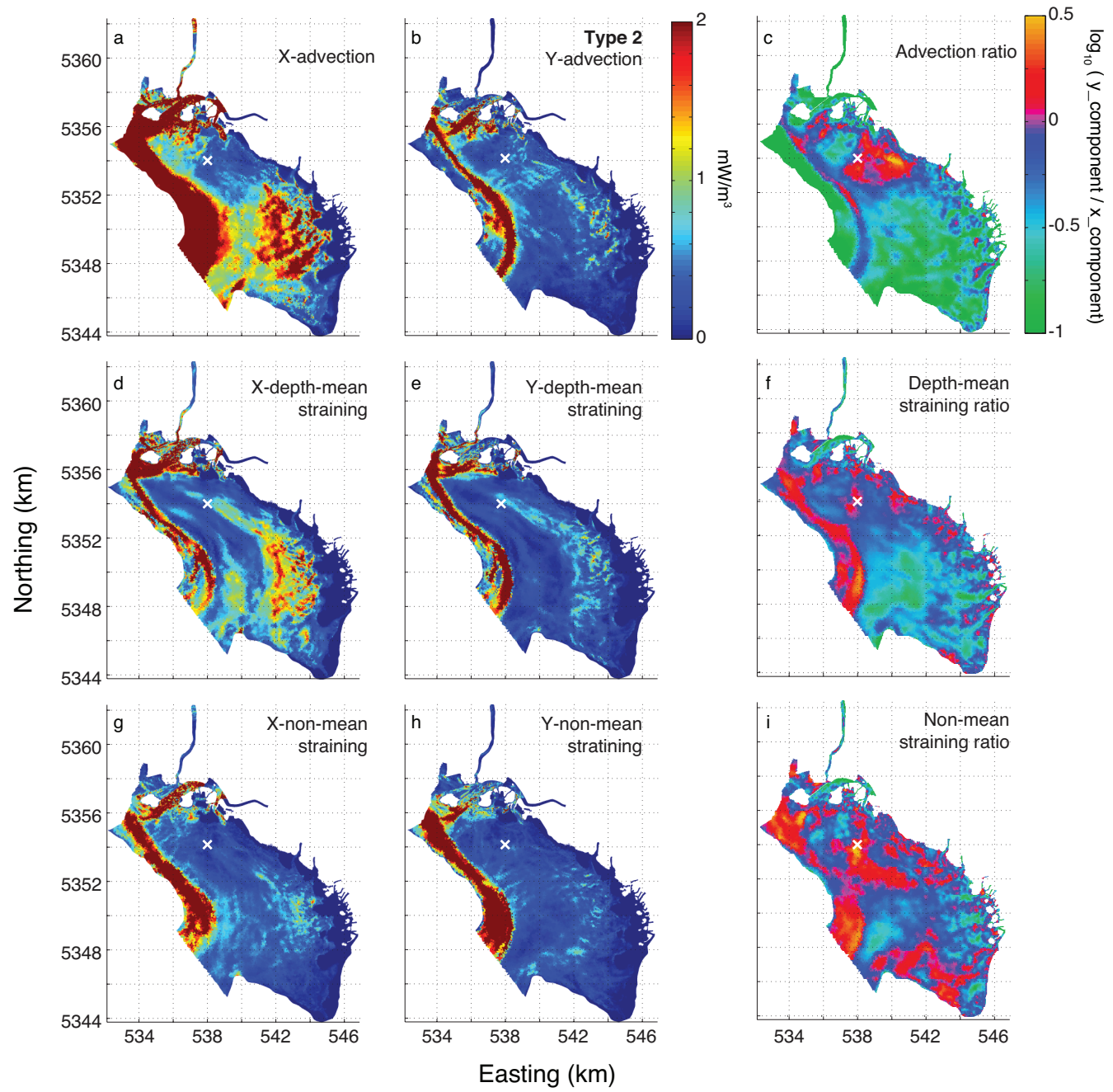

Figure 4-6: The same as Fig. 4-5 but for type 2 tides. The $x$ - and $y$ - directions are defined by the velocity major and minor axes shown in Fig. 4-4d.

On the south and central flats, the tidal velocity is nearly rectilinear (Fig. 4-4) and the major axis of the velocity is aligned roughly with the direction of the density gradient, so rms advection is dominated by the $\mathrm{x}$-component. The $\mathrm{y}$-axis component of straining is slightly larger than that for advection on the south-central flats because the shear is not aligned perfectly with the mean velocity and the shear ellipse is more eccentric than that 
for mean velocity (compare Figs. 4-4a and $b$ with $4-4 c$ and d). On the north flats, the density and $\Phi$ gradients are smaller and not as well aligned with velocity or shear as those on the south-central flats (Fig. 4-4), and thus the total (x-plus y-direction) rms variability of the advection and straining are smaller. However, the major and minor axes of the velocity are nearly equal (Fig. 4-4), and the relatively strong flows and shear in the minor axis direction can advect and strain the density field along the north flats leading to relatively large ratios of $y$ - to $x$-axis contributions (Figs. 4-5- and 4-6c, f, and i).

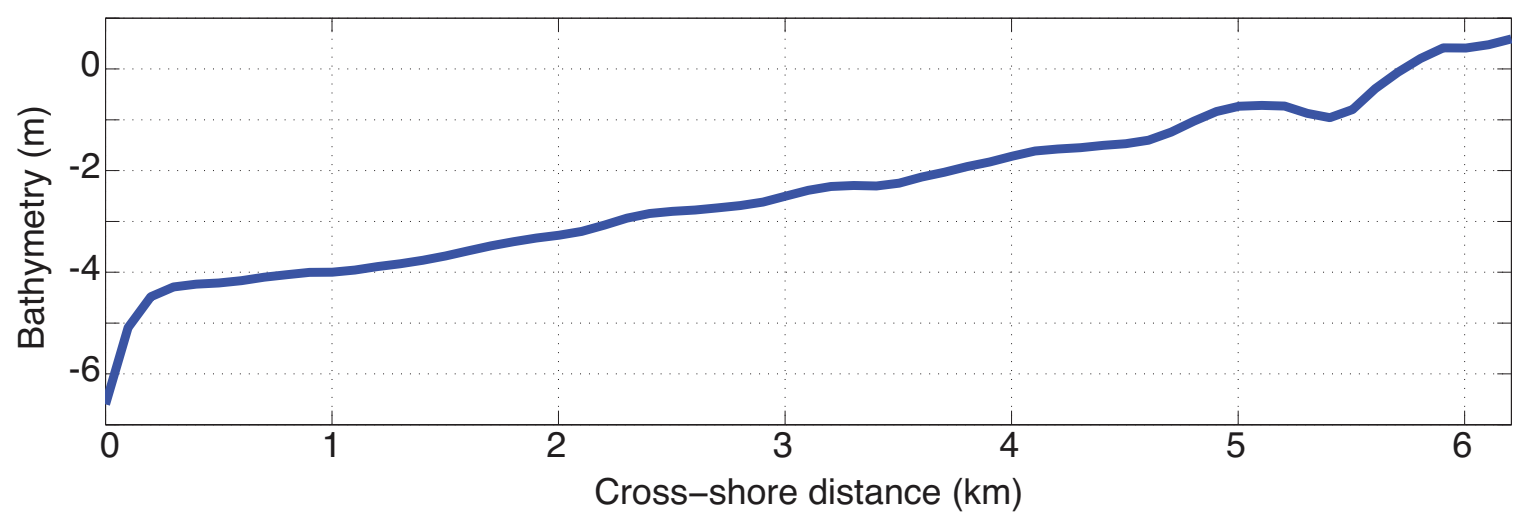

Figure 4-7: Bathymetry along the transect shown in Fig. 4-1.

Overall, the model results on the north flats show increased y-axis contributions compared with the field data results shown in Chapter 3. These differences are partly an effect of $\mathrm{x}$ - and $\mathrm{y}$ - directions being defined as the velocity major and minor axes rather than across and along bathymetric contours, and partly a result of different velocity and density distributions. Owing to this difference, it is necessary to interpret the model results in the context of relative distribution of velocity and density, rather than directly applying the model results to the real Skagit Bay tidal flats. Thus, in regions with rectilinear velocities that are roughly perpendicular to the isopycnals and stratification contours, such as near the south fork and in narrow channels or estuaries, the processes creating and destroying stratification are roughly two-dimensional. However, in regions with a relatively large velocity contribution in the minor axis direction or with the minor flow axis perpendicular to the isopycnals, such as can occur on the north flats, in ROFIs (e.g. de Boer et al., 2008), and on estuarine shoals (e.g. Ralston et al., 2010a), it is 
necessary to include both $\mathrm{x}$ - and $\mathrm{y}$-components to estimate the effects of the different processes accurately.

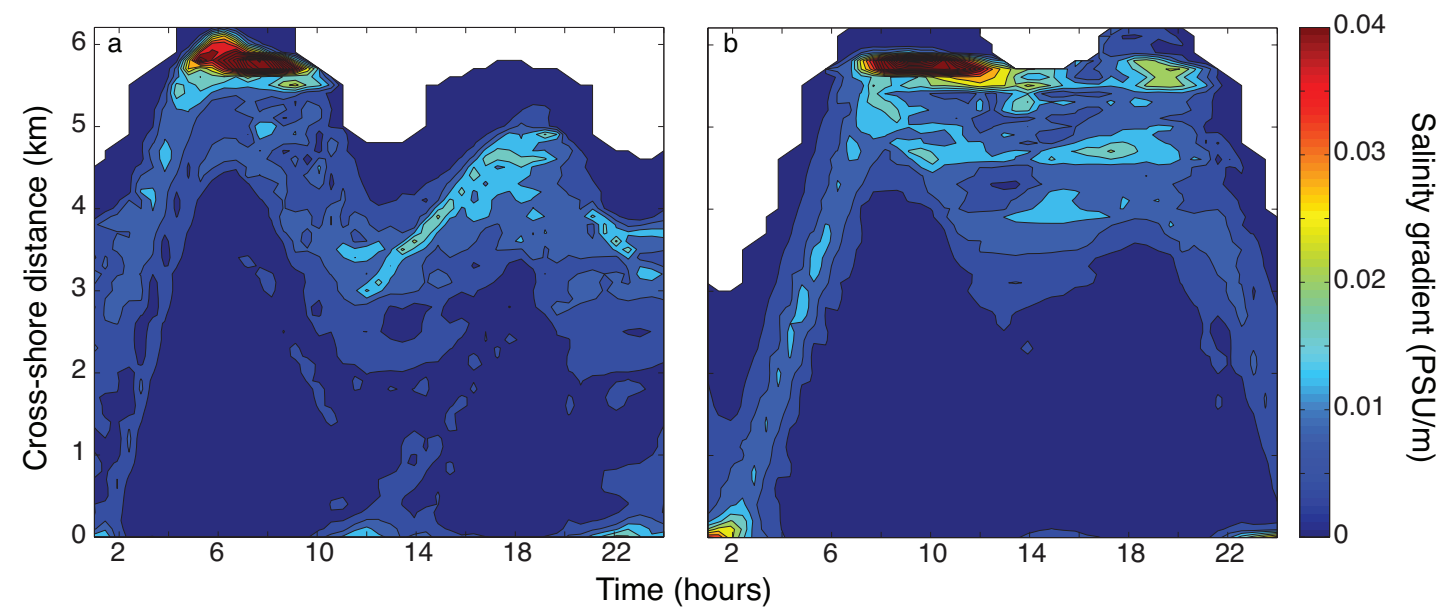

Figure 4-8: Cross-shore distance (positive onshore) versus time during the 24-h tidal cycle with contours of depth-averaged total salinity gradient magnitudes for phase-averaged type 1 (a) and type 2 (b) tides. Distance is along the transect shown in Fig. 4-1.

\subsubsection{Differences in ebb stratification processes between type 1 and type 2 tides}

The maximum rms depth-mean straining on the flats occurs slightly closer to the marshes during type 2 than during type 1 tides (compare Fig. 4-6f with Fig. 4-5f). The cross-shore transect shown in Fig. 4-1 is used to examine this difference in more detail. The transect was chosen to be in the region with nearly rectilinear velocity and the largest straining signal to minimize the effects of y-direction processes and to focus on straining effects. The transect profile is shown in Fig. 4-7. The more shoreward straining during type 2 tides is owing to small offshore velocities during the weak ebb allowing the salt wedge, and thus the region with the strongest horizontal salinity gradients (Fig. 4-8), to remain close to the marshes for a longer period of time. In addition, during type 2 tides, stratification increases throughout the weak ebb and flood owing to the weak flows (and 
mixing). The maximum stratification often is largest following the weak flood (compare Fig. 4-9b time $=19 \mathrm{~h}$ with $9 \mathrm{a}$ time $=7 \mathrm{~h}$, and see Ralston et al., 2010a; Giddings et al., 2011).

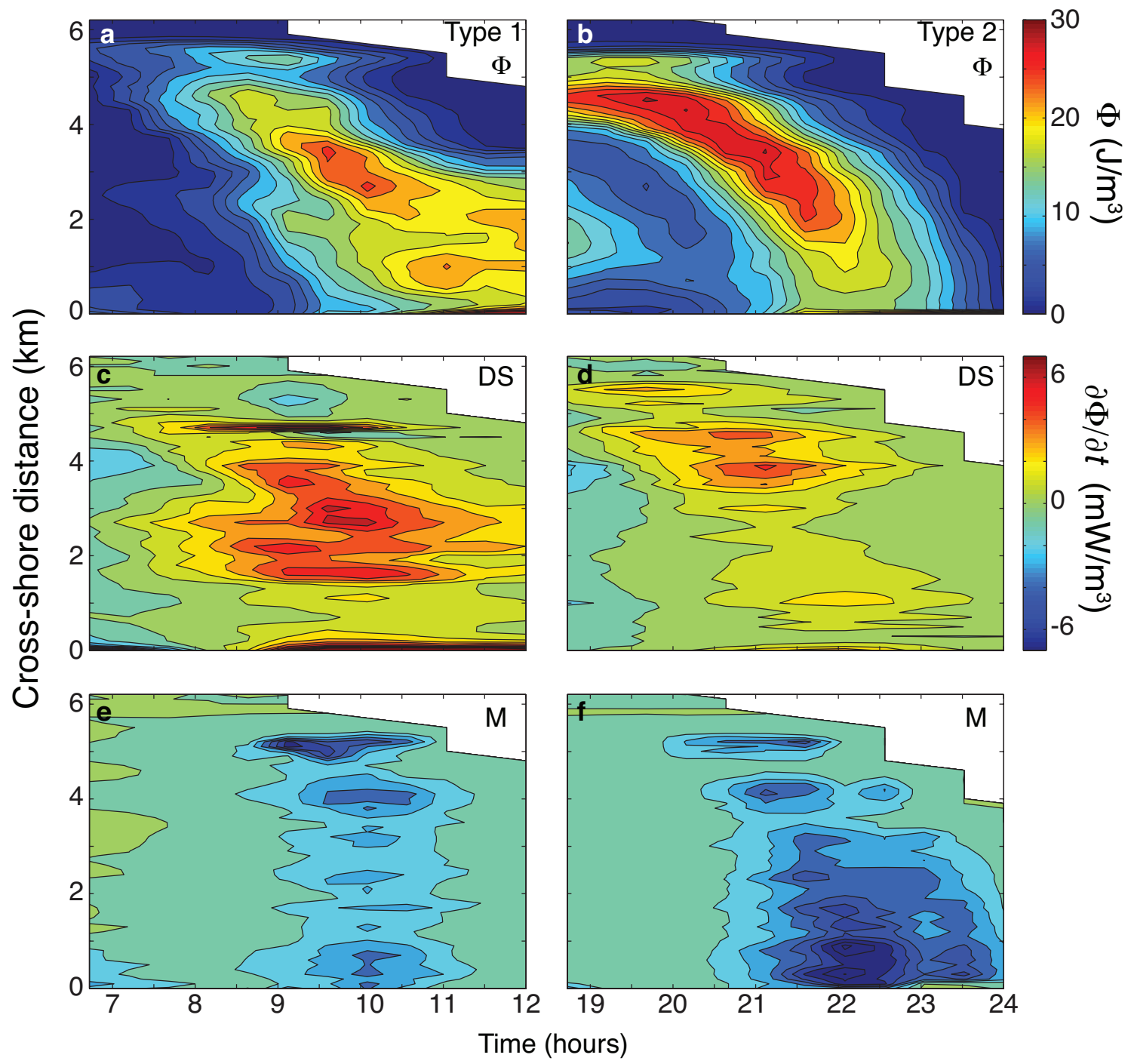

Figure 4-9: Cross-shore position (positive onshore) versus time during the ebb with contours of $\Phi$ (a and b), depth-mean straining (c and d) and mixing (e and f) for phase-averaged type 1 (a, c, and e) and type 2 (b, $d$ and $f$ ) tides. Times are subsets of those in Fig. 4-8.

During type 1 ebbs, strong velocity shear (not shown) and moderate horizontal salinity gradients (Fig. 4-8a) cause strong straining over most of the flats throughout most of the 
ebb (yellow to red contours in Fig. 4-9c), while mixing remains moderate to weak owing to moderate velocities. Thus, the stratification increases until about mid ebb (Fig. 4-9a, time about 9 hrs). During type 2 ebbs, $\Phi$ is large and increasing until time $\sim 21 \mathrm{~h}$ but then weakens rapidly because the large ebb velocity leads to mixing outcompeting straining (Figs. 4-9b, d, and f). Thus, in contrast to type 1 tides in which the water on the offshore flats and the gutter is stratified at low tide (Fig. 4-9a, $\Phi \sim 20$ at $\mathrm{x}=0$ and time $=12 \mathrm{~h}$ ) and de-stratifies during the flood, during type 2 tides the water on the flats and gutter destratifies on the ebb (Fig. $4-9 b, \Phi \sim 0$ at $x=0$ and time $=24$ h) and the flood starts with well-mixed water.

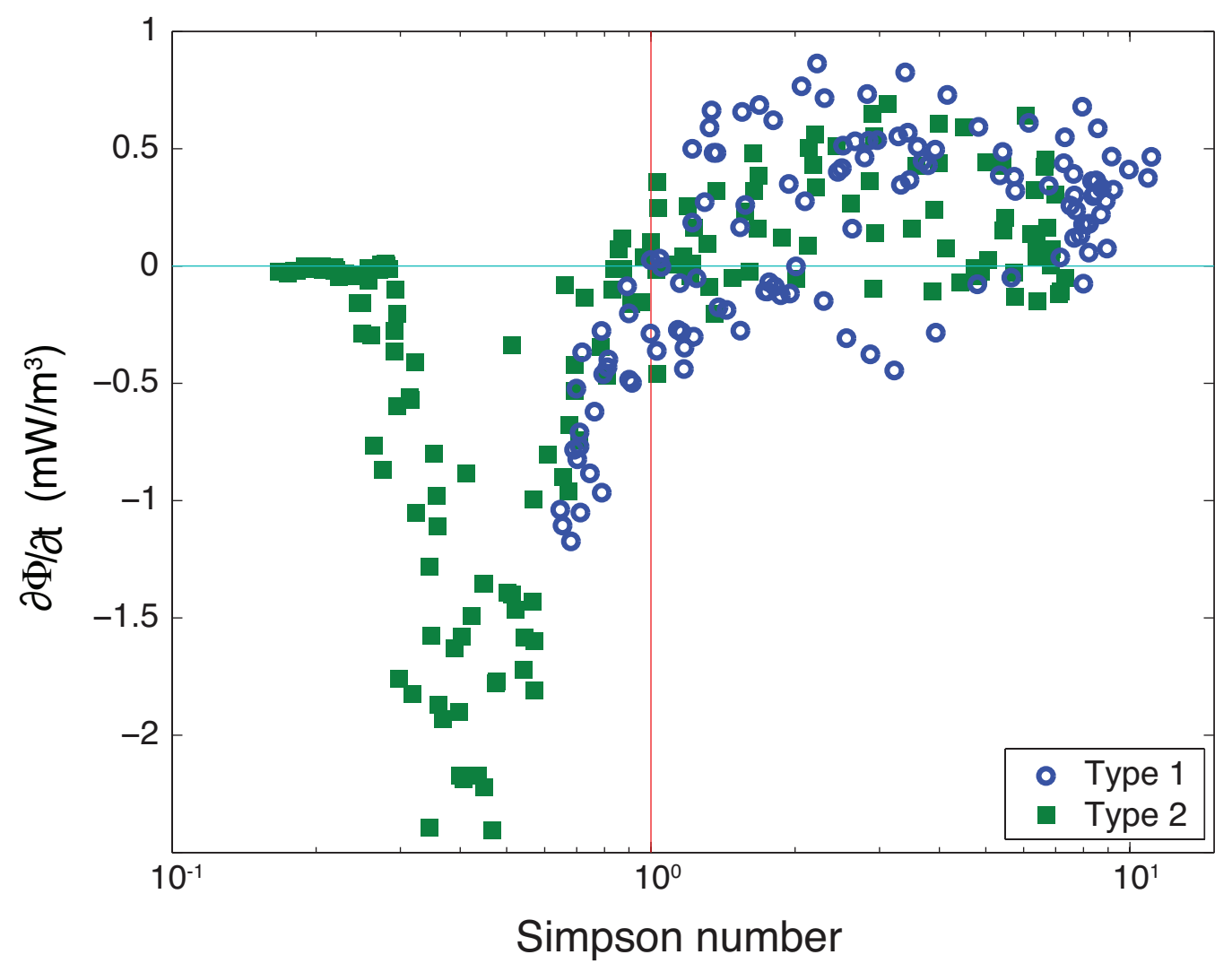

Figure 4-10: $\partial \Phi / \partial t$ vs. flat-averaged instantaneous Simpson number during ebb tides. Each point is a model timestep during an ebb tide. 


\subsection{Discussion}

\subsubsection{Ebb tide changes in stratification}

The difference in stratification magnitudes at the end of the type 1 and 2 ebbs at least partly results from differences in the ratio of straining to mixing. This relationship can be characterized using the Simpson number $(\mathrm{Si})$, which has been formerly called the horizontal Richardson number (Burchard et al., 2011; Verspecht et al., 2009; Stacey et al., 2001; Simpson et al., 1990). The Simpson number can be conceptualized by comparing the scaling of the mixing and depth-mean straining terms (Simpson et al., 1990). The scaling of the depth-mean straining term, expressed in terms of gravity, horizontal density gradient, velocity, and depth is:

$[D S] \approx g \frac{\partial \rho}{\partial x} U D$

while the mixing term scaling is:

$[M] \approx \rho_{0} \frac{U^{3}}{D}$

Choosing the friction velocity as the appropriate velocity scale after the scaling shown by Stacey et al. (2001), Si can be expressed as the ratio of [DS] to [M]:

$S i=\frac{g}{\rho_{0}} \frac{\partial \rho}{\partial x} \frac{D^{2}}{U_{*}^{2}}$

where $U_{*}$ is the friction velocity, $D$ is the water depth, $x$ is horizontal distance, $\rho$ is water density, and $\rho_{0}$ is a reference density (here $1000 \mathrm{~kg} / \mathrm{m}^{3}$ ). For the following calculations, all quantities are averaged across the tidal flats to minimize the effects of advection of $\Phi$ and it is assumed that on average the density gradient and the depth-averaged velocity are aligned, so the magnitudes of each are used in the calculations. The resulting tidal-flataveraged but time-varying value of $\mathrm{Si}$ can be described as:

$S i=\frac{g}{\rho_{0}}|\nabla \rho| \frac{|D|^{2}}{\left|U_{*}\right|^{2}}$

where the vertical bars are defined as:

$|\chi|=\frac{\sum \chi_{i} A_{i}}{\sum A_{i}}$ 
where $\chi$ denotes an arbitrary spatially-varying quantity, $\chi_{i}$ is the value of that quantity at cell or node index $\mathrm{i}, \mathrm{A}_{\mathrm{i}}$ is the area associated with that cell or node, and the summation is over all locations on the tidal flat portion of the domain that are underwater.

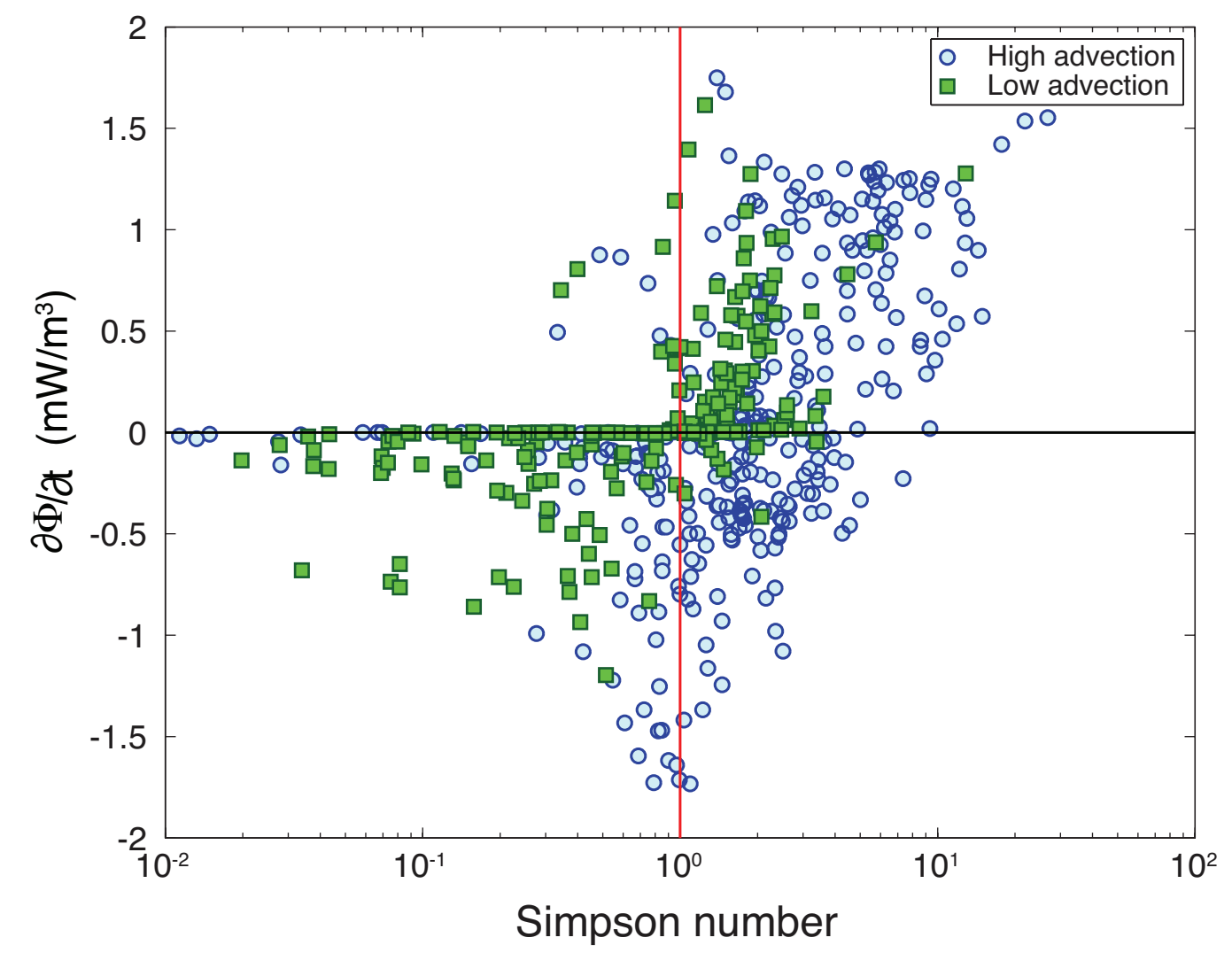

Figure 4-11: Local $\partial \Phi / \partial \mathrm{t}$ vs. instantaneous Simpson number during ebb tides. The location corresponds to that examined in Chapter 3. Each point is a model timestep during an ebb tide with a high (blue circles) or low (green squares) advection term.

For $\mathrm{Si}>1, \partial|\Phi| / \partial \mathrm{t}$ tends to be positive, indicating increasing average $\Phi$, while $\mathrm{Si}<1$ is associated with negative $\partial|\Phi| / \partial t$ (Fig. 4-10). For the type 2 tides (Fig. 4-10 green squares), $\mathrm{Si}$ is less than unity throughout the latter half of the ebb and the water becomes well mixed. For type 1 tides (Fig. 4-10 open circles), Si is rarely less than unity, and the water remains stratified at the end of the ebb. Decreasing $|\Phi|$ does occur for $\mathrm{Si}>1$, which is a result of the mean velocity advecting $\Phi$ offshore on the ebb, off of the tidal flats 
proper. In addition, the very low magnitudes of $\partial|\Phi| / \partial \mathrm{t}$ occurring at small Si values are associated with very shallow flows where the water column is already mixed.

Local values of $\nabla \rho, U_{*}$, and $D$ were used to determine a local value of $\mathrm{Si}$ on the northern midflats that could be compared with the data presented in Chapter 3 (Fig. 4-11). The assumption of parallel density gradient and flow velocity is retained, although this may overestimate the relevant value of the density gradient and $\mathrm{Si}$ in the north-western region of the flats (Fig. 4-4). The local and flat-averaged $\partial \Phi / \partial t$ and $\mathrm{Si}\left(\mathrm{Si}_{\mathrm{L}}\right)$ are similar, but the local values are more often in the lower-right quadrant of high $\mathrm{Si}_{\mathrm{L}}$ and negative $\partial \Phi / \partial \mathrm{t}$ owing to the effects of local advection overwhelming the balance between mixing and straining (Fig. 4-11). Eliminating data points corresponding to advection values higher than the median removed most of the points in the lower right quadrant. The remainder of the samples in the lower right quadrant may violate the assumption of cross-isopycnal velocity. Removing times with high advection preferentially removes high $\mathrm{Si}_{\mathrm{L}}$ samples which is consistent with the results from the data section (Chapter 3) showing depthmean straining and advection having similar magnitudes.

Measurements were insufficient to determine $U_{*}$ directly from data, so a proxy based on the mean velocity was used to calculate $\mathrm{Si}_{\mathrm{L}}$ :

$U_{*}^{2}=C_{d} \bar{U}^{2}$

The value of $\mathrm{C}_{\mathrm{d}}$ used for the data was 0.0023 , which was determined from the relationship between $U_{*}$ and $\bar{U}$ in the FVCOM model at the midflat location. The FVCOM model correlation between $U_{*}$ and $\bar{U}$ was similar to that between $U_{*}$ and nearbottom velocity. The field data show that higher values of $\partial \Phi / \partial t$ were associated with higher values of $\mathrm{Si}_{\mathrm{L}}$ (Fig. 4-12), but there is a substantial amount of scatter that is not reduced by removing points with high values of advection (not shown). The scatter may be a result of non-parallel density gradients and flows at the measurement location, which is neglected in this formulation of $\mathrm{Si}_{\mathrm{L}}$. However, a larger proportion of the samples from 
the data than the model had high $\mathrm{Si}_{\mathrm{L}}$, which helps explain why stratification remained higher in the data than the model.

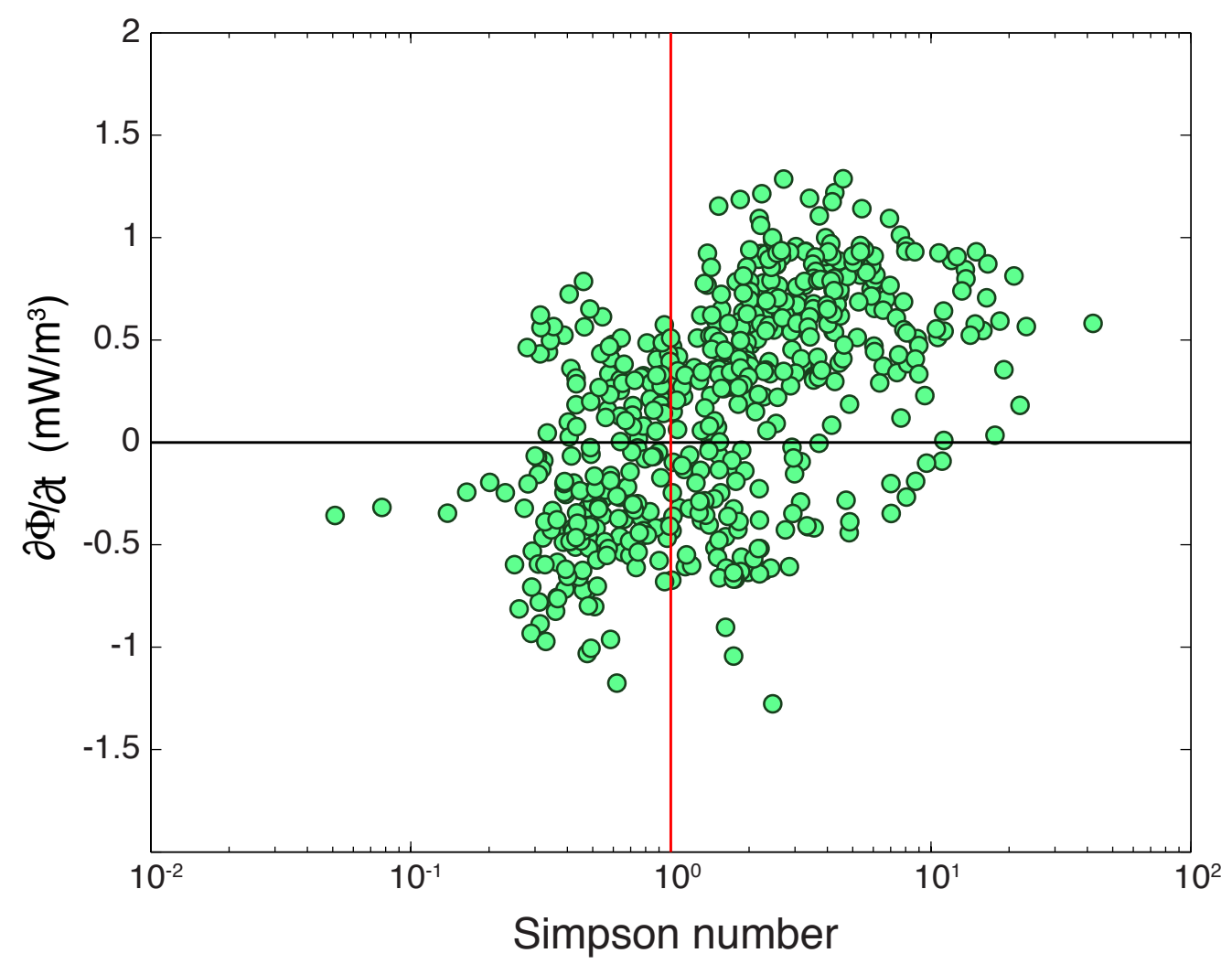

Figure 4-12: Local $\partial \Phi / \partial t$ vs. instantaneous Simpson number during ebb tides using field data from Chapter 3.

$\mathrm{Si}$ (and variations of this non-dimensional number) have been used to characterize spatial and temporal variations of estuarine dynamics (e.g., Simpson et al., 1990). Here it is shown that an instantaneous $\mathrm{Si}$ can be used to describe transitions from increasing to decreasing $\Phi$ on ebb tides. However, spatial averaging is preferable to remove advection effects that obscure the effects of mixing and depth-mean straining. Notably, Si is useful in tidal flat regions like this one where the tidal depth changes are comparable to the mean water depth, and not only in regions where tidal amplitudes are small compared to water depth (e.g. Burchard et al., 2011) 


\subsubsection{Density effects on the flow structure}

The FVCOM model was also used to investigate the effects of density on the circulation. The momentum balance in FVCOM uses the primitive equations, including the hydrostatic assumption, and can be written as (Chen et al., 2003):

$$
\begin{aligned}
& \frac{\partial u}{\partial t}+u \frac{\partial u}{\partial x}+v \frac{\partial u}{\partial y}+w \frac{\partial u}{\partial z}-f v=-\frac{1}{\rho_{0}} \frac{\partial P}{\partial x}+\frac{\partial}{\partial z}\left(K_{m} \frac{\partial u}{\partial z}\right)+F_{u} \\
& \frac{\partial v}{\partial t}+u \frac{\partial v}{\partial x}+v \frac{\partial v}{\partial y}+w \frac{\partial v}{\partial z}+f u=-\frac{1}{\rho_{0}} \frac{\partial P}{\partial y}+\frac{\partial}{\partial z}\left(K_{m} \frac{\partial v}{\partial z}\right)+F_{v} \\
& \frac{\partial P}{\partial z}=-\rho g
\end{aligned}
$$

where $u, v$, and $w$ are the velocity in the $x, y$ and $z$ directions, and $z$ is vertical up, $t$ is time, $f$ is the Coriolis parameter, $\rho$ is density and $\rho_{0}$ is a reference density, $P$ is pressure, $K_{m}$ is the eddy viscosity, $F_{u}$ and $F_{v}$ are horizontal momentum diffusion terms, and $g$ is gravitational acceleration. Non-uniform density affects the first two terms on the right hand side: the pressure gradient term and the shear or eddy viscosity term, respectively. 


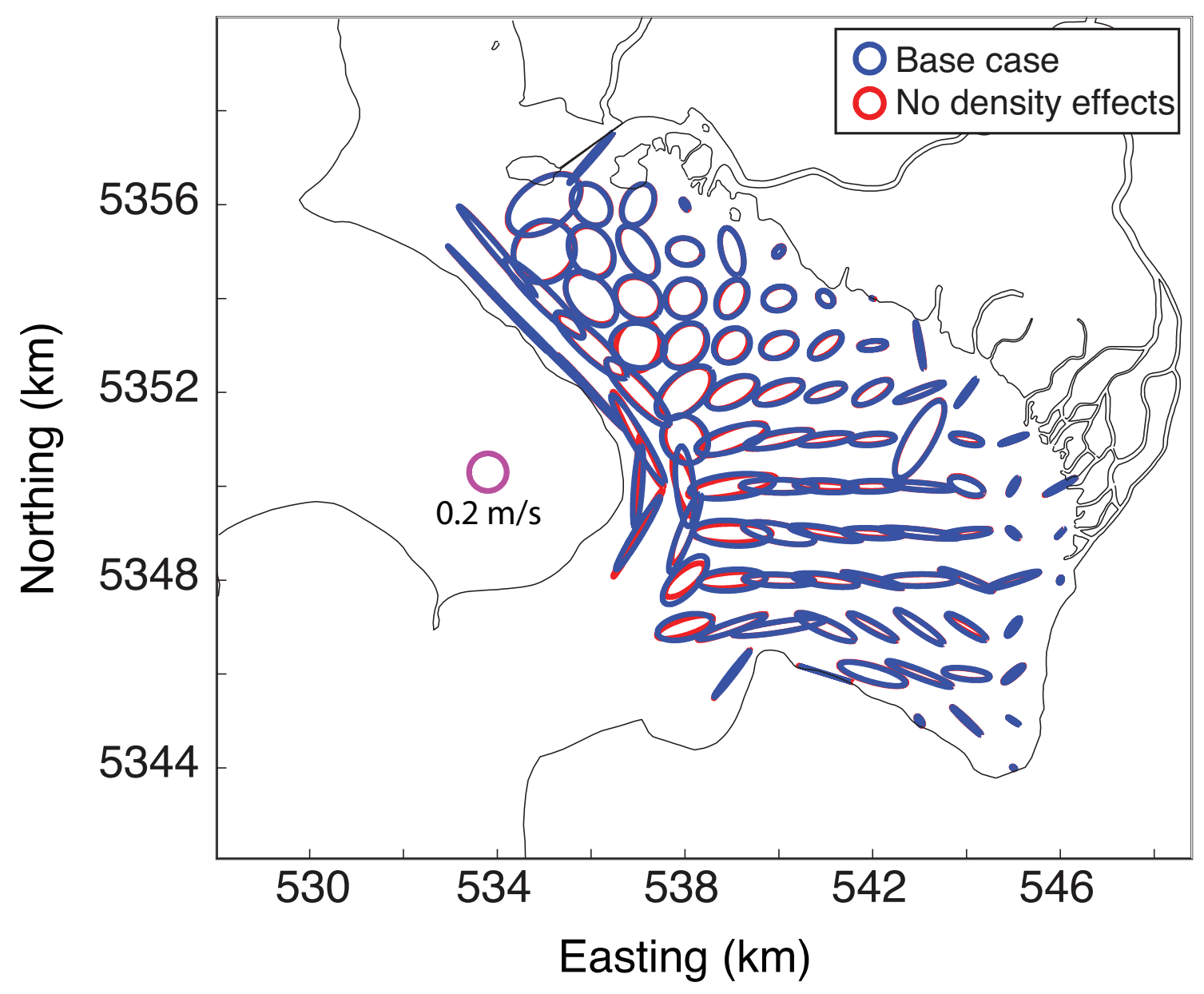

Figure 4-13: Ellipses encompassing the major and minor axes of depth-averaged velocity for the base (blue) and no-density cases (red). The pink circle represents $0.2 \mathrm{~m} / \mathrm{s}$.

Integrating the vertical pressure gradient over the water column results in pressure as a function of depth:

$P(z)=P_{0}+\int_{z}^{\eta} \rho g d z$

where $P_{0}$ is atmospheric pressure (uniform), and $\eta$ denotes the level of the surface.

Taking a horizontal derivative of $P(z)$ and using the Leibniz integral rule results in: 
$\frac{\partial P(z)}{\partial x}=\rho_{\eta} g \frac{\partial \eta}{\partial x}+\int_{z}^{\eta} \frac{\partial \rho}{\partial x} g d z$

where $\rho_{\eta}$ is the water density at the surface. The first term on the right is the barotropic pressure gradient, and the second term is the baroclinic pressure gradient, which is dependent primarily on horizontal density distributions, but also may be modified by the vertical density distribution (or stratification). The baroclinic pressure gradient will drive flows from regions of heavier to lighter water. The force associated with the baroclinic pressure gradient will tend to be small near the surface and increase in magnitude to the bed, but will be all in the same direction given a uniform density gradient and can thus affect both the depth-averaged flows and the shear.

Stable stratification leads to conversion of turbulent energy to potential energy as water parcels move vertically (rather than transfers of momentum), which is expressed as a reduction in the eddy viscosity. It can also inhibit the generation of turbulence in the first place. Overall, stratification results in greater total shear in the water column (Turner, 1973) as there is less interaction between water layers and the bottom stress slows the nearbed water more than the surface water. The effect of stratification on eddy viscosity is similar to that on eddy diffusivity $\left(\mathrm{K}_{\mathrm{v}}\right)$ for which one parameterization is (Munk and Anderson 1948):

$K_{v}=K_{0}\left(1+3.33 R_{i}\right)^{-\frac{3}{2}}$

where $\mathrm{K}_{0}$ is eddy diffusivity without stratification and $\mathrm{R}_{\mathrm{i}}$ is the Richardson number, which increases with increasing vertical density gradients. Stratification will thus always affect the distribution of the velocity in the water column. Stratification in the absence of horizontal density gradients may also affect the depth-averaged velocity through a reduction in the bottom drag coefficient, requiring greater water velocity to acheive bottom stress that balances the barotropic pressure gradient. 


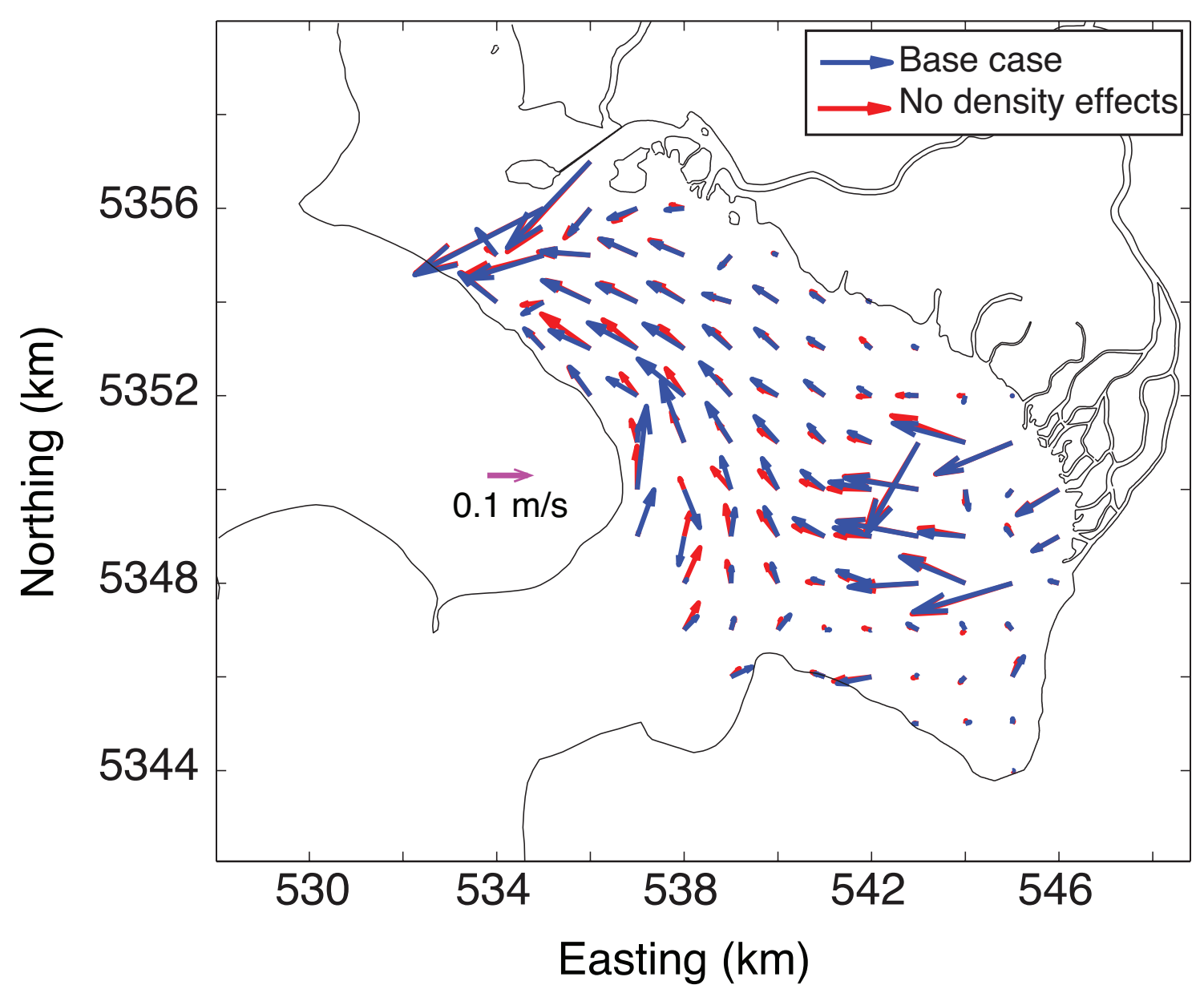

Figure 4-14: Residual flow vectors for the base (blue) and no-density cases (red). The pink arrow corresponds to $0.1 \mathrm{~m} / \mathrm{s}$.

To illustrate the effects of density and stratification on the flows, The FVCOM model is run with the same initial conditions (including spatial salinity gradients), but with the salinity treated as a passive tracer, removing all effects of density differences (no-density case). Thus, in the no-density case, the baroclinic pressure term and the density effect on the eddy viscosity are neglected. These results are compared with a standard (base case) model run for late June. Major and minor axes of velocity and integrated shear are determined for each two-week-long model run. 


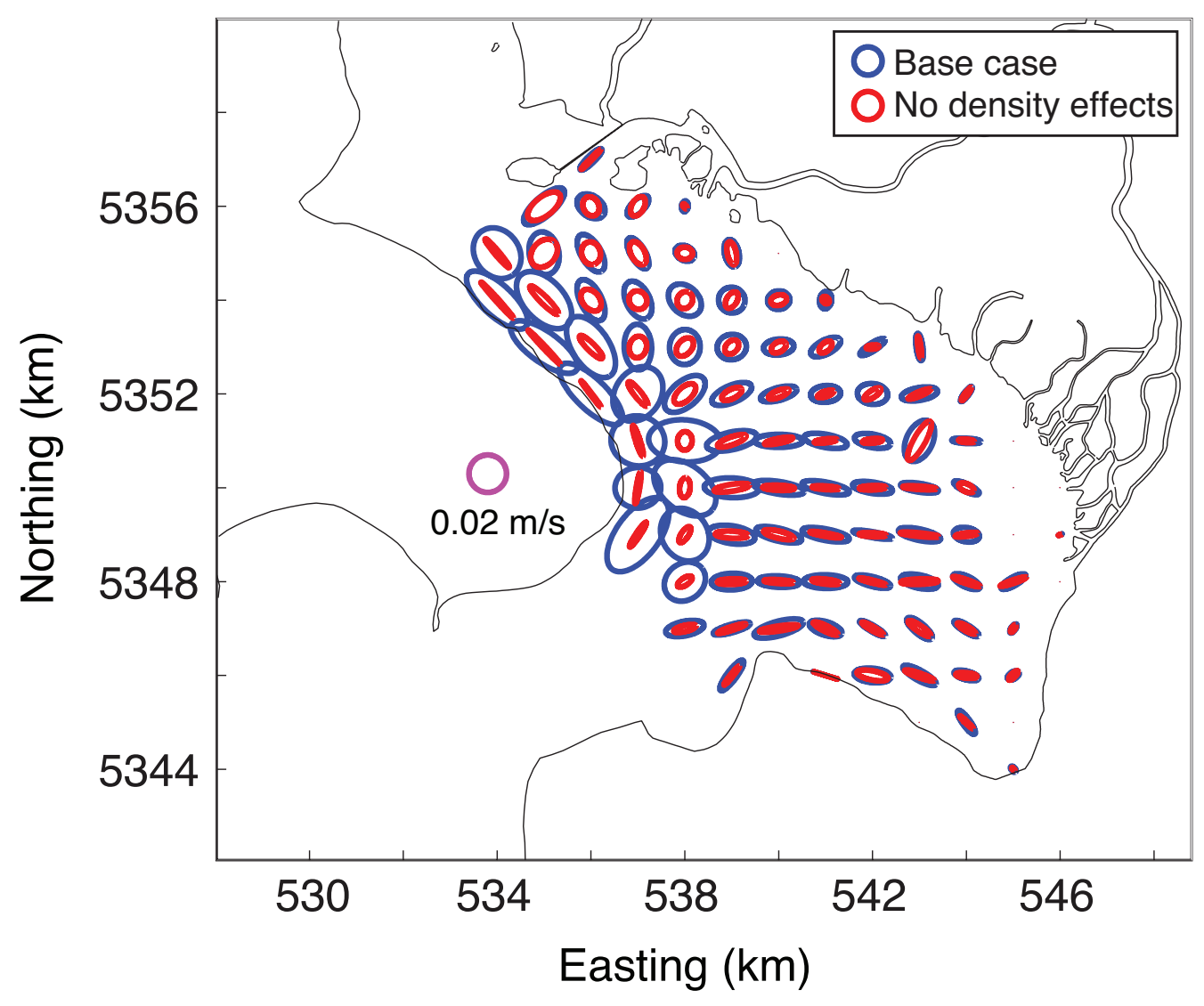

Figure 4-15: Ellipses encompassing the major and minor axes of depth-integrated shear for the base (blue) and no-density cases (red). The pink circle represents $0.02 \mathrm{~m} / \mathrm{s}$.

The variability over a tidal cycle of the depth-averaged velocity is similar for both model runs (Fig. 4-13). The largest differences in the ellipses shown for mean velocity occur on the offshore flats and in the gutter. The baroclinic pressure gradient scales with the depth as well as the density gradient, and thus tends to be smaller in shallow water. However, although the depth-averaged baroclinic pressure gradient is small, there is a measureable effect on the magnitude and direction of the residual flows (Fig. 4-14). Furthermore, the density gradients and stratification significantly increase the shear (Fig. 4-15), especially 
in the gutter and on the north flats where the tides are not rectilinear. Even in the shallow areas by the south fork, the variable density makes a difference in shear. Thus, stratification will more significantly affect processes that depend on the depth distribution of the velocity, such as those driven by nearbed flows.

\subsection{Summary}

On the south-central flats, advection and straining are roughly aligned with the velocity major axis, which is roughly aligned with the density gradient direction. In contrast, on the north flats, the major and minor axes of the tidal velocity variability are nearly equal but neither is aligned with the density or $\Phi$ gradient, and the advection and straining have nearly equal contributions along the major and minor axes of the velocity. Likewise, observations on the north flats (Chapter 3 ) showed that velocity magnitudes were similar in all directions, so the orientation of the processes depended on the density gradient, which was primarily cross-shore. In addition, the FVCOM model shows stratifying processes that are stronger overall on the southern flats because of the near-alignment of velocity or shear and density gradient in that location.

The importance of mixing to destratifying the water column depends on the tidal range. In this early July period type 1 tides had a relatively small tidal range, and stratification persists until low tide because the velocities remain relatively weak and mixing is small. In contrast, the early July type 2 tides with a large total tidal range, and strong flows mix the water column during the strong ebb. The Simpson number, which takes into account the horizontal density gradient, the depth, and the friction velocity, can be used to evaluate the relative importance of mixing and straining. Mixing dominates over straining when the instantaneous flat-averaged or local Simpson number is less than unity, and straining dominates when the Simpson number is greater than unity. Local advection causes scatter in the local results. The Simpson number also was useful in determining the relative importance of mixing and straining to the field data. 
Although the tidal variability of depth-averaged velocity is insensitive to density effects, the variability of the velocity shear and the magnitude and direction of the residual flows are affected by the inhomogeneous density. 


\section{Conclusions and future directions}

In this thesis, observations and FVCOM-simulations of water levels, velocities, and densities in Skagit Bay, Washington, are used to investigate the processes leading to production, destruction, and movement of stratification on the tidal flats. Conclusions for each of the primary questions are listed below.

1. What processes affect the stratification, and what causes spatial variations in the magnitudes of these processes?

The dominant processes controlling stratification on the Skagit Bay tidal flats are advection and depth-mean straining, with mixing on strong ebb tides and during periods of high stratification. On the strong floods, a salt wedge with a near vertical interface is transported onshore, while on strong ebbs the salt-wedge is strained and mixed as it is advected offshore. The magnitude of the advection (depth-mean straining) depends on the magnitude of the stratification (density) gradient and the velocity (shear) as well as the angle between them. Numerical simulations (using FVCOM) suggest that stratification is stronger on the south flats because the velocity major axis and the density gradients are roughly aligned. These results suggest that narrow estuaries and tidal flat channels where the major flow axis is aligned with the salinity gradient are likely to have larger magnitudes of stratification (for fixed freshwater discharge and tidal velocities) than regions with similar flow magnitudes in both directions and strong along-isopycnal flows.

2. What is the relative importance of cross- and alongshore processes, and what controls this balance?

On the south flats, tidal velocities are roughly rectilinear, and thus processes are small in the minor axis direction (roughly alongshore). On the north flats, the shear is roughly parallel with the isopycnals, and thus there is little alongshore straining despite strong 
alongshore shear during the type 2 higher low water, except on the offshore portions of the north flats. However, alongshore advection is significant over most of the north flats because stratification is spatially variable and alongshore flows are strong during the weak ebb and flood. Owing to the alongshore advection, cross-shore straining, and weak depth-averaged flows (resulting in little mixing) during this period, stratification increases until the second high tide, resulting in larger magnitudes of stratification during type 2 (nearly diurnal) than type 1 (roughly semi-diurnal) tides, similar to results from prior studies of salt-wedge estuaries.

3. Where is stratification generated and destroyed?

The observations suggest that stratification is generated near the measurement location on the north flats (straining dominates over mixing), which is about $1.5 \mathrm{~m}$ shallower than lower low water. Decreased stratification often was owing to advection, as the stratified water is transported towards the central flats, or out of the bay and into the deeper water of Puget Sound and the Strait of Juan de Fuca. Numerical (FVCOM) simulations suggest the dominance of generation (owing to straining) or destruction (owing to mixing) of stratification on the flats reflects an instantaneous Simpson number greater or less than unity, respectively.

Future work related to these results includes:

- Comparing model predictions of spatial variability of stratification for low and high discharge periods.

- Quantitatively comparing field data results from different time periods

- Although the combined cross- and alongshore transects used here were deployed only during late August, separate cross- and alongshore transects were deployed from late June until mid-August (including periods with a range of river discharge values).

- Evaluating the effects of wind and wave forcing. 
- Exploring the relevance of other non-dimensional numbers.

Future work that would improve our understanding of hydrodynamics on sandy tidal flats with freshwater input includes:

- Collecting field data to evaluate stratification and mixing processes during storms with significant rainfall, winds, and/or waves.

- Using model simulations and new field data to examine the effects of the presence of multidirectional processes on the sediment transport near the north flats (including trapping of sands on the Skagit flats).

- Comparing Skagit Bay to flats on the sides of estuaries to examine the effects of different orientations of the fresh- and saltwater sources 


\section{Appendix: Mixing Parameterization}

The mixing term $\mathrm{M}$ in the stratification balance uses a common parameterization of the vertical buoyancy flux (Nepf and Geyer, 1996; Becker et al., 2009; Ralston et al., 2010b) based on the eddy diffusivity $K_{v}$. The eddy diffusivity is estimated using parameterizations of the turbulence produced in the bottom boundary layer modified by the ability of stratified flow to support turbulence (Munk and Anderson, 1948). The eddy diffusivity was calculated by $K_{v}=K_{0}\left(1+3.33 R_{i}\right)^{-3 / 2}$, where $K_{0}$ is the estimated eddy diffusivity for an unstratified water column and $R_{i}$ is the bulk Richardson number. Extending a boundary layer method (Becker et al., 2009), $K_{0}$ is calculated by $K_{0}=0.4 C_{0} u_{*} z_{b}\left(1-\frac{z_{b}}{D}\right)$ where $C_{0}=0.1$ is based on a fit to the stratification balance and to model predictions of $K_{v}$ (Ralston et al, 2012) $u_{*}$ is the friction velocity, $z_{b}$ is the smaller of the height above the bed or the thickness of the bottom boundary layer, and $D$ is the total water depth. $C_{0}$ was added here as a scaling factor since the original boundary layer parameterizations were for well-mixed or weakly stratified conditions and strongly overpredict the eddy diffusivity for the highly stratified conditions found on the Skagit Bay tidal flats. An isotropic estimate is used for the friction velocity, given by $u_{*}^{2}=$ $C_{d}\left(\bar{u}^{2}+\bar{v}^{2}\right)$, where $\bar{u}$ and $\bar{v}$ are the depth-averaged cross- and alongshore velocities, respectively, and the drag coefficient $C_{d}$ is 0.001 . The data collection methods did not allow for more accurate estimates of the friction velocity by direct measurement of turbulence. The Richardson number is calculated by $R_{i}=\frac{g D}{\bar{\rho}} \frac{\Delta \rho}{(\Delta u)^{2}+(\Delta v)^{2}}$, where $g$ is gravitational acceleration, $\bar{\rho}$ is the depth-averaged density, and $\Delta \rho, \Delta u, \Delta v$ are the maximum difference in density, cross-shore velocity, and alongshore velocity, respectively (Byun and Wang, 2005). The thickness of the bottom boundary layer $\left(H_{B B L}\right)$ is estimated by $H_{B B L}=u_{*}\left(\frac{g}{\bar{\rho} R_{i}} \cdot \frac{\partial \bar{\rho}}{\partial x}\right)^{-1 / 2}$ (Stacey and Ralston, 2005). 
Alternate methods evaluated for the mixing parameterization include a constant and uniform $K_{v}$, a depth-varying gradient $R_{i}$ calculated by $R_{i}=\frac{g}{\bar{\rho}} \frac{\delta \rho_{i}}{\delta z}\left[\left(\frac{\delta u_{i}}{\delta z}\right)^{2}+\left(\frac{\delta v_{i}}{\delta z}\right)^{2}\right]^{-1}$, a constant and uniform $K_{0}$, a depth-uniform $K_{0}$ calculated by $K_{0}=0.4 u_{*} \frac{D}{10}$, and combinations thereof. Unrealistic values of $R_{i}$ are obtained when calculated in a depthvarying manner owing to the constant extrapolation method used to obtain density and velocity values throughout the water column. Constant and uniform $K_{0}$ or $K_{v}$ were rejected because they do consider the effects of stratification and flow speed. The choice of the method used was based on the best fit of the total dynamic balance. 


\section{References:}

Banas, N.S., Hickey, B.M., MacCready, P., Newton, J.A., 2004. Dynamics of Willapa Bay, Washington: A highly unsteady, partially mixed estuary. Journal of Physical Oceanography, 34(11), 2413-2427.

Becker, M.L., Luettich, R.A., Seim, H., 2009. Effects of intratidal and tidal range variability on circulation and salinity structure in the Cape Fear River Estuary, North Carolina. Journal of Geophysical Research, 114(C4), C04006, doi:10.1029/2008JC004972.

Blanton, J.O., Lin, G., Elston, S.A., 2002. Tidal current asymmetry in shallow estuaries and tidal creeks. Continental Shelf Research, 22, 1731-1743.

Burchard, H., 2009. Combined effects of wind, tide, and horizontal density gradients on stratification in estuaries and coastal seas. Journal of Physical Oceanography, 39(9), 2117-2136.

Burchard, H., Hofmeister, R., 2008. A dynamic equation for the potential energy anomaly for analysing mixing and stratification in estuaries and coastal seas. Estuarine, Coastal and Shelf Science, 77(4), 679-687, doi:10.1016/j.ecss.2007.10.025.

Burchard, H., Hetland, R.D., Schulz, E., Schuttelaars, H.M., 2011. Drivers of residual estuarine circulation in tidally energetic estuaries: straight and irrotational channels with parabolic cross-section. Journal of Physical Oceanography, 41(3), 548-570, doi: 10.1175/2010JPO4453.1.

Byun, D.S., Wang, X.H., 2005. The effect of sediment stratification on tidal dynamics and sediment transport patterns. Journal of Geophysical Research, 110(C3), C03011, doi:10.1029/2004JC002459.

Chant, R.J., Stoner, A.W., 2001. Particle trapping in a stratified flood-dominated estuary. Journal of Marine Research, 59, 29-51.

Chen, C., Liu, H., Beardsley, R.C., 2003. An unstructured grid, finite-volume, threedimensional, primitive equations ocean model: Application to coastal ocean and estuaries. Journal of Atmospheric and Oceanic Technology, 20, 159-186.

Chen, S.N., Geyer, W.R., Sherwood, C.R., Ralston, D.K., 2010. Sediment transport and deposition on a river-dominated tidal flat: An idealized model study. Journal of Geophysical Research, 115, C10040, doi:10.1029/2010JC006248. 
Cheng, P., Wilson, R.E., Chant, R.J., Fugate, D.C., Flood, R.D., 2009. Modeling influence of stratification on lateral circulation in a stratified estuary. Journal of Physical Oceanography, 39, 2324-2337, doi:10.1175/2009JPO4157.1.

de Boer, G.J., Pietrzak, J.D., Wenterwerp, J.C., 2008. Using the potential energy anomaly equation to investigate tidal straining and advection of stratification in a region of freshwater influence. Ocean Modelling, 22(1-2), 1-11, doi:10.1016/j.ocemod.2007.12.003.

Dyer, K. 1986. Coastal and Estuarine Sediment Dynamics. John Wiley, New York. 342 p.

Elgar, S., Raubenheimer, B., 2011. Currents in a small sandy tidal channel. Continental Shelf Research, 31, 9-14, doi:10.1016/j.csr.2010.10.007.

Fan, D.D., Guo, Y.X., Wang, P., Shi, J.Z., 2006. Cross-shore variations in morphodynamic processes of an open-coast mudflat in the Changjiang Delta, China: With an emphasis on storm impacts. Continental Shelf Research, 26(4), 517-538, doi:10.1016/j.csr.2005.12.011.

Fortunato, A.B., Baptista, A.M., 1996. Evaluation of horizontal gradients in sigmacoordinate shallow water model. Atmosphere-Ocean, 34(3), 489-514.

Fortunato, A.B., Baptista, A.M., Luettich, R.A., 1997. A three-dimensional model of tidal currents in the mouth of the Tagus estuary. Continental Shelf Research, 17(14), 16891714.

Fortunato, A.B., Oliviera, A., Baptista, A.M., 1999. On the effect of tidal flats on the hydrodynamics of the Tagus estuary. Oceanologica Acta, 22(1), 31-44.

Friedrichs, C.T., Aubrey, D.G., 1988. Non-linear tidal distortion in shallow well-mixed estuaries: a synthesis. Estuarine, Coastal and Shelf Science, 27(5), 521-545.

Geyer, W.R., 1993. The importance of suppression of turbulence by stratification on the estuarine turbidity maximum. Estuaries, 16 (1), 113-125.

Geyer, W.R., Farmer, D.M., 1989. Tide-induced variation of the dynamics of a salt wedge estuary. Journal of Physical Oceanography, 19, 1060-1072.

Geyer, W.R., Trowbridge J.H., Bowen M.M., 2000. The dynamics of a partially mixed estuary. Journal of Physical Oceanography, 30, 2035-2048.

Giddings, S.N., Fong, D.A., Monismith, S.G., 2011. Role of straining and advection in the intratidal evolution of stratification, vertical mixing, and longitudinal dispersion of a 
shallow, macrotidal, salt wedge estuary. Journal of Geophysical Research, 116(C3), C03003, doi:10.1029/2010JC006482.

Grossman, E.E., Stevens, A., Gelfenbaum, G., Curran, C., 2007. Nearshore circulation and water column properties in the Skagit River Delta, northern Puget Sound, Washington - Juvenile Chinook salmon habitat availability in the Swinomish Channel, U.S. Geological Survey Scientific Investigations Report 2007-5120. U.S. Geological Survey, Reston, Virginia.

Havens, K.J., Varnell, L.M., Bradshaw, J.G., 1995. An assessment of ecological conditions in a constructed tidal marsh and two natural reference tidal marshes in coastal Virginia. Ecological Engineering 4, 117-141.

Hofmeister, R., Burchard, H., Bolding, K., 2009. A three-dimensional model study on processes of stratification and de-stratification in the Limfjord. Continental Shelf Research, 29(11-12), 1515-1524, doi:10.1016/j.csr.2009.04.004.

Jay, D.A., Smith, J.D., 1990. Circulation, density distribution and neap-spring transitions in the Columbia River estuary. Progress in Oceanography, 25(1-4), 81-112, doi:10.1016/0079-6611(90)90004-L.

Kim, B.O., 2003. Tidal modulation of storm waves on a macrotidal flat in the Yellow Sea. Estuarine, Coastal and Shelf Science, 57(3), 411-420, doi:10.1016/S02727714(02)00369-4.

Kim, T.W., Cho, Y.K., 2011. Calculation of heat flux in a macrotidal flat using FVCOM. Journal of Geophysical Research, 116(C3), C03010, doi:10.1029/2010JC006568.

Kim, T.W., Cho, Y.K., You, K.W., Jung, K.T., 2010. Effect of tidal flat on seawater temperature variation in the southwest coast of Korea. Journal of Geophysical Research, 115(C2), C02007, doi:10.1029/2009JC005593.

Kirby, R., 2000. Practical implications of tidal flat shape. Continental Shelf Research, 20(10-11), 1061-1077.

Lacy, J.R., Stacey, M.T., Burau, J.R., Monismith, S.G., 2003. Interaction of lateral baroclinic forcing and turbulence in an estuary. Journal of Geophysical Research, 108(C3), 3089, doi:10.1029/2002JC001392.

Lee, H.J., Jo, H.R., Chu, Y.S., Bahk, K.S., 2004. Sediment transport on macrotidal flats in Garolim Bay, west coast of Korea: significance of wind waves and asymmetry of tidal currents. Continental Shelf Research, 24(7-8), 821-832, doi:10.1016/j.csr.2004.01.005. 
Marques, W.C., Fernandes, E.H.L., Moller, O.O., 2010. Straining and advection contributions to the mixing process of the Patos Lagoon coastal plume, Brazil. Journal of Geophysical Research, 115(C6), C06019, doi:10.1029/2009JC005653.

Marques, W.C., Fernandes, E.H.L., Rocha, L.A.O., 2011. Straining and advection contributions to the mixing process in the Patos Lagoon estuary, Brazil. Journal of Geophysical Research, 116(C3), C03016, doi:10.1029/2010JC006524.

Monismith, S., Burau, J.R., Stacey, M., 1996. Stratification dynamics and gravitational circulation in northern San Francisco Bay, in Hollibaugh, J.T., (Ed.), San Francisco Bay: The Ecosystem. American Association for the Advancement of Science, San Francisco, Calif., pp. 123-153.

Munk, W.H., Anderson, E.R., 1948. Notes on a theory of the thermocline. Journal of Marine Research, 7(3), 276-295.

Murphy, A.H., 1988. Skill Scores based on the mean square error and their relationships to the correlation coefficient. Monthly Weather Review, 116(12), 2417-2425.

Nepf, H.M., Geyer, W.R., 1996. Intratidal variations in stratification and mixing in the Hudson estuary. Journal of Geophysical Research, 101(C5), 12079-12086.

Nicolle, A., Karpytchev, M., 2007. Evidence for spatially variable friction from tidal amplification and asymmetry in the Pertuis Breton (France). Continental Shelf Research, 27(18), 2346-2356, doi:10.1016/j.csr.2007.06.005.

Nidzieko, N.J. 2010. Tidal asymmetry in estuaries with mixed semidiurnal/diurnal tides. Journal of Geophysical Research, 115(C8) C08006, doi:10.1029/2009JC005864.

Peters, H., 1997. Observations of stratified turbulent mixing in an estuary: Neap-tospring variations during high river flow. Estuarine, Coastal, and Shelf Science, 45, 69-88, doi:10.1006/ecss.1996.0180.

Peters, H., Bokhorst, R., 2000. Microstructure observations of turbulent mixing in a partially mixed estuary. Part I: Dissipation rate. Journal of Physical Oceanography, 30, 1232-1243.

Peters, H., Bokhorst, R., 2001. Microstructure observations of turbulent mixing in a partially mixed estuary, Part II: salt flux and stress. Journal of Physical Oceanography, 31, 1105-1119.

Ralston, D.K., Stacey, M.T., 2005a. Longitudinal dispersion and lateral circulation in the intertidal zone. Journal of Geophysical Research, 110(C7), C07015, doi:10.1029/2005JC002888. 
Ralston, D.K., Stacey, M.T., 2005b. Stratification and turbulence in subtidal channels through intertidal mudflats. Journal of Geophysical Research, 110(C8), C08009, doi:10.1029/2004JC002650.

Ralston D.K., Stacey, M.T., 2007. Tidal and meteorological forcing of sediment transport in tributary mudflat channels. Continental Shelf Research, 27(10-11), 1510-1527, doi:10.1016/j.csr.2007.01.010.

Ralston, D.K., Geyer, W.R., Lerczak, J.A., 2010a. Structure, variability, and salt flux in a strongly forced salt wedge estuary. Journal of Geophysical Research, 115, C06005, doi:10.1029/2009JC005806.

Ralston D.K., Geyer, W.R., Lerczak, J.A., Scully, M., 2010b. Turbulent mixing in a strongly forced salt wedge estuary. Journal of Geophysical Research, 115(C12), C12024, doi:10.1029/2009JC006061.

Ralston, D.K., Geyer, W.R., Traykovski, P.A., Nidzieko, N.J., 2012. Effects of estuarine and fluvial processes on sediment transport over deltaic tidal flats. Continental Shelf Research, submitted.

Rippeth, T.P., Fisher, N.R., Simpson, J.H., 2001. The cycle of turbulent dissipation in the presence of tidal straining. J. Phys. Oceanogr., 31(8), 2458-2471.

Simpson, J.H., Bowers, D., 1981. Models of stratification and frontal movement in shelf seas. Deep-Sea Research, 28(7), 727-738.

Simpson, J.H., Brown, J., Matthews, J., Allen, G., 1990. Tidal straining, density currents, and stirring in the control of estuarine stratification. Estuaries, 13(2), 125-132.

Speer, P.E., Aubrey, D.G., 1985. A study of non-linear tidal propagation in shallow inlet estuarine systems Part 2: Theory. Estuarine Coastal and Shelf Science, 21(2), 207-224.

Stacey, M.T., Ralston, D.K., 2005. The scaling and structure of the estuarine bottom boundary layer. Journal of Physical Oceanography, 35(1), 55-71.

Stacey, M.T., Monismith, S.G., Burau, J.R., 1999. Observations of turbulence in a partially stratified estuary. Journal of Physical Oceanography, 29, 1950-1970.

Stacey, M.T., Burau, J.R., Monismith, S.G., 2001. Creation of residual flows in a partially stratified estuary. Journal of Geophysical Research, 106(C8), 17,013-17,037, doi:10.1029/2000JC000576. 
Suzuki, T., 2001. Oxygen-deficient waters along the Japanese coast and their effects on the estuarine ecosystem. Journal of Environmental Quality, 30, 291-302.

Talke, S.A., Stacey, M.T., 2008. Suspended sediment fluxes at an intertidal flat: The shifting influence of wave, wind, tidal, and freshwater forcing. Continental Shelf Research, 28, 710-725.

Turner, J.S., 1973. Buoyancy effects in fluids. Cambridge University Press. New York, New York. 368p.

Valle-Levinson, A., Atkinson, L.P., 1999. Spatial gradients in the flow over an estuarine channel. Estuaries, 22(2A), 179-193.

Verspecht, F., Rippeth, T.P., Howarth, M.J., Souza, A.J., Simpson, J.H., Burchard, H., 2009. Processes impacting on stratification in a region of freshwater influence: Application to Liverpool Bay. Journal of Geophysical Research, 114, C11022, doi:10.1029/2009JC005475.

von Karman, T., 1930. Mechanische Ähnlichkeit und Turbulenz. Nachrichten von der Gesellschaft der Wissenschaften zu Göttingen, Fachgruppe 1 (Mathematik) 5, 58-76.

Wang, B., Fringer, O.B., Giddings, S.N., Fong, D.A., 2009. High resolution simulations of a macrotidal estuary using SUNTANS. Ocean Modelling, 26(1-2), 60-85, doi:10.1016/j.ocemod.2008.08.006.

Wang, B., Fringer, O.B., Gross, E.S., Giddings, S.N., Fong, D.A. Monismith, S.G., 2011. Modeling and understanding turbulent vertical mixing in a macrotidal salt wedge estuary. J. Geophys. Res., 116(C2), C02036, doi:10.1029/2010JC006135.

Webster, A.L., Ogston, A.S., Nittrouer, C.A., 2012. Delivery, reworking and export of fine-grained sediment across the sandy Skagit River tidal flats. Continental Shelf Research, submitted.

Wiles, P.J., van Duren, L.A., Häse, C., Larsen, J., Simpson, J. H., 2006. Stratification and mixing in the Limfjorden in relation to mussel culture. Journal of Marine Systems, 60(12), 129-143, doi:10.1016/j.jmarsys.2005.09.009.

Yang, Z.Q., Khangaonkar, T., 2009. Modeling tidal circulation and stratification in Skagit River estuary using an unstructured grid ocean model. Ocean Modelling, 28(1-3), 34-49, doi:10.1016/j.ocemod.2008.07.004. 